\title{
HENDERSON AYRES
}

O uso de FSH exógeno estimula o crescimento folicular final e a função luteínica de vacas Holandesas em lactação sincronizadas para Inseminação Artificial em Tempo Fixo? 


\section{Henderson Ayres}

\section{O uso de FSH exógeno estimula o crescimento folicular final e a função luteínica de vacas Holandesas em lactação sincronizadas para Inseminação Artificial em Tempo Fixo?}

Tese apresentada ao Programa de Pós-Graduação em Reprodução e Produção Animal da Faculdade de Medicina Veterinária e Zootecnia da Universidade de São Paulo para a obtenção do título de Doutor em Ciências

Departamento:

Reprodução Animal

Área de concentração:

Reprodução Animal

Orientador:

Prof. Dr. Pietro Sampaio Baruselli

São Paulo 
Autorizo a reprodução parcial ou total desta obra, para fins acadêmicos, desde que citada a fonte.

DADOS INTERNACIONAIS DE CATALOGAÇÃO-NA-PUBLICAÇÃO

(Biblioteca Virginie Buff D’Ápice da Faculdade de Medicina Veterinária e Zootecnia da Universidade de São Paulo)

T.2492

Ayres, Henderson

FMVZ

$\mathrm{O}$ uso de FSH exógeno estimula o crescimento folicular final e a função luteínica de vacas Holandesas em lactação sincronizadas para Inseminação Artificial em Tempo Fixo? / Henderson Ayres. -- 2011.

$114 \mathrm{f.}:$ il.

Tese (Doutorado) - Universidade de São Paulo. Faculdade de Medicina Veterinária e Zootecnia. Departamento de Reprodução Animal, São Paulo, 2011.

Programa de Pós-Graduação: Reprodução Animal.

Área de concentração: Reprodução Animal.

Orientador: Prof. Dr. Reprodução Animal.

1. Vacas holandesas. 2. Progesterona. 3. Corpo lúteo. 4. Sincronização. 5. Gonadotrofina I. Título. 


\section{UNIVERSIDADE DE SÃO PAULO}

\section{CERTIFICADO}

Certificamos que o Projeto intitulado "Efeito do FSH em protocolo para inseminação artificial em tempo fixo para vacas Holandesas de alta produção", protocolado sob o $\mathrm{n}^{\circ} 1570 / 2008$, utilizando 720 (setecentos e vinte) vacas, sob a responsabilidade do Prof. Dr. Pietro Sampaio Baruselli, está de acordo com os princípios éticos de experimentação animal da Comissão de Bioética da Faculdade de Medicina Veterinária e Zootecnia da Universidade de São Paulo e foi aprovado em reunião de 18/03/09.

(We certify that the Research "Effect of FSH on protocol for timed artificial insemination in high producing Holstein cows", protocol number 1570/2008, utilizing 720 (seven hundred twenty) cows, under the responsibility Prof. Dr. Pietro Sampaio Baruselli, agree with Ethical Principles in Animal Research adopted by Bioethic Commission of the School of Veterinary Medicine and Zootechny of University of São Paulo and in the meeting of day 03/18/09).

São Paulo, 20 de março de 2009

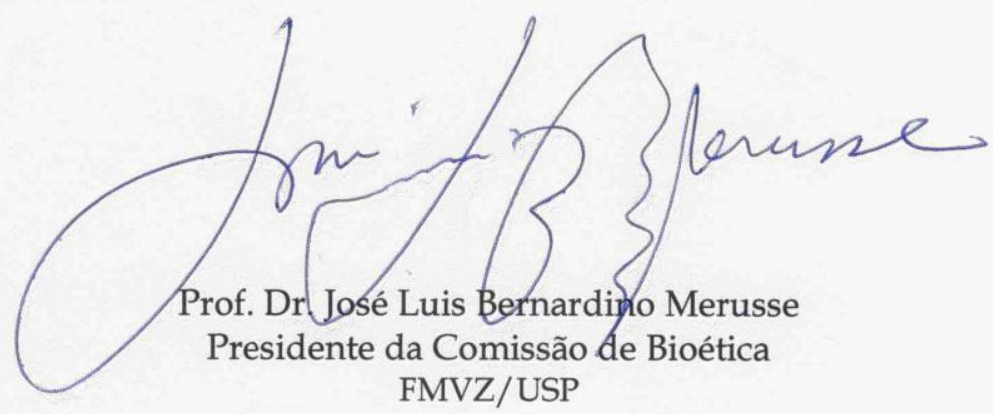




\section{FOLHA DE AVALIAÇÃO}

Nome: AYRES, Henderson

Título: O uso de FSH exógeno estimula o crescimento folicular final e a função luteínica de vacas Holandesas em lactação sincronizadas para Inseminação Artificial em Tempo Fixo?

Tese apresentada ao Programa de Pós-Graduação em Reprodução e Produção Animal da Faculdade de Medicina Veterinária e Zootecnia da Universidade de São Paulo para a obtenção do título de Doutor em Ciências

Data:

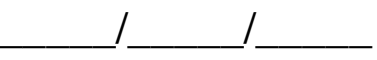

\section{Banca Examinadora}

Prof. Dr.

Assinatura:

Prof. Dr.

Assinatura:

Prof. Dr.

Assinatura:

Prof. Dr.

Assinatura:

Prof. Dr.

Assinatura:
Instituição:

Julgamento:

Instituição:

Julgamento:

Instituição:

Julgamento:

Instituição:

Julgamento:

Instituição:

Julgamento: 
Aos meus queridos pais, José e Maria (in memorian), pelo apoio incondicional em todas as minhas decisões e ações

Aos meus irmãos, Peterson e Arley pela amizade e apoio

Aos meus sobrinhos queridos Peterson e Beatriz

Dedico 


\section{AGRADEÇO}

À Deus por me dar forças, ajudar e me guiar na vida.

Ao meu QUERIDO Pai que me proporcionou uma base familiar, ensinamentos e sempre me apoiou em todas as minha decisões.

A minha QUERIDA MÃE que infelizmente não pode acompanhar (em vida) a finalização de mais uma fase, mas sempre esteve ao meu lado me apoiando e me auxiliando a encontrar o melhor caminho.

Ao meu irmão PETERSON pela confiança incondicional na pessoal que sou e por muitas vezes acreditar mais em mim do que eu mesmo.

Ao meu irmão ARLEY por me mostrar que na vida tudo é conseqüência de um trabalho e força de vontade e, principalmente mostrar "que o mundo dá voltas".

Às minhas cunhadas TÂNIA E LUCIANA o apoio e a alegria de formarmos uma maravilhosa família.

Aos meus queridos sobrinhos PETINHO E BIA pela alegria que trouxeram a nossa casa e vida.

Ao PROF. DR. PIETRO SAMPAIO BARUSELLI amigo adquirido nestes 9 anos trabalhando juntos. Trabalho que iniciou na minha iniciação científica. Espero continuarmos ao menos trabalhando em colaboração. Obrigado pelo exemplo de pessoa, de trabalhador e de dedicação. Com você pude aprender muito sobre a vida, o trabalho e o contato pessoal. Obrigado pela amizade nascida e desculpa se faltei em algum momento como orientado ou pessoa, mas meu intuito sempre foi procurar o caminho acerto, realizar o trabalho da melhor forma possível.

Ao GRANDISSIMO amigo PROF. DR. MILO CHARLES WILTBANK (meu $1^{\circ}$ co-orientador), uma pessoa indescritível em todos os campos. Proporcionou-me pela primeira vez abrir minha mente para uma visão diferente das coisas, de mudar de campo de atuação e postura. Nunca irei esquecer a confiança depositada em mim, assim como todo o apoio 
mesmo após sair do seu laboratório. Margarino, nunca mais tive um Thanksgiving igual ao da sua casa!!!

Ao amigo PROF. DR. JOSÉ EDUARDO PORTELA SANTOS (meu $2^{\circ}$ co-orientador), pela amizade que fizemos durante o StarMilk e que propiciou a oportunidade de voltar mais uma vez ao USA e realizar diversos experimentos, tanto de campo, quanto moleculares. Pelos ensinamentos que até ele não sabe que me deu. Valeu Zé.

À todos os professores do Departamento de Reprodução Animal (VRA) pelos ensinamentos, dedicação e amizade. Prof. DR. RENATO CAMPANARUT BARNABE e Profa. DRA VALQUIRIA HYPPOLITO BARNABE pela sinceridade, carisma e exemplo de dedicação (espero voltar aos churrascos e ver vocês, prometo temperar o frango); ao Prof. DR. MARIO BINELLI pelo exemplo de cientista e pela confiança depositada na minha pessoa (infelizmente você não foi meu orientador, mas o considero desta maneira); a Profa. DRA. MARIA HELENA .... pela amizade incondicional e maezonha que você é!!!; ao Prof. DR. JOSÉ ANTONIO VISINTIN pelo exemplo da boa ambição e dedicação ao que ama, a Profa. DRA. CAMILA INFANTOSI VANNUCCHI (possessiva) pela amizade que construímos nestes anos todos de VRA; ao Prof. DR MARCELO ALCINDO DE BARROS VAZ GUIMARÃES, pelo exemplo de serenidade e condutas, ao Prof DR. ED HOFFMANN MADUREIRA pela amizade, ensinamentos, disponibilidade para discussão e pelas boas risadas proporcionadas em churrascos e momentos de descontração, Profa DRA. CLAUDIA BARBOSA FERNANDES pela boa amizade que firmamos tão rápido (Professora eu só quero dançar!!!)

À todos os funcionários do VRA pelo apoio e eficiência, sem vocês as nossas pesquisa não seria possível, em especial à DONA SILVIA pelo exemplo de vida, trabalho e serenidade. Como é bom chegar todos os dias às 7 da manhã e encontrar a senhora com o seu belo sorriso no rosto!!!

Às minhas amigas secretárias HARUMI SHIRAISHI e THAÍS SOTO pela amizade e ajuda incondicional em todos os momentos que sempre necessitei de vocês e, principalmente pela amizade pura e verdadeira que construímos.

À todos os veterinários de campo com quem passei desde 1999, tenho certeza que aprendi um pouco com cada um e hoje sou o conjunto das influencias que vocês tiveram sobre mim. 
Ao médico veterinário e amigo CARLOS ALBERTO RODRIGUES, sempre disponível para nos ouvir e tentar cooperar em todos os projetos de pesquisa.

Ao meu amigo JORGE GONZALES, sem você não teria aprendido tanto, não teria treinado tanto, não teria a oportunidade de praticar a arte de vender, nunca foi fácil lhe vender uma idéia para você. Porém você sempre foi nosso companheiro, seja nos projetos simples, seja nas "buxas", seja nos nossos projetos ou nos projetos de outros grupos de trabalho. Com você aprendi um pouco mais sobre companheirismo, confiança e profissionalismo, obrigado.

Ao quase irmão JOSÉ EDUARDO GARDENAL, pelo companheirismo em horas boas e ruins, e por ter me proporcionado descobrir o que é a amizade verdadeira. Por todos os momentos que passamos juntos, pelos conselhos (sei que os segui ao contrario), pela oportunidade de iniciarmos uma "sociedade", grande abraço.

Ao meu amigo RENO Roldi de Araujo, bixinha. Iniciamos como colegas em Madison, porém isso transformou em amizade. Bixinha, muito obrigado por toda a ajuda.

Alexandre Henrily de Souza (Cabecinha de Neném) obrigado pela confiança empregada em mim. Tenho certeza que você foi importantíssimo para a minha formação como profissional e pessoa, proporcionando a possibilidade de poder conhecer novas pessoas e lugares e, pelo exemplo de responsabilidade profissional e de membro de uma família, pelos conselhos e conversas, se hoje sei um pouquinho sobre gado de leite, você foi que iniciou tudo isso.

Aos AMIGOS Manoel Francisco de Sá Filho (Mané, Gaúcho, Burchecha de Burdoge) por ter me ensinado muito no meu inicio na pós e por ter sido sempre um amigo; Lindsay Unno Gimenes (Japinha) pela amiga, e companheira que é; José Nélio pela pessoa que aos poucos foi demonstrando ser, obrigado pelo convívio, ponderações e divertidos momentos de convívio e Rodrigo Sala pela ajuda e serenidade.

Aos amigos Nélcio Antônio Tonizza de Carvalho (Cabecinha de Macaco) amigo incondicional e que traz alegria onde esta; Everton Luiz Reis (Cabeção) pela amizade e profissionalismo, José Ribamar de Souza Torres Júnior (Preto, Índio Veio) pela amizade, alegria e ajuda, Marcio Leão Ferraz pessoa sempre aberta e pronta para nos ajudar nas intermináveis aspirações, Gabriel Crepaldi pelo convívio e ponderações; Alessandra 
Ambrosio pela amizade, confiança e risada contagiante e verdadeira. Para todos os pósgraduandos que passaram pelo laboratório e pude trabalhar a conviver nestes anos todos.

Aos meus "amigos da Florida", Fabio Lima (3 Fronha), Bianca (Dura), Mauricio, Rafael (Carcaça), (Brutus), Isabela, Bryan, Eduardo (Gaúcho), Ana, Aline, Luciano, Manabo, Guilherme (Troxa), Fernanda, Britiney Wall (Sugar), Willian Thatcher, Dr. Risco, Dr Dalh, muito obrigado por me ajudarem e fazerem minha vida mais leve em momentos tão duros e/ou dificies.

À Rafael Bisinotto (Vergalho) e Leandro (Primo) pela excelentissima convivência que tivemos, a transformação da sala de vocês em moradia, pelos longos momentos de discussão de trabalhos, pensamentos, aflições e alegrias. Vocês presenciaram momentos muito dificieis da minha vida, porém nunca arredaram o pé do meu lado, apesar de não concordarem comigo. Construimos e consolidamos uma grande amizade, muito obrigado por tudo e saibam que quando precisarem estarei aqui para retrubuir tudo.

À todos os estagiários que contribuíram para a realização de nossos trabalhos.

Ao Márcilio por ser um amigo disposto a ajudar, ensinar e discutir a qualquer momento. Não esquecendo dos nossos churrascos.

À todos os amigos do VRA (Alê, Mazza, Rê, Fabiola, Cris, Liegie, Camila, Zeca, Paulo, Rodriguinho, Fernanda, Fer Loira, Mariana, Fura, Julia, Rafa, Everton, Lili, Marina, Zé Rodrigo, Milton, à todos que passaram e pudemos dividir momentos e experiência) valeu galera.

À Priscila do LDH pela paciência e realização das dosagens de progesterona dos nossos experimentos.

À Agindus as e fazenda Campestre, por ter aberto as portas para a realização desse e outros muitos experimentos. E todos os funcionários (Zelão, Paulinho, Ernando, Gisele, Beco, Lalá, cozinheiras), pois sem vocês NENHUMA vaca teria sido tratada!!!!

À Tecnopec pelos hormônios doados a este experimento. 
À Pfizer, Biogenesis, Ouro Fino e outras tantas empresa pela grande ajuda durante os nossos diversos experimentos paralelos, sem vocês nossa produção seriam a quem da realizada.

À CAPES, pelo indispensável suporte financeiro concedido através da bolsa de Doutorado.

A Nutricell nutrientes celulares, mais uma vez fazendo parte das minhas pesquisas e cedendo ultrason para o uso nos experimentos.

À Allan Ganéo pelo auxilio e ajuda na coleta das imagens de Doppler Colorido.

Agradeço a Roberta Machado Ferreira que soube conviver de formar harmonioso e intensa. Nunca deixou de me apoiar nas minhas decisões e por ter aprendido a conviver comigo no trabalho, sei que não sou fácil!!! Você tem um grande potencial, vá atrás do seu sonho pessoal e realização proficional. Não tenha medo. Valeu Ro.

Obrigado Lais Mendes Vieira (Kokota) por ter ajudado nos nossos projetos e tese. Continue sendo esta pessoa tão proativa e responsável, você poderá ir longe. Acredito muito no seu potencial.

A MSD Saúde Animal, minha "velha" e nova casa. Começamos este relacionamento à 8 anos e hoje estou vestindo completamento a sua camisa.

Ao amigo João Paulo Barbuio, pela pessoa que é, pelos ensinamentos de conduta profissional e pela confiança profissional incondicional que tem em $\mathrm{mim}$. Sei o quanto você foi e é responsável pela minha pessoal na empresa. Serei sempre grato.

Aos meus amigos de MSD, Vanessa Masson, Guilherme Rother, Alessandra Japa Issaka, Renatão Teixeira, Eduardo Adorno, João Paulo Costa, Isabela, Kamila Cunha, Denise Pereira, Otoniel Gomide, Fernando Belasco, Alessio Mercurio, Lucio, Tiago Arantes e, principalmente, meu querido chefe e amigo Luiz Gustavo Zito de Moraes. Missão dada é missão cumprida. Quem é cavera aqui???

Aos meus eternos amigos e companheiros de barco e vida (Mela, Ale, Ivo, Tati, Luis, Rosana, Mucha, Rosana, Mauri, Roberta, Matias, Mari). Esta é uma família que nunca se 
separa, pois ela foi formada com base na amizade e companherismo que a raia nos proporcionou.

Enfim, a todos aqueles que convivi e que pude tirar palavras e ensinamentos proveitosos. Peço desculpas se omiti algum nome, pois ainda tem muitos que deveriam estar aqui e, tenham certeza que o que importa é a gratidão presente dentro de cada um e não a simples escrita de um nome.

OBRIGADO A TODOS! 
"Eu acredito demais na sorte.

Tenho constatado que, quanto mais duro eu trabalho mais sorte eu tenho."

Thomas Jefferson 
Este trabalho foi realizado nas seguintes instituições:

- Faculdade de Medicina Veterinária e Zootecnia, Universidade de São Paulo - São Paulo (SP, Brasil);

- Dairy Science Department, University of Wisconsin - Madison (WI, EUA). 


\section{RESUMO}

AYRES, $H$. O uso do FSH exógeno estimula o crescimento folicular final e a função luteínica de vacas Holandesas em lactação sincronizadas para Inseminação Artificial em Tempo Fixo? [Does exogenous FSH increase the final follicular growth and lutea function for TAl in lactating Holstein cows?]. 2011. $114 \mathrm{f}$. Tese (Doutorado em Ciências) - Faculdade de Medicina Veterinária e Zootecnia, Universidade de São Paulo, São Paulo, 2011.

Vacas leiteira de alta produção têm apresentado declínio da eficiência reprodutiva. Essa redução é devido a causas multifatoriais, entre elas a baixa concentração de estradiol (E2) no proestro e a baixa concentração de progesterona (P4) no ciclo estral subsequentente. O objetivo deste trabalho foi comparar 0 uso de gonadotrofina exógena na dinâmica folicular e na taxa de prenhez de vacas submetidas ao protocolo Ovsynch (Experimento 1) ou a protocolos utilizando P4 e E2 (Experimento 2). No Experimento 1, animais de primeiro serviço foram présincronizados com dois protocolos (Presynch ou Double-Ovsynch). Já os animais de segundo ou mais serviços foram resincronizados com o protocolo Resynch. Os animais receberam $\mathrm{GnRH}\left(1^{\circ} \mathrm{GnRH}\right)$, seguido 7 dias depois pela adiministração de prostaglandina F2 $\alpha$ (PGF2 $\alpha$ ). Nesse momento os animais foram divididos homogeneamente por paridade e número de inseminação em um de dois tratamentos: sem FSH (Ovsynch, $\mathrm{n}=561$ ) ou com FSH (Ovsynch + FSH, $\mathrm{n}=571$ ). O segundo $\mathrm{GnRH}\left(2^{\circ} \mathrm{GnRH}\right)$ foi administrado 56 horas após a PGF2a e a inseminação em tempo fixo foi realizada 16 horas após. Amostras de sangue foram colhidas no $1^{\circ}$ e no $2^{\circ} \mathrm{GnRH}$, na PGF2 $\alpha$ e 6 e 13 dias após o $2^{\circ} \mathrm{GnRH}$ para dosagem de P4. Ainda, no $2^{\circ} \mathrm{GnRH}$ dosou-se também E2 No Experimento 2, os animais foram sincronizados no dia 0 com um dispositivo de P4 associado a $2 \mathrm{mg}$ de benzoato de estradiol. Oito dias após o dispositivo foi removido e os animais receberam uma dose de PGF2 $\alpha$. Neste mesmo momento, as vacas foram divididas homogeneamente por paridade, número de serviços prévios, escore de condição corporal e presença de CL no inicio do protocolo em três tratamentos: Controle (sem tratamento adicional; $n=232$ ); eCG (400 UI de eCG; $n=232$ ) e FSH (20 mg de $\mathrm{FSH} ; \mathrm{n}=230$ ). Todos os animais receberam $\mathrm{GnRH}$ e foram insemados $56 \mathrm{~h}$ após a retirada do dispositivo. Foram colhidas amostras de sangue a cada 48h do dia 11 ao dia 22. No Experimento 1, não houve efeito do FSH na concetração sérica de E2 no $2^{\circ} \mathrm{GnRH}(P=0,88)$, no tamanho do maior folículo no $2^{\circ} \mathrm{GnRH}(P=0,63)$, na taxa 
de ovulação ao $2^{\circ} \mathrm{GnRH}(\mathrm{P}=0,69)$ ou na concentração sérica de $\mathrm{P} 4$ no $6^{\circ}(\mathrm{P}=$ $0,15)$ e $13^{\circ}(P=0,36)$ dia após o $2^{\circ} \mathrm{GnRH}$. A taxa de prenhez foi semelhante ( $P>$ $0,05)$ entre os animais tratados com Ovsynch $(36,2 \%)$ e Ovsynch + FSH $(39,1 \%)$. No Experimento 2, os tratamentos não alteraram o diâmetro do folículo ovulatório ( $P=$ $0,15)$, o intervalo entre a remoção do dispositivo de $P 4$ e a ovulação $(P=0,30)$ e a taxa de ovulação $(P=0,44)$. Não houve efeito de tratamento na concentração sérica de $\mathrm{P} 4(\mathrm{P}=0,15)$. A taxa de prenhez foi diferente entre os tratamentos aos 30 dias após a IATF (Controle $=28,0^{\mathrm{a}}$ vs FSH $=18,7^{\mathrm{b}}$ vs eCG $=29,7^{\mathrm{a}} \% ; \mathrm{P}=0,01$ ), mas não aos 60 dias (Controle $=21,6$ vs FSH $=16,1$ vs eCG $=24,1 \% ; P=0,08$ ) e na perda de gestacional (Controle $=18,8$ vs $F S H=14,0$ vs eCG $=18,4 \% ; P=0,39$ ). Assim, o tratamento com FSH não estimulou o crescimento folicular final e a função luteínica de vacas leiteiras de alta produção sincronizadas com os protocolos Ovsynch e P4/E2.

Palavras-chave: Vacas holandesas. Progesterona. Corpo lúteo. Sincronização. Gonadotrofina. 


\section{ABSTRACT}

AYRES, $H$. Does exogenous FSH increase the final follicular growth and lutea function for TAl in lactating Holstein cows? [O uso de FSH exogenous estimula o crescimento folicular final e a função luteínica de vacas Holandesas em lactação sincronizadas para Inseminação Artificial em Tempo Fixo?]. 2011. 114 f. Tese (Doutorado em Ciências) - Faculdade de Medicina Veterinária e Zootecnia, Universidade de São Paulo, São Paulo, 2011.

Fertility in high-producing dairy cows has decreased over the years, which has been associated with reduced estradiol (E2) concentrations during proestrus and suboptimal progesterone (P4) concentrations during early stages of gestation. The objectives of the present study were to evaluate the effects of exogenous gonadotropins on follicular dynamics and risk of pregnancy per artificial insemination (P/AI) in cows subjected to the Ovsynch protocol (Experiment 1) or to a P4/E2-based timed Al protocol (experiment 2). In experiment 1, cows were enrolled in the Ovsynch protocol (GnRH, 7 d PGF2 $\alpha, 56$ h GnRH, 16 h IA) either after presynchronization (Presynch or Double-Ovsynch; first Al postpartum) or $32 \mathrm{~d}$ after previous Al. At the PGF2 $\alpha$ injection, cows were blocked by parity and number of $\mathrm{Al}$ and, within each block, randomly allocated to eitherreceive $20 \mathrm{mg}$ of $\mathrm{FSH}$ at the moment of the PGF2 $\alpha($ Ovsynch $+\mathrm{FSH}, \mathrm{n}=571$ ) or to remain as untreated control (Ovsynch, $\mathrm{n}=$ 561). Blood was sampled at the $1^{\text {st }}$ and $2^{\text {nd }} \mathrm{GnRH}$ and PGF2 $\alpha$ injections, as well as on $d 6$ and 13 after the 2 nd $\mathrm{GnRH}$ to access P4 and E2 (at the $2^{\text {nd }} \mathrm{GnRH}$ only) concentrations. In experiment 2, cows were received a P4 device and $2 \mathrm{mg}$ of estradiol benzoate. The device was removed $8 \mathrm{~d}$ later concurrently with an injection of PGF2 $\alpha$, followed by an injection of GnRH and Al at 56 h.At the PGF2 $\alpha$ injection, cows were blocked by parity, number of $\mathrm{Al}$, body condition score, and presence of a $\mathrm{CL}$ at device insertion.Within each block, cows were randomly allocated to receive either $20 \mathrm{mg}$ of FSH (FSH, n = 230), 400 IU of eCG (eCG, $n=232$ ), or no additional treatment at the moment of the PGF2 $\alpha$ (Control, $n=232$ ). Blood was sampled at every $48 \mathrm{~h}$ from 1 to $12 \mathrm{~d}$ after Al. In experiment 1, there was no effect of FSH on serum E2 at the $2^{\text {nd }} \mathrm{GnRH}(P=0.88)$, follicle diameter at the $2^{\text {nd }} \mathrm{GnRH}(P=0.63)$, ovulatory response to the $2^{\text {nd }} \mathrm{GnRH}(P=0.69)$, or serum $P 4$ on $d 6(P=0.15)$ and 13 $(P=0.36)$ after the $2^{\text {nd }} \mathrm{GnRH}$. Also, P/Al was similar $(P>0.05)$ between Ovsynch (36.2\%) and Ovsynch + FSH (39.1\%). In experiment 2, treatment did not affect ovulatory diameter $(P=0.15)$, interval from $P 4$ device removal and ovulation $(P=$ 
0.30), ovulatory response to the $2^{\text {nd }} \mathrm{GnRH}(P=0.44)$, and serum $P 4(P=0.15)$. Interestingly, treatment with $\mathrm{FSH}$ reduced $(\mathrm{P}=0.01) \mathrm{P} / \mathrm{Al}$ on $\mathrm{d} 30$ (Control $=28.0^{\mathrm{a}}$ vs. $\mathrm{FSH}=18.7^{\mathrm{b}}$ vs. eCG $=29.7^{\mathrm{a}} \%$ ), but not on d 60after timed $\mathrm{Al}$ (Control $=21.6 \mathrm{vs}$. $\mathrm{FSH}=16.1$ vs. eCG $=24.1 \% ; \mathrm{P}=0.08)$. The risk of pregnancy loss was not affected by treatment (Control $=18.8$ vs. FSH $=14.0$ vs. $\mathrm{eCG}=18.4 \% ; \mathrm{P}=0.39$ ). In conclusion, treatment with $\mathrm{FSH}$ failed to enhance the final growth of the ovulatory follicle and did not improve luteal function after Al in high-producing dairy cows synchronized with either the Ovsynch or P4/E2-based timed Al protocols.

Keywords: Holstein cows. Progesterone. Corpus luteum. Synchronization. Gonadothrophin. 


\section{LISTA DE FIGURAS}

Figura 1 - Desenho experimental esquemático dos tratamentos das vacas de primeiro (Presynch-Ovsynch, $n=317$ ou Double-Ovsynch, $n=$ 330) ou demais (Resynch, $n=485$ ) serviços. US = Avaliações ultrassonográficas, Sangue $=$ coleta de sangue, $d=$ dias e $h=$ horas.

Figura 2 - Concentração sérica de progesterona (P4) no momento da administração do $2^{\circ} \mathrm{GnRH}$ das vacas que não apresentaram luteólise após tratamento com protocolo Ovsynch com ou sem a suplementação de FSH, Madison, 2007

Figura 3 - Taxa de prenhez de vacas Holandesas em lactação tratadas ou não com FSH no momento da indução de luteólise $\left(\mathrm{PGF}_{2 \alpha}\right)$ no protocolo Ovsynch, de acordo com o mês de inseminação, Madison, 2007.

Figura 4 - Curva ROC representando a precisão com que o escore de condição corporal prevê a ocorrência de prenhez à inseminação. Maior sensibilidade combinada (57,0\%, intervalo de confiança de $95 \%=53,0$ a 61,8$)$ e especificidade $(50,8 \%$, intervalo de confiança de $95 \%=46,9$ a 54,6\%) foi detectada em $>2,75$. A área sob a curva foi de 0,54 (intervalo de confiança de 95\%= 0,51 a 0,57). Madison, 2007

Figura 5.- Curva ROC representando a precisão com que o número de serviços prevê a ocorrência de prenhez à inseminação. Maior sensibilidade combinada $(63,6 \%$, intervalo de confiança de $95 \%$ $=58,8$ a 68,2$)$ e especificidade $(46,7 \%$, intervalo de confiança de $95 \%=43,0$ a $50,5 \%$ ) foi detectada em $\leq 1$. A área sob a curva foi de 0,55 (intervalo de confiança de $95 \%=0,52$ a 0,58). Madison, 2007

Figura 6 - Desenho esquemático experimental dos tratamentos para a inseminação artificial em tempo fixo sem $(n=232)$ ou com suplementação de eCG ( $n=232)$ ou FSH $(n=230)$ de vacas Holandesas. US = Avaliações ultrassonográficas, Sangue = coleta de sangue, $\mathrm{d}=$ dias, $\mathrm{h}=$ horas. *Avaliações ultrassonograficas realizada no dia 0 e 8 . ** Avaliações ultrassonográficas realizadas a cada $12 \mathrm{~h}$ por $96 \mathrm{~h}$ após a retirada do dispositivo de $\mathrm{P} 4$ ou até detecção da ovulação. ***Coleta de sangue e avaliação ultrassonográfica realizada a cada 2 dias por 11 dias após a ovulação sincronizada. Diagnósticos de gestação realizados por ultrassonografia e palpação transretal 30 e 60 dias após a IATF, respectivamente.

Figura 7 - Diâmetro ovulatório (LSmeans \pm EPM; $\mathrm{mm}$ ) de folículos persistentes ou não

Figura 8. - Distribuição do momento de ovulação (h) após a remoção do dispositivo de progesterona conforme o intervalo entre os 
exames ultrassonográficos $(A)$ e porcentagem de animais que apresentaram ovulação entre 60 e 72 horas e 84 e 96 horas após a retirada de fonte de P4 (B), São Pedro, 2008

Figura 9 - Diâmetro do folículo ovulatório (LSmeans \pm EPM; mm) em cada intervalo entre os exames ultrassonográficos. O gráfico $A$ contém dados de todos os animais que apresentaram ovulação (de folículo persistente ou não). O gráfico B contém dados apenas dos animais que ovularam folículo(s) que não foi(ram) classificado(s) como persistente(s), São Pedro, 2008.

Figura 10 - Curva de regressão do momento de ovulação após a retirada da fonte de progesterona (MOV) e o diâmetro do folículo ovulatório (mm). A linha contínua representa o valor previsto pela equação de regressão. As linhas tracejadas representam o intervalo de confiança de 95\% para a média. As linhas pontilhadas representam o intervalo de confiança de 95\% para um valor previsto, São Pedro, 2008.

Figura 11 - Volume do CL (A) e concentração sérica de progesterona (B) durante o diestro após a ovulação sincronizada em vacas Holandesas suplementadas ou não com gonadotrofinas exógenas (FSH ou eCG; média $\pm E P M ; n=68$ ). Os dados foram normalizados para o dia da ovulação (dia 0). Médias seguidas por expoentes minúsculos $(a, b$ e $c)$ diferiram $(P<0,05)$ entre os dias do mesmo tratamento. Médias seguidas por expoentes maiúsculos (A e $B$ ) diferiram $(P<0,10)$ no mesmo dia entre tratamentos. São Pedro, 2008.

Figura 12 - Taxa de prenhez aos 30 e 60 dias após a IATF e perda gestacional em vacas Holandesas de alta produção suplementadas com gonadotrofinas exógenas de acordo com a estação do ano (verão ou inverno).

Figura 13 - Curva ROC representando a precisão com que o escore de locomoção prevê a ocorrência de prenhez aos 30 dias. Maior sensibilidade combinada $(77,4 \%$, intervalo de confiança de $95 \%$ $=70,5$ a 83,3\%) e especificidade (36,2\%, intervalo de confiança de $95 \%=32,0$ a $40,5 \%$ ) foram detectadas no valor $\leq 1$. A área sob a curva foi de 0,57 (intervalo de confiança de 95\% = 0,53 a 0,60). São Pedro, 2008

Figura 14 - Curva ROC representando a precisão com que o escore de locomoção prevê a ocorrência de prenhez aos 60 dias. Maior sensibilidade combinada $(79,7 \%$, intervalo de confiança de $95 \%$ $=72,2$ a 86,0\%) e especificidade (35,9\%, intervalo de confiança de $95 \%=31,9$ a $40,1 \%$ ) foram detectadas no valor $\leq 1$. A área sob a curva foi de 0,58 (intervalo de confiança de $95 \%=0,54 \mathrm{a}$ 0,61). São Pedro, 2008

Figura 15 - Equações e representação gráfica da probabilidade de prenhez aos 30 e 60 dias em relação ao escore de locomoção no início do protocolo de sincronização da ovulação para a IATF de vacas 
Holandesas de alta produção de leite $(P=0,004$ e $P=0,002$, respectivamente). São Pedro, 2008.

Figura 16 - Curva ROC representando a precisão com que o número de lactações prevê a ocorrência de prenhez aos 30 dias. Maior sensibilidade combinada (41,2\%, intervalo de confiança de $95 \%$ $=33,9$ a $48,9 \%)$ e especificidade $(67,1 \%$, intervalo de confiança de $95 \%=62,8$ a $71,1 \%$ ) foram detectadas no valor $\leq 1$. A área sob a curva foi de 0,55 (intervalo de confiança de $95 \%=0,50$ a 0,58). São Pedro, 2008

Figura 17 - Curva ROC representando a precisão com que o número de lactações prevê a ocorrência de prenhez aos 60 dias. Maior sensibilidade combinada (43,4\%, intervalo de confiança de $95 \%$ $=35,1$ a $51,9 \%)$ e especificidade (67,1\%, intervalo de confiança de $95 \%=63,0$ a $71,0 \%$ ) foram detectadas no valor $\leq 1$. A área sob a curva foi de 0,55 (intervalo de confiança de 95\% $=0,51 \mathrm{a}$ 0,59). São Pedro, 2008

Figura 18 - Equações e representação gráfica da probabilidade de prenhez aos 30 e 60 dias em relação à paridade de vacas Holandesas de alta produção de leite com ovulação sincronizada para IATF $(P=$ 0,04 e $\mathrm{P}=0,02$, respectivamente; Primípara $=1$ e multípara $=0$ ). São Pedro, 2008.

Figura 19 - Representação gráfica da probabilidade de perda gestacional entre 30 e 60 dias em relação à produção de leite de vacas Holandesas de alta produção de leite com ovulação sincronizada para IATF $(P=0,03)$. São Pedro, 2008 


\section{LISTA DE TABELAS}

Tabela 1 - Taxa de prenhez de vacas de corte submetidas a diferentes protocolos para inseminação artificial em tempo fixo com ou sem a administração de eCG ou FSH...

Tabela 2 - Dias em lactação, número de lactações, escore de condição corporal (ECC) e escore de locomoção (média \pm EPM) de vacas em lactação tratadas ou não com FSH durante o protocolo Ovsynch, Madison, 2007 (média \pm EPM)

Tabela 3 - Características de dinâmica folicular e dosagem hormonal analisadas em momentos específicos do protocolo Ovsynch com ou sem a tratamento com FSH em vacas Holandesas em lactação, Madison 2007 (média \pm E.P.M.; P4 = progesterona; E2 = estradiol).

Tabela 4 - Efeito da paridade na taxa de prenhez de vacas Holandesas em lactação tratadas ou não com FSH no momento da indução de luteólise $\left(\mathrm{PGF}_{2 \alpha}\right)$ no protocolo Ovsynch, Madison, 2007.

Tabela 5 - Efeito da classe de escore de condição corporal na taxa de prenhez de vacas Holandesas em lactação tratadas ou não com FSH no momento da indução de luteólise $\left(\mathrm{PGF}_{2 \alpha}\right)$ no protocolo Ovsynch, Madison, 2007.

Tabela 6 - Efeito do número de serviços na taxa de prenhez prenhez de vacas Holandesas em lactação tratadas ou não com FSH no momento da indução de luteólise $\left(\mathrm{PGF}_{2 \alpha}\right)$ no protocolo Ovsynch, Madison, 2007

Tabela 7 - Dias em lactação, número de lactações, número prévios de serviços prévios, produção de leite, escore da condição corporal (ECC) e escore de locomoção (média \pm EPM) de vacas Holandesas de alta produção tratadas com protocolo para IATF com ou sem a adição de FSH ou eCG, São Pedro, 2008

Tabela 8 - Efeito dos diferentes protocolos de IATF (sem suplementação ou suplementado com FSH ou eCG) sobre parâmetros foliculares (média \pm EPM) final de vacas Holandesas de alta produção, São Pedro, 2008

Tabela 9 - Área total (pixels) do CL (média \pm EPM) durante os 11 dias posteriores à ovulação sincronizada de vacas Holandesas de alta produção suplementadas ou não com gonadotrofinas exógenas (FSH ou eCG), em diferentes estaçãos do ano. São Pedro, 2008

Tabela 10 - Características ultrassonográficas do CL (média \pm EPM) durante 11 dias posteriores à ovulação sincronizada de vacas Holandesas de alta produção suplementadas ou não com gonadotrofinas exógenas (FSH ou eCG), em diferentes estaçãos do ano. São Pedro, 2008 
Tabela 11 -Taxa de prenhez aos 30 e 60 dias (média \pm EPM) após a IATF e perda gestacional em vacas Holandesas de alta produção suplementadas ou não com gonadotrofinas exógenas. Descalvado e São Pedro, 2008-09

Tabela 12 -Taxa de prenhez aos 30 e 60 dias (média \pm EPM) após a IATF e perda gestacional em vacas Holandesas de alta produção suplementadas ou não com gonadotrofinas exógenas durante o verão. Descalvado e São Pedro, 2008-09

Tabela 13 - Taxa de prenhez aos 30 e 60 dias (média \pm EPM) após a IATF e perda gestacional em vacas Holandesas de alta produção suplementadas ou não com gonadotrofinas exógenas durante o inverno. Descalvado e São Pedro, 2008-09

Tabela 14 - Taxa de prenhez aos 30 dias após a IATF em vacas Holandesas de alta produção com DEL inferior a 80 dias, de primeiro serviço, com ou sem presença de $C L$ no início do protocolo de sincronização e tratadas ou não com gonadotrofinas exógenas. Descalvado e São Pedro, 2008-09 


\section{LISTA DE QUADROS}

Quadro 1 - Modelos finais de acordo com a variável analisada. P4 = progesterona; E2 = estradiol; ECC = escore de condição

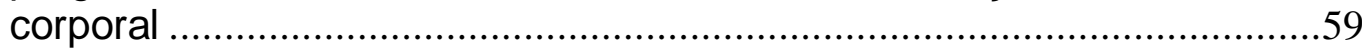

Quadro 2 - Modelos finais de acordo com a variável analisada..................................72 


\section{LISTA DE SIGLAS}

BE

Primer

$\mathrm{CL}$

d

E2

ECC

eCG

ECP

EPM

FD

FSH

$g$

$\mathrm{GnRH}$

$\mathrm{h}$

hCG

HE

IM

IATF

$\mathrm{Kg}$

$\mathrm{LH}$

$\mu \mathrm{g}$

$\mathrm{mg}$

$\mathrm{ml}$

$\mathrm{mm}$

n

$\mathrm{ng}$

NRC

${ }^{\circ} \mathrm{C}$

$\mathrm{P}$

P4 benzoato de estradiol

dispositivo intravaginal liberador de progesterona

corpo lúteo

dia

estradiol

escore de condição corporal

gonadotrofina coriônica equina

cipionato de estradiol

erro padrão da média

folículo dominante

hormônio folículo estimulante

grama / gravitacional

hormônio liberador de gonadotrofinas

hora

gonadotrofina coriônica humana

hematoxilina-eosina

intramuscular

inseminação artificial em tempo fixo

kilograma

hormônio luteinizante

micrograma

miligrama

mililitro

milímetro

número de unidades experimentais

nanograma

Nutrient requirements of dairy cattle

grau Celsius

nível de significância

progesterona 
$\mathrm{pg}$ picograma

PGF2 $\alpha$

prostaglandina $F$ dois alfa

SAS

statystical analysis system

UI

unidades internacionais

US

ultra-som/ ultra-sonografia

vs

versus 


\section{LISTA DE SÍMBOLOS}

$\begin{array}{ll}\circledR & \text { marca registrada } \\ \% & \text { porcentagem } \\ \beta & \text { Letra grega Beta } \\ \alpha & \text { Letra grega Alpha } \\ \pi & \text { Letra grega } \mathrm{PI}\end{array}$




\section{SUMÁRIO}

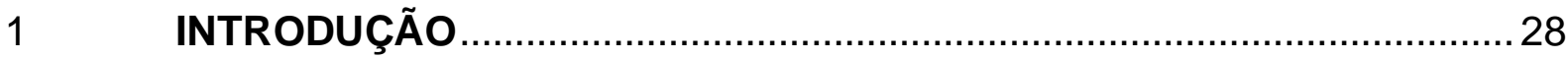

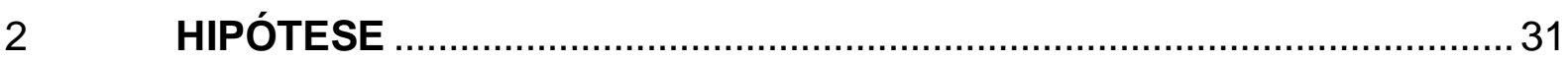

3 OBJETIVOS

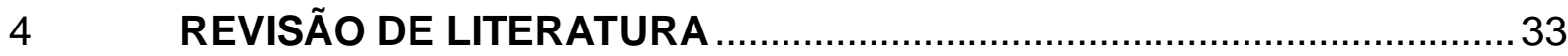

4.1 O CICLO ESTRAL DE VACAS LEITEIRAS .............................................. 33

4.2 FORMAÇÃO DO CORPO LUTEO, FUNÇÃO LUTEAL E LUTEOLISE .......36

4.3 SICRONIZAÇÃO DA OVULAÇÃO E INSEMINAÇÃO ARTICIAL EM

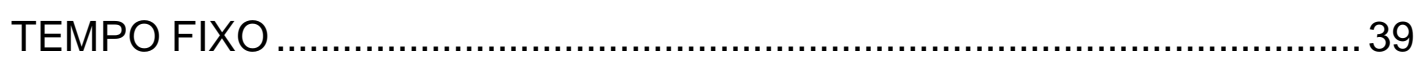

5 EXPERIMETO 1 - SUPLEMENTAÇÃO COM FSH NO PROTOCOLO OVSYNCH ................................................................. 52

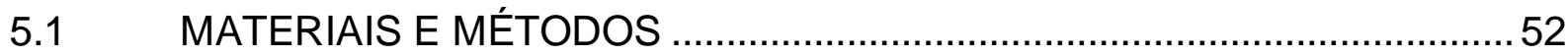

5.5.2 Protocolos hormonais utilizados e diagnóstico de gestação ………….......53

5.5.3 Avaliação ultrassonográfica ovariana e uterina ........................................56

5.5.4 Coleta de sangue e dosagem hormonal para avaliação da função

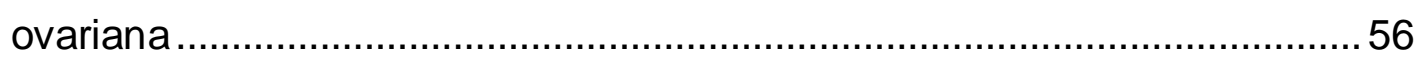

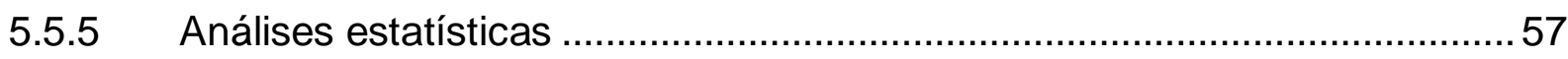

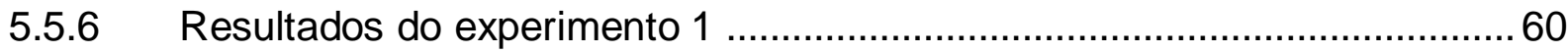

6 EXPERIMENTO 2 - SUPLEMENTAÇÃO COM FSH OU eCG EM PROTOCOLO A BASE DE PROGESTERONA E ESTRADIOL ................66

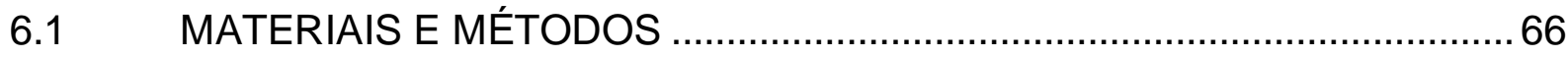

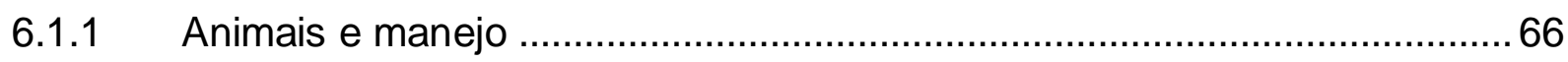

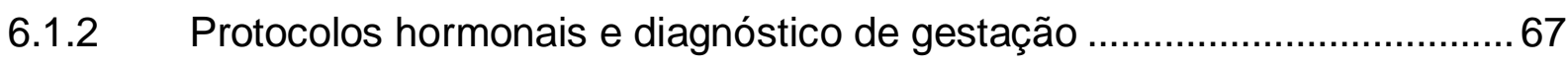

6.1.3 Avaliação ultrassonográfica ovariana e uterina ......................................... 68

6.1.4 Avaliação ultrassonográfica color-doppler .............................................. 70

6.1.5 Coleta de sangue e dosagem hormonal para avaliação da função

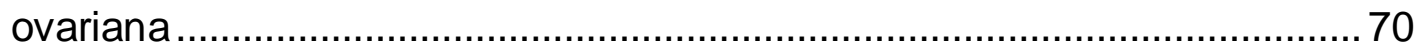

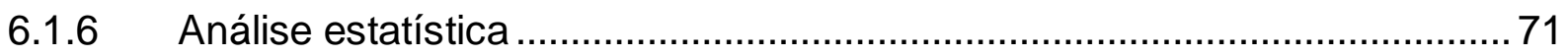

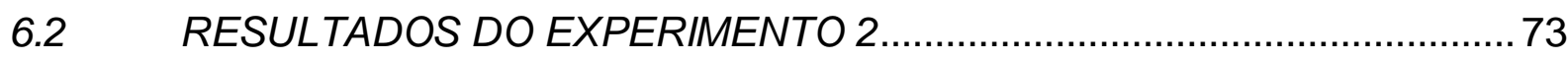

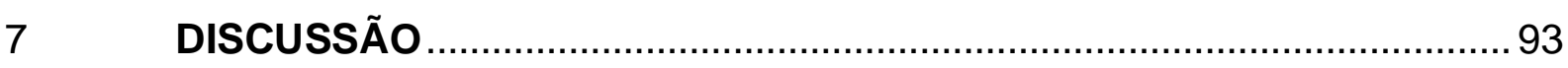

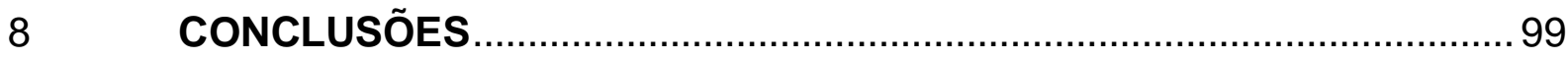

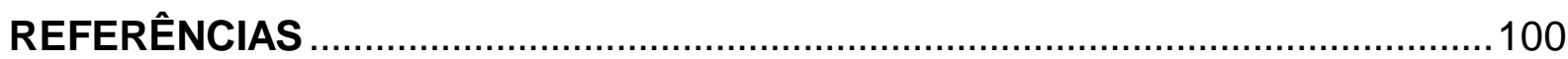




\section{INTRODUÇÃO}

Nas últimas décadas, os rebanhos leiteiros passaram por um intenso processo de seleção visando o aumento da produção de leite. Entretanto, este aumento da produção leiteira foi acompanhado por um declínio da eficiência reprodutiva destes animais (WASHBURN et al., 2002; SARTORI et al., 2002; LOPEZ et al., 2004). Sabe-se que fêmeas com maior produção de leite apresentam menor expressão e duração do estro, refletindo em uma maior dificuldade para a sua detecção (NEBEL et al., 1997; DRANSFIELD et al., 1998; LOPEZ et al., 2004). Como consequência, em sistemas nos quais os animais são inseminados com base na detecção visual de cio, menor taxa de serviço é alcançada e a eficiência reprodutiva é diminuída.

Na tentativa de solucionar o problema da baixa taxa de serviço relacionada à ineficiência na detecção de cios, pesquisadores desenvolveram protocolos hormonais que sincronizam o momento do estro (ODDE, 1990), facilitando sua observação. Mais adiante, Pursley et al. (1995) desenvolveram um protocolo hormonal chamado Ovsynch, cuja combinação de tratamentos com análogos do hormônio liberador de gonadotrofinas $(\mathrm{GnRH})$ e prostaglandina $F_{2 \alpha} \quad\left(P G F_{2 \alpha}\right)$ possibilitou a sincronização da ovulação e, assim, a realização da inseminação artificial em tempo fixo (IATF). Outro grupo de pesquisa desenvolveu tratamentos a base de implantes ou dispositivos contendo progesterona $\left(\mathrm{P}_{4}\right)$ ou seu análogo sintético (progestágeno) associados à ésteres de estradiol para sincronizar a emergência de uma nova onda de crescimento folicular (BÓ et al., 1995). Independentemente dos hormônios utilizados, esses tratamentos foram desenvolvidos com o intuito de facilitar o manejo, adiantar a primeira inseminação pós-parto e aumentar a eficiência reprodutiva de bovinos de leite e de corte.

Apesar de todo o desenvolvimento de protocolos hormonais voltados para a reprodução, baixas taxas de concepção são alcançadas, principalmente em bovinos de leite de alta produção sob sistema de confinamento. Nessa categoria animal, as taxas de concepção anuais não ultrapassam 35\% em quase todo o mundo. As baixas taxas de concepção em bovinos leiteiros têm causa multifatorial. Acredita-se que uma das possíveis razões para a baixa fertilidade seja a baixa concentração de 
estradiol $\left(E_{2}\right)$ circulante durante o proestro quando protocolos para IATF são utilizados, ou mesmo a baixa concentração de $\mathrm{P}_{4}$ no ciclo subsequentente. Isso pode ser conseqüência da indução prematura da ovulação, ou seja, quando a ovulação é induzida artificialmente, os folículos têm menor diâmetro (menor produção de $E_{2}$ ) quando comparados aos de ovulações espontâneas, assim, os corpos lúteos (CL) formados também serão menores (menor produção de $\mathrm{P}_{4}$ ).

Vacas de leite de alta produção têm o agravante de apresentarem aumento do metabolismo hepático de acordo com a fase da lactação, o que afeta tanto as concentrações circulantes de $E_{2}$ no proestro, como as de $P_{4}$ no diestro. Nesse contexto, Sangsritavong et al. (2002) mostraram que a alta taxa de metabolismo hepático de esteróides é a principal causa de menores concentrações sanguíneas de $\mathrm{P}_{4}$ em vacas de alta produção. Assim, estratégias que possibilitassem aumentar a produção de $\mathrm{P}_{4}$ pelo $\mathrm{CL}$ após a ovulação poderiam ser interessantes. Uma das estratégias propostas foi a utilização da gonadotrofina coriônica equina (eCG) no momento da retirada do dispositivo de $\mathrm{P}_{4}$ para estimular o crescimento folicular $\mathrm{e}$ aumentar o tamanho e a capacidade esteroidogênica do CL de vacas de leite. Essa mesma abordagem já havia sido utilizada em gado de corte com sucesso, ou seja, vacas e novilhas tratadas com eCG tiveram maiores concentrações sanguíneas de $\mathrm{P}_{4}$ no diestro subsequente à IATF (BARUSELLI et al., 2004; SÁ FILHO et al., 2010a), refletindo melhores taxas de concepção (BARUSELLI et al., 2003; PENTEADO et al., 2005; SÁ FILHO et al., 2010a,b), especialmente quando os animais estão em anestro e com baixo escore de condição corporal (ECC; BARUSELLI et al., 2004). De forma semelhante, quando a eCG foi utilizada, Souza (2008) obteve melhora na taxa de concepção de vacas leiteiras com baixo ECC e aumento da concentração de $\mathrm{P}_{4}$ no ciclo estral subsequente ao protocolo.

Outro hormônio diretamente envolvido no crescimento folicular e na produção de esteróides é o hormônio folículo estimulante (FSH). Sabe-se que o FSH é responsável pelo estímulo da produção de estradiol pelos folículos ovarianos (SENGER, 2003) e que a elevação das concentrações de FSH leva ao aumento da conversão de andrógenos para estrógenos através do aumento da atividade da enzima aromatase (SPINOSA et al., 2006). Assim, folículos mais maduros, com mais receptores para $\mathrm{FSH}$, aromatizam mais andrógenos e, consequentemente, produzem mais estradiol. Com base nessas informações, folículos expostos por 
mais tempo ao FSH poderiam secretar maiores concentrações de estradiol, reduzindo os problemas relacionados a alta metabolização desse hormônio.

Com este intuito, Santos et al. (2007), utilizaram diferentes doses de FSH (10, 20 ou $30 \mathrm{mg}$ ) ou $400 \mathrm{UI}$ de eCG no momento da administração de PGF P̧a $_{2}$ e avaliaram seu efeito na taxa de prenhez de vacas Nelore em anestro. Nesse trabalho, foi possível observar melhora na fertilidade dos animais após o uso de eCG e FSH. Assim, a suplementação com FSH ou eCG no momento da indução da luteólise, passou a ser vista como uma possível ferramenta para melhorar o desenvolvimento final do folículo dominante, aumentar o volume do $C L$ e a concentração de progesterona no ciclo subsequente, levando a melhora da fertilidade de vacas Holandesa de alta produção. 


\section{HIPÓTESE}

Estratégias para melhorar o crescimento folicular final podem aumentar a fertilidade em bovinos submetidos à protocolos de IATF (SÁ FILHO et al., 2009). Dentro destas estratégias, incluem-se o tratamento com gonadotrofinas exógenas (BARUSELLI et al., 2004; SOUZA, 2008; SÁ FILHO et al., 2009). Assim, com base nessas observações a hipótese do presente estudo foi de que a suplementação com FSH no momento da indução da lutólise: (1) melhora o crescimento final do folículo dominante (aumento do diâmetro e da concentração circulante de estradiol), (2) aumenta o volume do $\mathrm{CL}$ e a concentração de progesterona após a ovulação, levando assim (3) a melhora da fertilidade de vacas Holandesa de alta produção. 


\section{OBJETIVOS}

- Avaliar o efeito do tratamento com FSH no diâmetro do maior folículo, na concentração circulante de estrógeno, na espessura do endométrio uterino no momento do segundo GnRH e a taxa de ovulação após o segundo GnRH do protocolo Ovsynch;

- Avaliar o efeito do tratamento com FSH no diâmetro do folículo ovulatório, na taxa, no momento e na distribuição das ovulações, assim como no volume do CL e na concentração de progesterona após a ovulação sincronizada de vacas submetidas ao protocolo com progesterona e estrógeno;

- Avaliar o efeito do tratamento com FSH na taxa de prenhez de animais submetidos aos protocolos Ovsynch e a base de progesterona e estrógeno. 


\section{REVISÃO DE LITERATURA}

\subsection{O CICLO ESTRAL DE VACAS LEITEIRAS}

Nos primeiros estudos cujo enfoque foi determinar a duração do ciclo estral de vacas leiteiras, foi relatada uma duração média de 22 dias, com 82,8\% dos ciclos variando de 17 a 26 dias (OLDS; SEATH, 1951). Posteriormente, o ciclo estral foi definido como o intervalo entre duas ovulações consecutivas e sua duração média passou a ser considerada 23 dias, com base em avaliações em vacas lactantes nãoinseminadas (SAVIO et al., 1990; SARTORI et al., 2004).

O ciclo estral pode ser dividido em quatro períodos: proestro, estro, metaestro e diestro (SENGER, 2003; PETER et al., 2009). O proestro tem início com a regressão estrutural e funcional do CL e é caracterizado pelo aumento da síntese de $\mathrm{E}_{2}$ pelos folículos pré-ovulatórios (WETTERMANN et al., 1972). As concentrações circulantes de $E_{2}$ em vacas lactantes aumentam do dia da luteólise até o estro, quando alcançam o valor máximo médio ao redor de 7,9 pg / mL (SARTORI et al., 2004). A literatura refere que esta concentração máxima é inferior as encontradas tanto em novilhas leiteiras (9,7 a 11,3 pg / mL;. WETTERMANN et al., 1972; SARTORi et al., 2004), quanto em vacas não lactantes (16,7 pg / mL; DE LA SOTA et al., 1993). Essas elevadas concentrações de $E_{2}$ na ausência de $P_{4}$ atuam no sistema nervoso central induzindo o comportamento de cio (BLACHE et al., 1991; ALLRICH, 1994) e determinando o fim do proestro e início do estro (SENGER, 2003; PETER et al., 2009).

O período de estro se estende do início do período de receptividade sexual até a ovulação do folículo dominante (SENGER, 2003; PETER et al., 2009). Durante o estro, a elevação nas concentrações circulantes de $E_{2}$ induz a liberação do pico pré-ovulatório de $\mathrm{GnRH}$ pelo hipotálamo, que por sua vez estimula a liberação do pico pré-ovulatório do hormônio luteinizante (LH) pela glândula pituitária (HAFEZ et al., 2008). Proestro e estro compõem a fase folicular do ciclo estral, que geralmente varia de 2 a 5 dias (SAVIO et al., 1990; SARTORI et al., 2004), representando cerca de $20 \%$ da duração do ciclo estral completo (PETER et al., 2009). 
Em contraste com a fase folicular, a fase lútea do ciclo estral é composta pelo metaestro e diestro, caracterizando-se pela presença de um $\mathrm{CL}$ funcional. $\mathrm{O}$ processo de luteinização das células da granulosa e da teca do folículo préovulatório para a formação do $\mathrm{CL}$ é iniciada pelo pico pré-ovulatório de LH. O período entre a ovulação e a presença de um CL maduro capaz de produzir grandes quantidades de progesterona é chamado de metaestro (PETER et al., 2009). O primeiro aumento significativo na concentração circulante de progesterona é detectado 4 dias após a ovulação (STABENFELDT et al., 1969), momento no qual finaliza o metaestro. Durante o diestro, a concentração de progesterona aumenta rapidamente a partir de dia $4(1,5 \mathrm{ng} / \mathrm{mL})$ até o $8^{\circ}$ dia do ciclo estral $(5,5 \mathrm{ng} / \mathrm{mL}$; STABENFELDT et al., 1969). Após este ponto, o aumento na concentração de progesterona ocorre em ritmo mais lento e atinge seu valor máximo no dia 16 do ciclo estral, quando alcança valores ao redor de $7 \mathrm{ng} / \mathrm{mL}$ (variando de 6,1 a 10,2 $\mathrm{ng}$ I mL; STABENFELDT et al., 1969). Estes valores absolutos mudam consideravelmente de acordo com o estagio lactacional e o nível de produção de leite. Isto ocorre devido ao aumento na taxa catabólica de esteróides ovarianos no fígado, decorrente do aumento da ingestão de matéria seca (SARTORI et al., 2004).

Durante a fase lútea do ciclo estral ocorrerá à emergência das ondas foliculares. Estas são detectadas nos dias -0,2 e 9,6 do ciclo estral, em novilhas com duas ondas foliculares e, -0,5, 9,0 e 16,0 em novilhas com três ondas foliculares (GINTHER et al., 1989). Foi demonstrado que o surgimento de ondas de crescimento folicular sempre é precedido por um pico de FSH (ADAMS et al., 1982).

A grande maioria dos folículos recrutados irá parar de crescer e entrar em processo de atresia. Isto permite o controle do número final dos folículos ovulatórios. Sabe-se que este controle é espécie-específico. Nas vacas, geralmente apenas um folículo é selecionado para se tornar dominante. O momento no qual ocorre a divergência folicular foi definido como o início da diferença nas taxas de crescimento entre o futuro folículo dominante e o seu maior subordinado (GINTHER et al., 1996a). Em novilhas da raça Holandesa, o desvio ocorre, em média, 2,8 dias após a emergência da onda folicular, quando o futuro folículo dominante atinge um diâmetro de $8,5 \mathrm{~mm}$.

Um dos mecanismos que levam ao desvio folicular em vacas é a mudança na dependência primária ao FSH para LH pelo folículo dominante. Na verdade, a concentração circulante de FSH diminui após a emergência folicular e se torna basal 
no momento do desvio (GINTHER et al., 1996a). A supressão do FSH é determinada principalmente pela presença do folículo dominante. Este folículo é capaz de produzir inibina, a qual associada ao E2 promoverá a supressão das concentrações de FSH (ADAMS et al., 1992). A inibição de FSH pelo folículo dominante parece ser seletiva e não afeta a concentração de LH (QUIRK; FORTUNE, 1986).

Concomitantemente a queda das concentrações de FSH, a codificação de ácido ribonucléico mensageiro (RNAm) para os receptores de LH nas células da teca aumentam com o tamanho folicular e a expressão dos receptores de LH nas células da granulosa é detectada somente em folículos saudáveis que passaram do diâmetro de desvio (XU et al., 1995).

Além disso, mudanças intrafoliculares no sistema do fator de crescimento semelhante à insulina (IGF) têm sido sugeridas para acionar as variações na capacidade de resposta às gonadotrofinas que levam ao desvio morfológico e funcional do foliculo. Beg et al. (2001) demonstraram que o maior folículo (futuro dominante) apresenta aumento da quantidade de IGF-1 livre e reduzidas concentrações de proteínas de ligação do fator de crescimento semelhante à insulina (IGFBP) em comparação com o segundo maior folículo.

Durante o diestro, a presença de um CL funcional e elevadas concentrações circulantes de progesterona impedem o aumento da freqüência de pulsos de LH liberado pela hipófise e o aumento pré-ovulatório de gonadotrofinas. Devido ao apoio insuficiente de LH, o folículo dominante da onda não ovulatória para de crescer e sofre atresia. Em vacas não-gestantes o endométrio iniciará entre os dias 17 e 19 do ciclo estral, a liberação pulsátil de prostaglandinas (PG) $F 2 \alpha$, levando assim à luteólise (KINDAHL et al., 1976a; SAVIO et al., 1990; SARTORI et al., 2004).

Após a emergência da segunda onda, o folículo dominante da primeira onda atinge estágio avançado de atresia e então, o folículo dominante presente no momento da luteólise continua a crescer e secretar quantidades crescentes de estradiol. Na ausência de progesterona o estradiol folicular age no hipotálamo para induzir uma onda pré-ovulatória de $\mathrm{GnRH}$, seguido por uma onda de gonadotrofinas (LH) liberada pela hipófise, que culmina com a ovulação. 


\subsection{FORMAÇÃO DO CORPO LUTEO, FUNÇÃO LUTEAL E LUTEOLISE}

A transição folicular-luteal é um processo dinâmico que envolve uma série de mudanças bioquímicas e estruturais do folículo pré-ovulatório após o pico de LH (REYNOLDS; REDMER, 1999; NISWENDER et al., 2000). Isto inclui a diferenciação das células da teca e da granulosa em células luteinizadas, o remodelamento, 0 crescimento do tecido e o aumento da produção de progesterona (P4). Para suprir esta demanda, é essencial que haja crescimento de vasos e estabelecimento de uma rede de suprimento sanguíneo (REYNOLDS; REDMER, 1999; NISWENDER et al., 2000).

O pico de secreção de LH acarreta complexas alterações estruturais e funcionais no folículo maduro, as quais estão estreitamente associadas ao aumento do fluxo sanguíneo na parede do folículo pré-ovulatório (ACOSTA et al., 2003). Sabe-se que o primeiro aumento detectável na concentração de estradiol plasmático coincide com o aumento da vascularização (área de fluxo sangüíneo) na parede do folículo maduro (ACOSTA; MIYAMOTO, 2004). Assim, parece haver uma íntima associação entre diâmetro folicular, concentração de estradiol no fluido folicular e área vascular (MATTIOLI et al., 2001). Acredita-se que o aumento do fluxo sanguíneo nas células da parede do folículo pré-ovulatório possa aumentar a oferta de gonadotrofinas, nutrientes, substratos hormonais e outros componentes do sangue necessários para a ovulação (ACOSTA; MIYAMOTO, 2004). A complexidade estrutural e secretória e outras modificações funcionais que ocorrem no ovário próximo ao momento da ovulação estão intimamente associadas às mudanças no fluxo sangüíneo no interior da parede do folículo pré-ovulatório (no prelo) ${ }^{1}$.

O primeiro evento associado com a formação do CL é a mudança na produção de estradiol para progesterona pelas células luteínicas. Estudos sobre expressão gênica das células foliculares (granulosa e teca) durante o período peri-

\footnotetext{
${ }^{1}$ AYRES, H.; MINGOTI, G. Z. Angiogênese, vascularização e uso do ultrassom Doppler colorido como ferramenta de avaliação das estruturas ovarianas. Revista Brasileira de Reprodução Animal. (no prelo)
} 
ovulatório em sistemas de cultivos celulares indicam que a esteroidogênese é inicialmente inibida de maneira coordenada. O transporte do colesterol através da membrana externa da mitocôndria permanece inalterado durante os estágios finais de desenvolvimento do folículo ovulatório (NIMZ et al., 2009). Entretanto as enzimas responsáveis pela conversão de colesterol até estradiol (P450scc, 3ß-HSD, P450aromatase nas células da granulosa e P450c17 e 3ß-HSD em células da teca) estão amplamente reduzidas após o pico pré-ovulatório de LH (VOSS; FORTUNE, 1993a; VOSS; FORTUNE, 1993b). Logo, as concentrações deste hormônio são reduzidas entre 4 e 10 horas após o pico pré-ovulatório de LH (KOMAR et al., 2001).

Após a ovulação, o novo CL se desenvolve rapidamente a partir da ruptura da parede do folículo e o tecido remanescente folicular é extensamente reorganizado durante a formação do CL. O desenvolvimento do CL é caracterizado pela alta vascularização ativa e pela ocorrência de repetidas mitoses das células esteroidogênicas. A intensidade do processo angiogênico dentro do $C L$ atinge um pico em 2-3 dias após a ovulação (REYNOLDS et al., 2000), o que acarreta um aumento do fluxo sanguíneo (área e velocidade; ACOSTA et al., 2003), indicando desenvolvimento luteal normal. Assim, a maioria das células esteroidogênicas maduras do CL estão em contato com um ou mais capilares (REYNOLDS et al., 1992). Como resultado deste processo, o CL torna-se uma das estruturas mais vascularizadas (GAYTAN et al., 1999) e recebe a maior taxa de fluxo sanguíneo por unidade de tecido de todo o organismo (WILTBANK et al., 1988).

O sistema de vascularização do CL serve como uma rota de entrega de substâncias biológicas, pois fornece nutrientes para as células lúteinicas, substratos para produção de hormônios, além de receber hormônios estimuladores e/ou reguladores que são indispensáveis para a manutenção da secreção de P4 (no

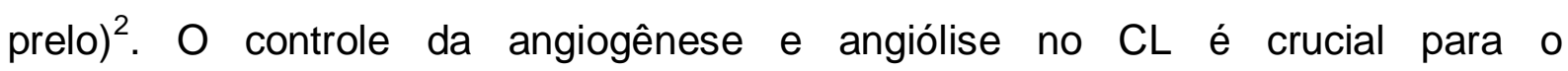
desenvolvimento e manutenção desta glândula. Este controle é realizado pela interação entre o fator de crescimento endotelial vascular (VEGF) e fator de crescimento fibroblástico (bFGF).

\footnotetext{
${ }^{2}$ AYRES, H.; MINGOTI, G. Z. Angiogênese, vascularização e uso do ultrassom Doppler colorido como ferramenta de avaliação das estruturas ovarianas. Revista Brasileira de Reprodução Animal. (no prelo)
} 
Outra característica importante do CL em desenvolvimento é a rápida taxa de crescimento dos tecidos e proliferação celular. Esta proliferação resulta em um aumento de 17,5 vezes da massa luteal em poucos dias (FARIN et al., 1986; JABLONKA-SHARIFF et al., 1993). O número de células luteínicas grandes permanece algo constante durante todo o desenvolvimento do $C L$, porém o seu volume aumenta 3 vezes entre os dias 4 e 16 do ciclo estral (FARIN et al., 1986). Durante o mesmo período, o número total de fibroblastos, células luteínicas pequenas e as células endoteliais aumentam 2,5; 3 e 6,5 vezes, respectivamente (FARIN et al., 1986).

Nos ovinos, as células luteínicas grandes correspondem apenas $4 \%$ do número total de células em um CL, no entanto, eles representam aproximadamente $25 \%$ do volume total da glândula e são responsáveis por 80 a $90 \%$ da produção de progesterona (FITZ et al., 1982; FARIN et al., 1986). Por sua vez, as células lúteinicas pequenas representam $19 \%$ do número total de células, $18 \%$ do volume luteal e produzem de 10 a $20 \%$ da progesterona. Apesar de uma maior capacidade esteroidogênica basal, as células luteínicas grandes não são estimuladas pelo LH. Entretanto, as células luteínicas pequenas podem aumentar a produção de progesterona de 2,3 para 12,4 vezes, quando estimuladas pelo LH (FITZ et al., 1982).

A função secretora do CL dependerá da capacidade esteroidogênica das células luteínicas, da quantidade de células esteroidogênicas e do fluxo sanguíneos da glândula. Tem sido demonstrado que a ovulação de folículos maiores resulta na formação de um maior $C L$, o qual leva a maiores concentrações de progesterona circulantes (VASCONCELOS et al., 2001).

O substrato para a síntese luteal de progesterona é o colesterol, geralmente obtidos a partir da hidrólise de ésteres de colesterol armazenado em gotículas lipídicas no citoplasma ou da circulação sanguínea (lipoproteína de baixa densidade - LDL ou lipoproteína de alta densidade - HDL; CAFFREY et al., 1979; NISWENDER et al., 2002). Acredita-se que em bovinos, a absorção do colesterol da corrente sangüínea ocorre a partir do HDL, isso acontece porque cerca de $90 \%$ do colesterol pré-formado circula na forma de HDL nesta espécie.

Uma vez no citoplasma, o colesterol livre é transportado para a mitocôndria através de proteínas de ligação e interação do citoesqueleto. O colesterol então é transportado para a membrana mitocondrial interna pela proteína reguladora aguda 
da esteroidogênese (StAR). Na matriz mitocondrial, o colesterol é clivado pela P450scc para formar pregnenolona, que é convertida em progesterona pela $3 \beta-H S D$ no retículo endoplasmático liso (NISWENDER et al., 2002).

Se a vaca não estiver gestantante, o $\mathrm{CL}$ deve ser regredido no final do ciclo estral para proporcionar mais uma oportunidade para a ovulação e a concepção. Presumi-se que assim como em Guinea-pigs, os bovinos degradem extensivamente a PGF2 $\alpha$ após sua primeira passagem pelos pulmões (PIPER et al., 1970; DAVIS et al., 1985). A dinâmica da PGF2 $\alpha$ pode ser avaliada através da medição das concentrações circulantes de seu principal metabólito 15-ceto-13,14-diidro-PGF2a (PGFM; KINDAHL et al., 1976b). O processo de luteólise é desencadeada pela liberação endometrial de 4-5 pulsos de PGF2a dentro de um intervalo de 2 dias (KINDAHL et al., 1976a). A duração de cada pulso varia de 6 a 8 horas (GINTHER et al., 2010). Durante o período de regressão luteal, a amplitude dos pulsos PGFM diminui a partir do primeiro (578 pg / mL) ao último pulso (131 pg / mL). As concentrações de progesterona diminuem após o primeiro pulso de PGF2 $\alpha$ (KINDAHL et al., 1976a; GINTHER et al., 2010). Inicialmente tem-se aumento agudo no fluxo sanguíneo, seguido de um aumento transitório nas concentrações de progesterona entre 1 e 2 horas após o primeiro pulso luteolítico da PGF2a. Então ocorre a indução de liberação local de peptídeos vasoativos [Endotelina-1 (ET-1) e Angiotensina-II (Ang II)] que induzem a diminuição do suprimento sanguíneo (fluxo) que, conseqüentemente, resulta em vasoconstrição, acompanhada pela diminuição constante da concentração de P4 até valores basais (GINTHER et al., 2010). Tem sido sugerido que a ação coordenada de estradiol, progesterona e ocitocina são responsáveis pela síntese de PGF2 $\alpha$ endometrial em ruminantes (MCCRACKEN et al., 1999).

Também, a PGF2 $\alpha$ age nas células luteínicas grandes, ligando-se com alta afinidade ao receptor da proteína $G$ e induzindo a ativação de fatores e moléculas intracelulares (fosfolipase C, IP3, DAG, $\mathrm{Ca}^{2+}$ livre e PKC) que levam a redução da atividade da StAR e estimulação da apoptose (NISWENDER et al., 2002).

\subsection{SICRONIZAÇÃO DA OVULAÇÃO E INSEMINAÇÃO ARTICIAL EM TEMPO FIXO}


Os avanços na genética e no manejo possibilitaram o crescente aumento do número de vacas por rebanho. Entretanto, com esse aumento foi criado um novo problema para o manejo reprodutivo das vacas leiteiras: a detecção eficiente do estro. Os métodos tradicionais de detecção de estro são ineficientes quando aplicados em grandes rebanhos leiteiros por haver uma alta relação vacas/funcionários, resultando principalmente na diminuição da precisão e eficiência de detecção de estro (0 a 60\%; REIMERS et al., 1985; NEBEL et al., 1987). Sabe-se que a eficiência de detecção de estro (e conseqüentemente a taxa de serviço) é um dos mais importantes fatores que limitam o desempenho reprodutivo de vacas leiteiras. Se este parâmetro estiver aquém do desejado não é possível alcançar os almejados altos índices reprodutivos.

Uma maneira de contornar o declínio no desempenho reprodutivo de rebanhos leiteiros é a aplicação de métodos para controlar a dinâmica folicular e lútea. Aplicações de protocolos reprodutivos permitem a sincronização do desenvolvimento folicular, a regressão luteal e a sincronização do momento da ovulação, sem a necessidade da detecção do estro (BÓ et al., 1995). Em alguns estudos, as taxas de concepção após inseminação artificial em tempo fixo (IATF) são menores do que aquelas encontradas com a inseminação artificial (IA) tradicional. Porém, as taxas de prenhez geralmente são maiores após IATF devido ao fato de $100 \%$ das vacas serem inseminadas (100\% de taxa de serviço), fato que não ocorre na IA tradicional.

Os programas de sincronização do estro e ovulação têm sido desenvolvidos para maximizar o uso da (IA) após o término do período de espera voluntária (PEV) e melhorar o desempenho reprodutivo de rebanhos leiteiros. Portanto, os protocolos que permitem inseminação artificial em tempo fixo (IATF), para inseminar sem a necessidade de detecção de estro, foram desenvolvidos para aumentar as taxas de serviço em vacas (PURSLEY et al., 1995; KINDER et al., 1996). Geralmente, esses protocolos usam GnRH e PGF2a (protocolo Ovsynch; PURSLEY et al., 1995) ou estrógenos em conjunto com tratamentos de progesterona (BÓ et al., 1995; KINDER et al., 1996).

O recrutamento de novo grupo de folículos pode ser obtido através do tratamento com GnRH, o qual induz um pico endógeno de $\mathrm{LH}$ e FSH e conseqüentemente a ovulação do folículo dominante e recrutamento de uma nova 
onda (FERNANDES et al., 1978; MACMILLAN; THATCHER, 1991 ). A eficácia do $\mathrm{GnRH}$ para recrutar uma nova onda folicular depende da presença de um folículo dominante no ovário responsivo ao LH. No entanto, em animais da raça Holandesa a resposta ovulatória consistente ao $\mathrm{LH}$ foi observada somente quando o folículo dominante atingiu $10 \mathrm{~mm}$ ou mais de diâmetro em (SARTORI et al., 2001).

Thatcher et al. (1989) demonstraram que o tratamento com $\mathrm{GnRH} 7$ dias antes da administração de PGF2 $\alpha$ aumentou o número de animais sincronizados dentro de um período de 5 dias e a concentração de animais durante os dias 2 e 3 após a aplicação da PGF2 $\alpha$ em relação às vacas tratadas com uma única administração de PGF2a. A adição de mais uma administração de GnRH para sincronização da ovulação do folículo dominante deu origem ao protocolo Ovsynch (PURSLEY et al., 1995). Este protocolo consiste em uma primeira administração de GnRH para induzir a emergência de uma nova onda folicular, seguida da administração de PGF2 $\alpha$ sete dias após para induzir a regressão do corpo lúteo. Então, uma segunda injeção de GnRH foi administrada 48 horas após a PGF2 $\alpha$ e a inseminação 24 horas mais tarde.

Os dados da literatura têm demonstrado que o tempo de indução da ovulação após luteólise e intervalo entre a indução da ovulação e a Al tem modulado a taxa de prenhez. Pursley et al. (1998) observaram que a taxa de concepção foi significativamente reduzida apenas quando a inseminação era realizada 32 horas após o segundo GnRH do protocolo Ovsynch. No entanto, os mesmos autores relataram efeito quadrático do intervalo entre a última aplicação de GnRH e IATF e, que máxima taxa de concepção foi observada quando as vacas foram inseminadas 16 horas após o GnRH.

Com base nestes dados e procurando determinar o intervalo ótimo entre 0 pico de LH e o momento da inseminação, Brusveen et al. (2008) atrasaram a administração do segundo $\mathrm{GnRH}$ para 56 horas após a PGF2 a e mantiveram a inseminação às mesma 16 horas. Este ajuste do protocolo promoveu o aumento da taxa de prenhez e o estabelecimento deste protocolo (Ovsynch-56).

Procurando compreender melhor a variação de resultados do protocolo Ovsynch, Vasconcelos et al. (1999) verificaram que a fase do ciclo estral em que o protocolo de sincronização é iniciada afeta a taxa de ovulação ao primeiro e segundo $\mathrm{GnRH}$, emergência folicular, sincronia da ovulação e, conseqüentemente, a taxa de concepção. Neste estudo, foi verificado que animais entre os dias 5-9 do 
ciclo estral resultaram em maior fertilidade. Porém, quando o protocolo foi iniciada após o $10^{\circ}$ dia do ciclo estral, uma grande proporção de vacas apresentou regressão espontaneamente do $\mathrm{CL}$ antes da injeção de $\mathrm{PGF} 2 \alpha$, que tem sido associado com declínio da fecundidade (CHEBEL et al., 2006), devido a ovulação precoce (VASCONCELOS et al., 1999). Além disso, a capacidade do GnRH para induzir a ovulação do folículo dominante e sincronizar a emergência de uma nova onda folicular foi muito reduzida quando o protocolo foi iniciado entre os dias 1 e 4 do ciclo estral (VASCONCELOS et al., 2009; CERRI et al., 2009). Porém, a falta de ovulação em resposta ao primeiro $\mathrm{GnRH}$ foi associada com a presença de um folículo maior no final do protocolo e com reduzida fertilidade (VASCONCELOS et al., 1999; CERRI et al., 2009). Quando administrado em estágios aleatórios do ciclo estral, espera-se que apenas 50 a $60 \%$ dos animais tratados ovulem em resposta ao $\mathrm{GnRH}$, entretanto, apenas $41,1 \%$ ovularam quando este conceito foi testado em vacas leiteiras pós-parto (NAVANUKRAW et al., 2004).

Com base nestas informações, diversos estudos foram desenvolvidos para pré-sincronizar os animais e assim controlar o dia do ciclo estral no qual se inicia o Ovsynch e assim, melhorar eficiência de resposta ao tratamento. O protocolo mais tradicional e utilizado nos Estados Unidos é o Presynch. Ele consiste na administração de duas aplicações de PGF2 $\alpha$ com intervalo de 14 d entre elas e o início do protocolo Ovsynch 14 (NAVANUKRAW et al., 2004) ou 12 (MOREIRA et al., 2001) após a segunda dose de PGF2a. O uso do Presynch aumentou a taxa de prenhez em vacas cíclicas (MOREIRA et al., 2001) e todas as vacas (NAVANUKRAW et al., 2004).

Acredita que essa melhora deve ser causado por um aumento da proporção de vacas no início ou meados do diestro, melhorando assim a resposta ao primeiro $\mathrm{GnRH}$, aumento na proporção de vacas cíclicas com CL funcional ao GnRH e PGF2a, sincronização da emergência da onda folicular e prevenção da luteólise espontânea antes da conclusão do protocolo (VASCONCELOS et al., 1999; MOREIRA et al., 2000). Porém, não se sabe se ela alterou a taxa de ovulação ao $1^{\circ}$ GNRH, que é fundamental para melhorar a taxa de concepção (CHEBEL et al., 2006) devido a melhora na qualidade embrionária em vacas leiteiras (CERRI et al., 2009).

Recentemente, foi demonstrado que a redução do intervalo entre présincronização e IATF de 14 para 11 dias aumentou a resposta ovulatória ao primeiro 
GnRH do protocolo de IATF e melhorou a taxa de concepção (GALVÃO et al., 2007). Embora pré-sincronização com PGF2 $\alpha$ melhore a resposta à IATF, a PGF2 $\alpha$ não tem nenhum efeito sobre o ciclo estral de vacas anovular, limitando a eficácia dos programas pré-sincronização baseada unicamente em PGF2 $\alpha$.

Sabe-se que uma considerável percentagem vacas de leite apresenta condição anovular (20-30\%) no momento do primeiro GnRH do Ovsynch (MOREIRA et al., 2001; GÜMEN et al., 2003;. LOPEZ et al., 2005b). Logo, protocolos que estimulem a ciclicidade em vacas anovulares são de grande importância. Outra limitação dos protocolos Presynch (baseados apenas na administração de PGF2) é que tanto a fase folicular, quanto a lútea não são precisamente sincronizados.

Outra possibilidade de pré-sincronização seria a utilização de PGF2 $\alpha$ seguida da aplicação de GnRH 6 dias (G6G) antes do inicio do Ovsynch, pois desta forma tanto vacas ciclicas, quanto anovulares, poderiam responder a pré-sincronização. $O$ tratamento com G6G superou os outros tratamentos, aumentando a porcentagem de vacas com ovulação ao primeiro $\mathrm{GnRH}$ e a porcentagem de vacas que responderam a PGF2 $\alpha$ do Ovsynch. Como resultado, as vacas pré-sincronizadas como o G6G responderam melhor ao protocolo Ovsynch em comparação com os controles.

Um estudo posterior (SOUZA et al., 2008) utilizou um protocolo que foi chamado de Double-Ovsynch (pré-sincronização com o protocolo Ovsynch seguido 7 dias mais tarde por um outro protocolo Ovsynch para (ATF), a fim de estimular a ciclicidade e melhorar a sincronização dos animais com um protocolo présincronização. Foi demonstrado que o Double-Ovsynch foi eficiente em aumentar a taxa de concepção em relação ao Presynch-Ovsynch (SOUZA et al., 2008).

Outra maneira de realização da sincronização da ovulação para a realização de IATF seria utilização de P4 associada ao estrógeno (E2). A P4 e os progestágenos são substâncias que podem ser administradas por via oral (MGA), por implantes subcutâneos $\left(\right.$ SyncroMateB ${ }^{\circledR}$, Crestar $^{\circledR}$ ) ou por dispositivos intravaginais (PRID ${ }^{\circledR}, \mathrm{CIDR}^{\circledR}, \mathrm{DIB}^{\circledR}, \mathrm{PRIMER}^{\circledR}$, entre outros). O E2 foi originalmente incorporado à programas de sincronização de estro utilizando $\mathrm{P} 4$, para causar a lise do CL (PRATT et al., 1991; FANNING et al., 1992). No entanto, relatos posteriores demonstraram que a progesterona associada com o E2 foi responsável pela regressão do folículo e a sincronia de uma nova onda folicular (BÓ et al., 1991, 1993, 1994, 1995; CACCIA; BÓ, 1998). 
Os E2 tem a sua ação modulada pela presença ou não de $P 4$, seja ela endógena ou exógena. Assim, os E2 quando administrados na presença de P4, causam a diminuição dos níveis circulantes de FSH e LH provocando a regressão dos folículos gonadotróficos dependentes. Após a metabolização e a diminuição das concentrações plasmáticas de E2 verifica-se o surgimento de um pico de FSH e a emergência de uma nova onda de crescimento folicular. O mecanismo responsável pela supressão do crescimento folicular induzida pelo E2 parece ser mais sistêmico que local (BÓ et al., 2000).

O $17 \beta$-estradiol produzido pelo folículo na ausência de P4 leva à liberação de GnRH pelo hipotálamo, estimulando a produção de LH pela hipófise, culminando na ovulação (RATHBONE et al., 2001). Assim, a administração de E2 durante a fase folicular do ciclo estral associado ao E2 endógeno leva a um efeito ovulatório. Por isso é importante que elevados níveis de P4 estejam presentes no momento do início do tratamento para evitar um pico pré-ovulatório de LH (BÓ et al., 1994).

Então após a sincronização da emergência folicular, é preconizada a aplicação de $\mathrm{PGF}_{2 \propto}$ no momento da retirada da fonte de P4 para indução da luteólise e queda dos níveis endógenos de P4, propiciando condições favoráveis à ovulação.

Os fármacos utilizados para a indução da ovulação agem por retroalimentação positiva na liberação pulsátil de LH (E2 e GnRH) ou diretamente nos receptores de LH das células da granulosa e da teca dos folículos (hCG e LH). Os indutores de ovulação quando administrados isoladamente não são capazes de sincronizar adequadamente a ovulação para a IATF. No entanto, quando associados a P4, E2 e PGF2 $\alpha$ induzem ovulação sincronizada do folículo dominante presente no final do tratamento, possibilitando o emprego da IATF.

Segundo Clarke (1989) a resposta folicular ao tratamento com GnRH deve-se à liberação de LH, sendo que a concentração plasmática de P4 proveniente da fase luteínica não afeta a resposta hipofisária ao $\mathrm{GnRH}$, uma vez que a retroalimentação negativa da P4 sobre a liberação de LH ocorre no hipotálamo. Por outro lado, Cruz, Rubianes et al. (1997) e Valle e Kesler (1997) observaram que a aplicação de GnRH 30 ou 48 horas após a aplicação de PGF $_{2 \alpha}$ induziu um pico de LH com maior amplitude do que quando aplicado no início ou no meio da fase luteínica. Isto indica que, possivelmente, além do estágio de desenvolvimento folicular, as concentrações 
hormonais que precedem o pico de LH são importantes na determinação da resposta ovulatória. Logo, um período adequado de proestro é desejado em programas de IATF. Uma vantagem da utilização dos protocolos utilizando P4 associado ao estrógeno é o fato de não necessitarem de programas de présincronização. Porém, existem países onde o uso do estrógeno é proibido.

\subsection{PROMOTORES DE CRESCIMENTO FOLICULAR}

\subsubsection{Gonadotrofina coriônica equina (eCG)}

A presença de uma substância de ação gonadotrófica no soro de éguas e outros eqüídeos gestantes foi primeiro descrito por Cole e Hart (1930) A gonadotrofina sérica de éguas prenhas (PMSG) é um hormônio glicoprotéico secretado pelos cálices endometriais de equinos gestantes. Posteriormente, foi observado que este hormônio era produzido pela parte materna da placenta (ALLEN; MOOR, 1972). Ainda concluíram que uma melhor terminologia para esta glicoproteína seria gonadotrofina coriônica eqüina (eCG). Mais especificamente, estes autores descobriram que a eCG é produzida pelas células trofoblásticas presentes nos cálices endometriais de éguas prenhez. A eCG é composta de duas subunidades ( $\alpha$ - composta por 96 aminoácidos; e $\beta$ - composta por 149 aminoácidos). É descrito tanto ação $\mathrm{FSH}$, quanto LH mesma molécula (GOSPODAROWICS, 1972; LEGARDINIER et al., 2005). As ações de FSH e LH desta gonadotrofina eqüina também foi demonstrada em outras espécies (WARD; MOORE, 1979). Sabe-se que o pico de liberação de eCG ocorre ao redor dos 60 dias de gestação dos equinos, mas o aumento na liberação se dá ao redor de 40 dias de gestação e perdura até aproximadamente os 130 dias de gestação (MURPHY; MARTINUK, 1991). Sabe-se que no equinos a eCG causa ovulação ou luteinização de folículos e, conseqüentemente, aumento da progesterona circulante (URWIN; ALLEN, 1982). 
Uma característica importante da molécula de eCG é a existência de grande quantidade de carboidratos (aproximadamente $45 \%$ de sua massa) principalmente a $\mathrm{N}$-acetil neuramina (ou ácido siálico). Estes carboidratos estão presente na subunidade $\beta$ da molécula de eCG, o que proporciona uma grande meia vida a este composto químico (WARD; MOORE, 1979; MURPHY; MARTINUK, 1991). Martinuk et al. (1991) utilizando uma enzima chamada neuraminidase, retirou diferentes porcentagens de ácido siálico da molécula de eCG e mostraram que a meia-vida desta gonadotrofina esta intimamente relacionada à quantidade de ácido siálico presente na sua molécula. Por exemplo, quando cerca de $80 \%$ do ácido siálico foi retirado da molécula, os níveis circulantes de eCG já eram basais $1 \mathrm{~h}$ após sua administração. Porém, no grupo controle (sem incubação com neuraminidase), altos níveis circulantes de eCG estavam presentes mesmo $120 \mathrm{~h}$ após o tratamento. Ainda, além do alto peso molecular e da presença de ácido siálico, a molécula de eCG é carregada negativamente, o que dificulta a sua filtração glomerular e aumenta ainda mais sua meia-vida (LEGARDINIER et al., 2005). Devido a todos estes fatores, a meia-vida da eCG, quando aplicado em bovinos, é longa (cerca de 40h; MENZER et al., 1979). Ainda, as quantidades de ácido siálico e carboidrato podem variar bastante de eqüino para eqüino, conforme o estágio de gestação e conforme o tecido no qual foi coletado a molécula de eCG (MURPHY; MARTINUK, 1991). Além disso, a quantidade de eCG circulante varia bastante conforme a raça do animal, a sua idade e a presença de gestações gemelares. Por exemplo, animais de tração possuem níveis circulantes de eCG menores que em animais de menor peso corporal (MURPHY; MARTINUK, 1991).

A eCG pode ter função luteotrófica em eqüinos e outras espécies, sendo possível verificar aumentos nas concentrações circulantes de progesterona após o aumento natural ou devido a administração exógena (MURPHY; MARTINUK, 1991). Estas informações estão de acordo com um estudo de Daels et al. (1998), o qual demonstrou que a eCG tem importante ação luteotrófica durante a gestação de éguas.

Devido sua ação FSH, a eCG foi inicialmente utilizado em protocolos para superovulação em bovinos (GONZALES et al., 1994). Porém alguns autores observaram que devido à sua grande meia-vida, a eCG parece estar associada a presença de folículos anovulatórios (ELSDEN et al., 1978) e a produção de embriões de baixa qualidade (BOLAND et al., 1978; CRITSER et al., 1980). Desta forma, os 
procedimentos superovulatórios, em geral, passaram a utilizar outros compostos de gonadotrofinas nos programas de superovulação. Entretanto, o uso de protocolos de superovulação com ovulação induzida resultaram em taxas similares de produção de embrião quando a eCG foi utilizada (MARTINS et al., 2006). Assim, fica evidenciado que este fármaco pode ser utilizado em programas de superovulação, deste que se utilize indutores de ovulação.

Mais recentemente, a eCG têm sido incorporado em protocolos para IATF em vacas de corte (CAVALIERI et al., 1997) e leite (SOUZA, 2008). O tratamento com eCG na dose de 400 UI é altamente recomendado quando uma grande proporção dos animais se encontra em anestro (HUMBLOT et al., 1996; BARUSELLI et al., 2004) ou baixa condição corporal (SOUZA, 2008). Existem muitos relatos de aumentos na fertilidade após a incorporação da eCG em protocolos para IATF, principalmente em vacas de corte (BARUSELLI et al., 2004, SÁ FILHO et al., 2010). A melhora na taxa de concepção em animais que recebem a eCG na retirada do dispositivo intravaginal de P4, provavelmente, está relacionada ao aumento da taxa de ovulação de animais em anestro e aos maiores níveis de progesterona circulante no diestro (BARUSELLI et al., 2004), minimizando falhas no reconhecimento fetal da gestação (MANN; HARESIGN, 2001).

\subsubsection{Hormônio folículo estimulante (FSH)}

O hormônio folículo estimulante (FSH) é uma glicoproteína secretada pelas células gonadotróficas da adeno-hipófise. É constituída por duas subunidades de polipeptídeos ( $\alpha$ e $\beta$ ), com presença de ácido siálico em pontos específicos de cada subunidade. A subunidade $\alpha$ apresenta a mesma constituição química em todas as espécies. Já, a subunidade $\beta$ apresenta composição diferente e determina a atividade biológica dessa molécula (SPINOSA et al., 2006). Esta diferença é devido as variações na composição das quatro cadeias de carboidratos (em especial o seu teor de ácido siálico) ligado às duas (alfa e beta) subunidades protéicas (CHAPPEL, 1995), gerando assim diferentes isoformas. Estas isoformas diferem em seus pesos moleculares, potência biológica, meia-vida de eliminação e imunoreatividade 
(STANTON et al., 1992). O conteúdo de ácido siálico é o principal determinante da meia-vida, quanto maior o teor de ácido siálico, maior a acidez da isoforma e maior a meia-vida biológica (STANTON et al., 1992).

A variabilidade na resposta ovariana ao tratamento com $\mathrm{FSH}$ tem sido atribuída a fatores como pureza do hormônio (razão entre o conteúdo de FSH e LH; LINDSELL et al., 1986; GONZALEZ et al.,1990; WILLMOTT et al.,1990), quantidade de gonadotrofina administrada (GONZALEZ et al.,1990), via e local da administração e quantidade de gordura subcutânea (BO et al., 1994). A respeito da meia-vida do FSH a literatura possui dados conflitantes, pois existem relatos de meia-vida de 3060 min (DE ROOVER et al., 2008), assim como de 5 horas (DEMOUSTIER et al., 1988).

Acreditava-se que a ligação do FSH fosse restrita às células granulosas, entretanto foi demonstrado que o oócito também possui receptores de FSH (MÉDURI et al., 2002). Na célula da granulosa, a ligação ao receptor promove a síntese de AMP cíclico, o qual estimula a produção de proteína quinase, resultando em fosforilação de proteínas, o que apresenta como resposta imediata a produção de esteróides e, posterior síntese de RNA, DNA e proteínas (SPINOSA et al., 2006). Além disso, o FSH promove a estimulação da proliferação das células da granulosa, expressão de fator de crescimento epidérmico (EGF) e expressão de receptores LH (WANG; GREENWALD, 1994).

$\mathrm{O}$ FSH age em sinergismo com o estradiol para aumentar o número de receptores FSH nas células da granulosa (RICHARDS et al., 1976), desempenha papel na formação antro (GOLDENBERG et al., 1972; RICHARDS et al., 1975) e estimula a proliferação celular na granulosa (GOLDENBERG et al., 1972; RAO et al., 1978).

Estudos de utilizando ratas adultas, demonstraram a presença de receptores de FSH em todos os folículos com uma única camada de célula da granulosa. A quantidade destes receptores vão aumentando com o desenvolvimento de folículos saudáveis. Porém, após o pico de LH ocorre uma queda drástica na concetração deste receptores.

Quando ocorre o declínio das concentrações de FSH, os folículos começam a mostrar alterações características como a redução da atividade estrogênica, alterações nas concentrações de proteínas de alto e baixo peso molecular, perda da expressão dos receptores de FSH, redução dos níveis de RNA mensageiro do 
receptor de $\mathrm{FSH}$, que culmina com a apoptose das células da granulosa (SUNDERLAND et al., 1996, MIHM et al., 1997; MÉDURI et al., 2002). A prevenção desta diminuição, através da administração de quantidades fisiológicas de FSH, também impede a atresia do folículo subordinado e é associada a mudanças nas concentrações intrafoliculares de estradiol, inibina e as IGFBP's (ADAMS et al., 1993; MIHM et al., 1997; AUSTIN et al., 2002).

Diversos trabalhos têm mostrado que as concentrações basais de FSH são essenciais para a sobrevivência do folículo dominante (FD) e que a supressão de FSH a níveis inferiores aos basais normais predispõe à atresia do FD (ADAMS et al., 1992; TURZILLO; FORTUNE, 1993). Ainda, Hunter et al. (2004) afirmam que concentrações elevadas de FSH podem, por si só induzir o crescimento folicular até tamanho pré-ovulatório.

Recentemente o FSH foi utilizado em estudos com protocolos para IATF em vacas de corte (SANTOS et al., 2007a,b; SÁ FILHO et al., 2009; SALES et al., 2009; LIMA et al., 2010; MARTINS et al., 2010). Os objetivos desses experimentos foram avaliar se uma única dose de FSHp estimularia o crescimento final do folículo dominante até o estágio pré-ovulatório, com capacidade de responder a indução de ovulação (SANTOS et al., 2007a; SALES et al., 2009; MARTINS et al., 2010) e comparar as taxas de prenhez de vacas em anestro (SANTOS et al., 2007b; SÁ FILHO et al., 2009; SALES et al., 2009; LIMA et al., 2010; MARTINS et al., 2010) tratadas com FSH ou eCG no momento da administração de PGF2 $\alpha$ em programas utilizando dispositivo de progesterona e benzoato de estradiol.

Segue abaixo tabela 1 com os dados de taxa de prenhez destes estudos. 
Tabela 1 - Taxa de prenhez de vacas de corte submetidas a diferentes protocolos para inseminação artificial em tempo fixo com ou sem a administração de eCG ou FSH

\begin{tabular}{|c|c|c|c|c|}
\hline $\mathrm{N}^{0}$ de animais & Controle & eCG & $\mathrm{FSH}$ & Referência \\
\hline 232 & $\begin{array}{c}29,9 \% \\
(23 / 77)^{b}\end{array}$ & $\begin{array}{c}60,2 \% \\
(47 / 78)^{\mathrm{a}}\end{array}$ & $\begin{array}{c}59,7 \% \\
(46 / 77)^{\mathrm{a}}\end{array}$ & Santos et al., 2007 \\
\hline 709 & $\begin{array}{c}41,9 \% \\
(83 / 198)^{a^{\star}}\end{array}$ & $\begin{array}{c}43,3 \\
(81 / 187)^{a}\end{array}$ & $\begin{array}{c}34,0 \\
(110 / 324)^{b^{* *}}\end{array}$ & Sá Filho et al., 2009 \\
\hline 444 & $\begin{array}{c}43,9 \% \\
(65 / 148)^{b}\end{array}$ & $\begin{array}{c}62,3 \% \\
(91 / 146)^{a}\end{array}$ & $\begin{array}{c}43,3 \% \\
(65 / 150)^{b}\end{array}$ & Sales e t al., 2009 \\
\hline 421 & $\begin{array}{c}26,3 \% \\
(25 / 95)^{b}\end{array}$ & $\begin{array}{c}41,5 \% \\
(95 / 229)^{\mathrm{a}}\end{array}$ & $\begin{array}{c}22,7 \% \\
(22 / 97)^{b}\end{array}$ & Lima et al., 2010 \\
\hline 533 & $\begin{array}{c}38,9 \% \\
(69 / 177)^{b}\end{array}$ & $\begin{array}{c}55,9 \% \\
(99 / 177)^{\mathrm{a}}\end{array}$ & $\begin{array}{c}51,4 \% \\
(92 / 179)^{a}\end{array}$ & Martins et. al., 2010 \\
\hline
\end{tabular}

*remoção de bezerros; ** média dos animais tratados com Folltropin e Pluset

Ao analisarmos estes dados, podemos verificar que nos três primeiros estudos mostrados na tabela 1 acima, as taxas de prenhez com o uso da eCG foram superiores àquelas obtidas com o tratamento com o FSH. Porém, os últimos dois estudos demonstraram que o FSH é tão eficiente quanto a eCG. Estes dados estão completamente de acordo com os relatos de campo, já que os resultados têm apresentado as mesmas variações acima descritas.

Com respeito a dinâmica folicular, dois trabalhos (SALES et al., 2009; MARTINS et al., 2010) mensuraram o diâmetro do maior folículo no momento da aplicação ou não de eCG/FSH e no momento da IATF, além de avaliar a taxa de ovulação destes folículos. No estudo de Sales et al. (2009), foi notado que apenas a eCG aumentou o a taxa de crescimento folicular do maior folículo, o diâmetro do maior folículo na IATF, a taxa de ovulação e, conseqüentemente, a taxa de prenhez. Já no estudo de Martins et al. (2010), não foi notado aumento dos diâmetros foliculares, mas a taxa de ovulação foi superior nos grupos tratados com eCG ou FSH. Analisando os diâmetros foliculares encontrados pelos pesquisadores, acredita-se que um maior número de animais do estudo de Sales et al. (2009) apresentavam-se em anestro profundo que os animais de Martins et al. (2010). 
Todos estes resultados foram realizados em bovinos de corte, entretanto, não há relato da utilização do FSH em bovinos leiteiros. 


\section{EXPERIMETO 1 - SUPLEMENTAÇÃO COM FSH NO PROTOCOLO OVSYNCH}

\subsection{MATERIAIS E MÉTODOS}

\subsubsection{Animais e manejo}

Para a realização desse experimento foram utilizadas 1.132 vacas da raça Holandesa em lactação produzindo em média 41,5 litros por dia, dividias em duas propriedades comerciais localizadas no centro-sul de Wisconsin, EUA, sendo 900 vacas da Wager's Farms e 232 da Mystic Valley Dairy. No período de junho a novembro de 2007 foram conduzidos o teste de prenhez (com todas as vacas) e a dinâmica folicular ovariana, para a qual se utilizou um subgrupo de vacas do teste de prenhez ( $\mathrm{n}=197)$ exclusivamente em primeiro serviço. Todas as vacas permaneceram alocadas em galpões com canzis, água ad libitum e camas com com areia, às quais possuíam livre acesso. A dieta foi balanceada para atender ou exceder os requisitos nutricionais mínimos para bovinos leiteiros (NRC, 2001). As ordenhas foram realizadas três vezes ao dia em intervalos de 8 horas. Os tratamentos, avaliações ultrassonográficas e coletas de sangue foram realizados após a ordenha, enquanto as vacas estavam presas nos canzis na linha de alimentação. Todas as vacas receberam somatotropina bovina (500 mg / dose; Posilac, a Monsanto Co., St. Louis, MO, EUA) a cada 14 dias, a partir de 60 dias pós-parto. O escore de condição corporal (ECC) e de locomoção (EL) foram registrados utilizando o sistema de 5 pontos: 1 = magra a 5 = obesa (FERGUSON et al., 1994), e 1 = normal a 5 = claudicação extrema (SPRECHER et al., 1997), respectivamente. Todos os procedimentos foram aprovados pela Comissão de Bioética da Universidade de Wisconsin-Madison. 
5.5.2 Protocolos hormonais utilizados e diagnóstico de gestação

Semanalmente, um grupo de 35 a 65 vacas com $120 \pm 73$ dias em lactação (DEL) foi dividido em blocos experimentais por paridade e número prévio de serviços para compor o teste de prenhez. Posteriormente, foram distribuídas aleatoriamente em dois tratamentos: Ovsynch $(n=561)$ ou Ovsynch + FSH $(n=571)$. As vacas que seriam inseminadas pela primeira vez (primeiro serviço) foram tratadas com um de dois protocolos de pré-sincronização, Presynch ou Double-Ovsynch. As vacas com mais de um serviço foram tratadas com um protocolo de ressincronização (Resynch), o qual teve início 32 dias após IA anterior (Figura 1).

As vacas tratadas com Presynch-Ovsynch $(n=317)$ receberam duas injeções de PGF $_{2 \alpha}$ (Prostamate ${ }^{\circledR}, 25 \mathrm{mg}$ de dinoprost, IVX Animal Health, Inc., St. Joseph, MO) aos $42 \pm 3$ e $56 \pm 3$ DEL e 12 dias após a segunda PGF $_{2 a}$ o protocolo Ovsynch para inseminação foi iniciado.

As vacas tratadas com Double-Ovsynch $(n=330)$ receberam o primeiro $\mathrm{GnRH}$ (Ovacyst $^{\circledR}, 100$ mg de gonadorelina, IVX Animal Health, Inc., St. Joseph, MO) aos 51 \pm 3 DEL, seguido por uma injeção de $\mathrm{PGF}_{2 \alpha}$ sete dias depois e outra de GnRH 72 horas após a PGF ${ }_{2 \alpha}$. O segundo protocolo Ovsynch (para a inseminação) foi iniciado sete dias após o segundo GnRH.

O protocolo Ovsynch para inseminação consistiu na administração de $\mathrm{GnRH}$ $\left(1^{\circ} \mathrm{GnRH}\right)$ aos $68 \pm 3 \mathrm{DEL}$, seguido da administração de PGF $F_{2 \alpha}$ sete dias depois e $\mathrm{GnRH}\left(2^{\circ} \mathrm{GnRH}\right) 56$ horas após a administração de $\mathrm{PGF}_{2 \alpha}$. A IATF foi realizada 16 horas após o tratamento com o $2^{\circ} \mathrm{GnRH}$.

O protocolo Resynch $(n=485)$ teve início 32 dias após a inseminação prévia, com a administração de $\mathrm{GnRH}$. Sete dias depois foi realizado o diagnóstico de gestação e apenas as vacas não gestantes seguiram no protocolo, recebendo nessa ocasião $\mathrm{PGF}_{2 \alpha}$, seguida da segunda dose de $\mathrm{GnRH} 56$ horas após e realização da IATF 16 horas após o tratamento com o $2^{\circ} \mathrm{GnRH}$.

Independentemente do número de serviços e do protocolo de présincronização utilizado, as vacas que compuseram o Grupo Ovsynch + FSH receberam $20 \mathrm{mg}$ de FSH (Folltropin ${ }^{\circledR}$, Bioniche, Canadá) no momento da administração da $\mathrm{PGF}_{2 \alpha}$ do protocolo Ovsynch de inseminação. As demais não receberam suplementação com FSH. 
O sêmen de 12 touros foi utilizado e distribuído homogeneamente entre os tratamentos e fazendas. O diagnóstico de gestação foi realizado por palpação transretal 40 dias após a administração do $2^{\circ} \mathrm{GnRH}$. 


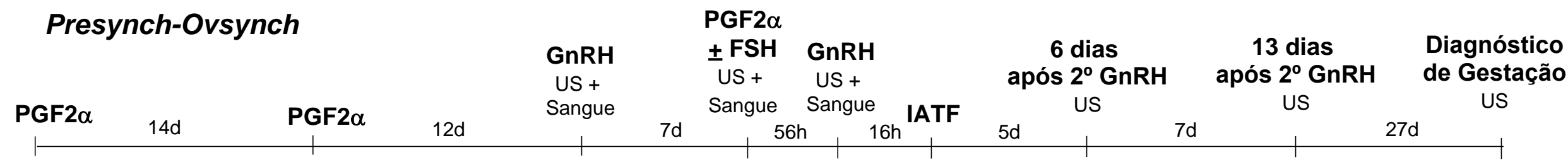

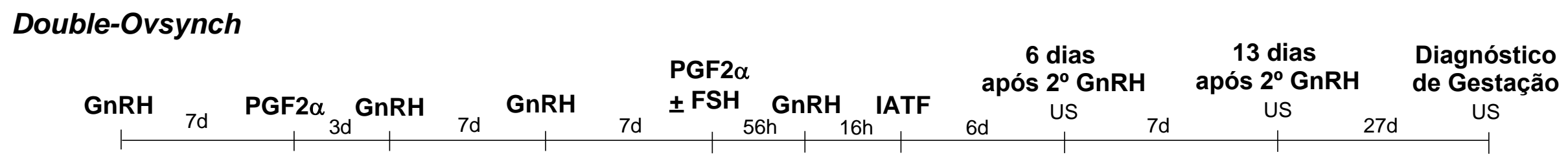

\section{Resynch}

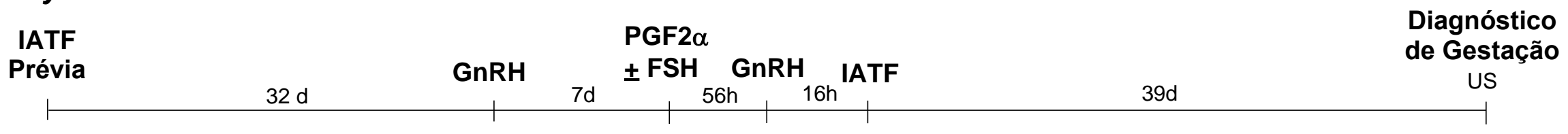

Figura 1 - Desenho experimental esquemático dos tratamentos das vacas de primeiro (Presynch-Ovsynch, $n=317$ ou Double-Ovsynch, $n=330$ ) ou demais (Resynch, $n=485$ ) serviços. US = Avaliações ultrassonográficas, Sangue $=$ coleta de sangue, $d=$ dias e $h=$ horas. 
5.5.3 Avaliação ultrassonográfica ovariana e uterina

A avaliação ultrassonográfica dos ovários (dinâmica folicular ovariana) e útero foi realizada em um subgrupo de 197 vacas de primeiro serviço do teste de prenhez (Ovsynch, $\mathrm{n}=102$ e Ovsynch + FSH, $\mathrm{n}=95$ ), utilizando um transdutor linear de 7,5 $\mathrm{MHz}$ (EASI-Scan®, BCF Technology Ltda, Livingston, Reino Unido). Os exames foram realizados no momento da administração do $1^{\circ} \mathrm{GnRH}(68 \pm 3 \mathrm{DEL})$, da PGF $2 \alpha$ (75 $\pm 3 \mathrm{DEL})$, do $2^{\circ} \mathrm{GnRH}(77 \pm 3 \mathrm{DEL})$, seis (83 $\left.\pm 3 \mathrm{DEL}\right)$ e 13 (90 $\left.\pm 3 \mathrm{DEL}\right)$ dias após o tratamento com o $2^{\circ} \mathrm{GnRH}$ do protocolo Ovsynch de inseminação. As avaliações foram realizadas para determinar a presença de CL no momento da administração do $1^{\circ} \mathrm{GnRH}$ e da $\mathrm{PGF}_{2 \alpha}$, a espessura endometrial e o diâmetro do maior folículo no momento da administração do $2^{\circ} \mathrm{GnRH}$ e a taxa de ovulação ao $1^{\circ}$ e $2^{\circ} \mathrm{GnRH}$.

A ovulação foi caracterizada pelo aparecimento de um novo CL no ovário no momento da administração de $\mathrm{PGF}_{2 \alpha}$ ou seis dias após a aplicação do $2^{\circ} \mathrm{GnRH}$ do protocolo Ovsynch de inseminação (Figura 1). A luteólise foi caracterizada pela ocorrência de concentrações de P4 inferiores a 0,5 ng / mL no momento da administração do $2^{\circ} \mathrm{GnRH}$ do protocolo de inseminação.

5.5.4 Coleta de sangue e dosagem hormonal para avaliação da função ovariana

Amostras de sangue foram coletadas por punção da veia ou artéria caudal mediana em um subgrupo de 197 vacas de primeiro serviço do teste de prenhez (Ovsynch, $n=102$ e Ovsynch + FSH, $n=95$ ). As coletas de sangue para dosagem de P4 foram realizadas antes da administração de cada fármaco (10 GnRH, PGF $2 \alpha$ e $2^{\circ} \mathrm{GnRH}$ ) do protocolo Ovsynch de inseminação e também 6 e 13 dias após o $2^{\circ}$ $\mathrm{GnRH}$. Para a dosagem de E2 a coleta foi realizada no momento do $2^{\circ} \mathrm{GnRH}$. Tubos com vácuo (Becton Dickinson, Franklin Lakes, NJ) individuais foram utilizados para esse fim. As amostras foram mantidas em temperatura ambiente de uma a três horas após a coleta e, posteriormente, refrigeradas a $4^{\circ} \mathrm{C}$ até o momento da 
centrifugação (3000 x g por 20 min). O soro foi separado e armazenado a $-20^{\circ} \mathrm{C}$ até a realização da dosagem das concentrações de P4 e E2.

As concentrações de P4 foram analisadas em todas as amostras de soro por radioimunoensaio (RIA), utilizando um kit comercial (Coat-A-Count, Siemens Healthcare Diagnostics, Los Angeles, CA). A sensibilidade do ensaio foi de 0,1 ng / $\mathrm{mL}$. As amostras foram analisadas em um único ensaio, sendo o coeficiente de variação (CV) intra-ensaio de 3,0\%. Os procedimentos utilizados foram descritos previamente por Souza et al. (2008).

As concentrações de E2 foram analisadas apenas nas amostras de soro referentes ao momento da administração do $2^{\circ} \mathrm{GnRH}$, por RIA, utilizando um kit comercial (Estradiol Double Antibody, Siemens Healthcare Diagnostics, Los Angeles, CA). Os procedimentos utilizados foram descritos previamente por Kulick et al (1999) e Bergfelt et al (2000), exceto com as seguintes modificações: (1) os padrões da curva (0,78 - $100 \mathrm{pg} / \mathrm{mL}$ ) foram preparados em soro livre de esteróides (soro bovino tratado com carvão vegetal); (2) o procedimento de extração realizado nos padrões e amostras de soro (500 $\mu \mathrm{L}$ em duplicata) foram realizados com $3 \mathrm{~mL}$ de éter etílico congelado, em banho maria com gelo seco e metanol; (3) o sobrenadante foi descartado e o decantado foi mantido nos tubos de ensaio para secagem durante a noite; (4) as amostras secas foram ressuspendidas com solução tampão de 0,1 \% de gelatina em PBS.

A sensibilidade do ensaio de E2 foi de 0,08 pg / $\mathrm{mL}$. As amostras foram analisadas em duplicata em três ensaios e repetidas quando o coeficiente de variação entre ambas foi maior do que 15\%. Amostras de alta (10 pg / mL), moderada (de $5 \mathrm{pg} / \mathrm{mL}$ ) e baixa $(2,5 \mathrm{pg} / \mathrm{mL}$ ) concentração foram incorporadas a cada ensaio e utilizadas para avaliar o CV. Os CV intra- e inter-ensaio foram de $6,2 \%$ e $7,7 \%$, respectivamente.

\subsubsection{Análises estatísticas}

Os testes de normalidade dos resíduos e homogeneidade das variâncias foram realizados utilizando o Guide Data Analysis do SAS. Dados que não preencheram os pressupostos para a análise de variância (ANOVA) foram 
transformadas em conformidade. As variáveis contínuas (concentração de P4 no momento da administração do $1^{\circ} \mathrm{GnRH}$, da $\mathrm{PGF}_{2 \alpha}$ e do $2^{\circ} \mathrm{GnRH}$, concentração de E2 no momento da administração do $2^{\circ} \mathrm{GnRH}$, tamanho do folículo dominante e espessura endometrial no momento da administração do $2^{\circ} \mathrm{GnRH}$ ) foram analisados por ANOVA, usando o procedimento GLIMMIX do SAS, versão 9.2 (SASISTAT, SAS Institute Inc., Cary, NC). Os dados de distribuição binomial (presença de CL no momento da administração do $1^{0} \mathrm{GnRH}$, taxa de ovulação ao $1^{\circ} \mathrm{GnRH}$, porcentagem de animais com concentração sérica de $\mathrm{P} 4$ menor ou igual a 0,50 ng / $\mathrm{mL}$ no momento da administração do $1^{\circ} \mathrm{GnRH}$, presença de $\mathrm{CL}$ no momento da administração da $\mathrm{PGF}_{2 \alpha}$, porcentagem de animais com concentração sérica de $\mathrm{P} 4$ maior ou igual a 1,00 ng / $\mathrm{mL}$ no momento da administração da $\mathrm{PGF}_{2 \alpha}$, taxa de luteólise, taxa de ovulação ao $2^{\circ} \mathrm{GnRH}$ e taxa de prenhez) foram avaliados por regressão logística multivariada, usando o procedimento GLIMMIX do SAS. As variáveis inclusas no modelo final estão apresentadas no quadro 1 . Os animais foram classificados para número prévio de serviços (primeiro ou segundo ou mais), classe de ECC [baixo $(<3,00)$ ou alto $(\geq 3,00)$ ]. Ainda foram testadas as interações entre mês, paridade e classe de ECC com tratamento.

A curva ROC (Receiver Operating Characteristic) foi utilizada para avaliar a acurácia com que algumas variáveis predizem a ocorrência de prenhez. As curvas foram geradas usando a opção de análise de curva de ROC do MedCalc versão 11.2.1 (MedCalc Software, Mariakerke, Bélgica) para determinar a precisão com que o ECC e o número de serviços prevêem a prenhez. A curva ROC é um gráfico de função linear no qual o eixo $Y$ mostra a taxa de verdadeiro-positivos (sensibilidade) e o X mostra a taxa de falso-positivos (100 - especificidade). A área sob a curva ROC é calculada pela somatória das áreas dos trapézios que dividem a curva e pode ser definida como a probabilidade de um indivíduo ter a taxa de verdadeiro-positivos maior do que a taxa de falso-positivos. 


\begin{tabular}{|c|c|}
\hline Item & Modelo \\
\hline Dias em lactação & Tratamento \\
\hline Número de lactações & Tratamento \\
\hline Número de serviços & Tratamento \\
\hline Escore de condição corporal & Tratamento \\
\hline Escore de locomoção & Tratamento \\
\hline $\begin{array}{l}\text { Porcentagem de animais com concentração de } \\
\text { P4 } \geq 1.00 \mathrm{ng} / \mathrm{ml} \text { no } 1^{\circ} \mathrm{GnRH}\end{array}$ & Tratamento \\
\hline Concentração de P4 no $1^{\circ} \mathrm{GnRH}$ & Tratamento \\
\hline Taxa de ovulação ao $1^{\circ} \mathrm{GnRH}$ & Tratamento \\
\hline $\begin{array}{l}\text { Porcentagem de animais com concentração de } \\
\text { P4 } \geq 1.00 \mathrm{ng} / \mathrm{ml} \text { na } \mathrm{PGF}_{2 \alpha}\end{array}$ & Tratamento \\
\hline Concentração de P4 na PGF ${ }_{2 \alpha}$ & Tratamento \\
\hline Taxa de luteólise & Tratamento \\
\hline Concentração de $\mathrm{E} 2$ no $2^{\circ} \mathrm{GnRH}$ & $\begin{array}{l}\text { Tratamento, número de lactações, diâmetro do } \\
\text { maior folículo no } 2^{\circ} \mathrm{GnRH} \text {, Taxa de ovulação ao } \\
1^{\circ} \mathrm{GnRH} \text {, concentração de } \mathrm{P} 4 \text { no } 1^{\circ} \text { e } 2^{\circ} \mathrm{GnRH}\end{array}$ \\
\hline Concentração de P4 no $2^{\circ} \mathrm{GnRH}$ & $\begin{array}{l}\text { Tratamento, classe de escore de condição } \\
\text { corporal, taxa de ovulação ao } 1^{\circ} \mathrm{GnRH}\end{array}$ \\
\hline $\begin{array}{l}\text { Concentração de } \mathrm{P} 4 \text { no } 2^{\circ} \mathrm{GnRH} \text { dos animais } \\
\text { que não apresentaram luteólise }\end{array}$ & Tratamento \\
\hline Espessura do endométrio & $\begin{array}{c}\text { Tratamento, número de lactações, classe de } \\
\text { escore de condição corporal, diâmetro do maior } \\
\text { folículo no } 2^{\circ} \mathrm{GnRH} \text {, concentração de P4 no } 2^{\circ} \\
\text { GnRH }\end{array}$ \\
\hline Diâmetro do maior folículo no $2^{\circ} \mathrm{GnRH}$ & $\begin{array}{l}\text { Tratamento, número de lactações, } \\
\text { concentração de P4 no } 2^{\circ} \mathrm{GnRH}\end{array}$ \\
\hline Taxa de ovulação ao $2^{\circ} \mathrm{GnRH}$ & $\begin{array}{l}\text { Tratamento, diâmetro do maior folículo no } 2^{\circ} \\
\text { GnRH }\end{array}$ \\
\hline Concentração de $\mathrm{P} 4$ seis dias após o $2^{\circ} \mathrm{GnRH}$ & $\begin{array}{l}\text { Tratamento, classe de número de serviços, } \\
\text { diâmetro do maior folículo no } 2^{\circ} \mathrm{GnRH} \\
\text { concentração de } \mathrm{P} 4 \text { no } 2^{\circ} \mathrm{GnRH}\end{array}$ \\
\hline $\begin{array}{l}\text { Concentração de P4 treze dias após o } 2^{\circ} \\
\text { GnRH }\end{array}$ & $\begin{array}{l}\text { Tratamento, classe de número de serviços, } \\
\text { número de lactações, diâmetro do maior folículo } \\
\text { no } 2^{\circ} \mathrm{GnRH} \text { concentração de } \mathrm{P} 4 \text { no } 2^{\circ} \mathrm{GnRH}\end{array}$ \\
\hline Taxa de prenhez & $\begin{array}{l}\text { Tratamento, mês, paridade, número de } \\
\text { serviços, classe de escore de condição corporal }\end{array}$ \\
\hline
\end{tabular}


5.5.6 Resultados do experimento 1

Semelhantes valores de DEL $(P=0,82)$, número de lactações $(P=0,94)$, número de inseminações $(P=0,82), \operatorname{ECC}(P=0,78)$ e escore de locomoção $(P=$ $0,90)$ foram observados entre as vacas dos tratamentos com e sem suplementação de FSH no teste de prenhez do experimento 1 (Tabela 2). A administração de FSH no momento do tratamento com $\mathrm{PGF}_{2 \alpha}$ no protocolo Ovsynch de inseminação não teve efeito sobre nenhuma das variáveis analisadas na dinâmica folicular ovariana. No entanto, na avaliação hormonal foi observado que vacas que receberam FSH apresentaram aumento da concentração de P4 no momento da administração do $2^{\circ}$ GnRH tanto na avaliação do total de animais $(P=0,03)$ quanto naquelas que não sofreram luteólise $(P<0,01 ;$ Tabela 3$)$. A concentração individual de $P 4$ no momento da administração do $2^{\circ} \mathrm{GnRH}$ das vacas que não sofreram luteólise está apresentada na figura 2.

Tabela 2 - Dias em lactação, número de lactações, escore de condição corporal (ECC) e escore de locomoção (média \pm EPM) de vacas em lactação tratadas ou não com FSH durante o protocolo Ovsynch, Madison, 2007 (média \pm EPM)

\begin{tabular}{lccc}
\hline & Controle & FSH & $P$ \\
\hline Dias em lactação & $121,5 \pm 3,16$ & $118,1 \pm 2,96$ & 0,82 \\
(variação) & $(74-506)$ & $(74-660)$ & \\
Número de lactações & $2,3 \pm 0,06$ & $2,3 \pm 0,06$ & 0,94 \\
(variação) & $(1-10)$ & $(1-10)$ & \\
Número de serviços & $2,06 \pm 0,07$ & $1,98 \pm 0,07$ & 0,82 \\
(variação) & $(1-11)$ & $(1-14)$ & \\
ECC & $2,88 \pm 0,02$ & $2,88 \pm 0,01$ & 0,78 \\
(variação) & $(2,00-4,75)$ & $(2,00-4,00)$ & \\
Escore de locomoção & $1,46 \pm 0,03$ & $1,48 \pm 0,03$ & 0,90 \\
(variação) & $(1-5)$ & $(1-4)$ & \\
\hline
\end{tabular}


Tabela 3 - Características de dinâmica folicular e dosagem hormonal analisadas em momentos específicos do protocolo Ovsynch com ou sem a tratamento com FSH em vacas Holandesas em lactação, Madison 2007 (média \pm E.P.M.; P4 = progesterona; E2 = estradiol).

\begin{tabular}{|c|c|c|c|}
\hline Variável & Controle & $\mathrm{FSH}$ & $\mathrm{P}$ \\
\hline $\begin{array}{l}\text { Porcentagem de animais com concentração de } \\
\text { P4 } \geq 1,00 \mathrm{ng} / \mathrm{mL} \text { no } 1^{\circ} \mathrm{GnRH}, \%(\mathrm{n} / \mathrm{n})\end{array}$ & $66,7(68 / 102)$ & $68,4(65 / 95)$ & 0,74 \\
\hline $\begin{array}{l}\text { Concentração de P4 no } 1^{\circ} \mathrm{GnRH}, \mathrm{ng} / \mathrm{mL} \\
\text { (variação) }\end{array}$ & $\begin{array}{c}1,69 \pm 0,14 \\
(0,00-9,60)\end{array}$ & $\begin{array}{l}1,66 \pm 0,12 \\
(0,00-5,30)\end{array}$ & 0,74 \\
\hline Taxa de ovulação ao $1^{\circ} \mathrm{GnRH}, \%$ (n/n) & $77,5(79 / 102)$ & $76,8(73 / 95)$ & 0,91 \\
\hline $\begin{array}{l}\text { Porcentagem de animais com concentração de } \\
P 4 \geq 1,00 \mathrm{ng} / \mathrm{mL} \text { na } \mathrm{PGF}_{2 \alpha}, \%(\mathrm{n} / \mathrm{n})\end{array}$ & $82,4(84 / 102)$ & $83,2(79 / 95)$ & 0,79 \\
\hline Concentração de P4 na PGF ${ }_{2 \alpha}$, ng/mL (variação) & $\begin{array}{l}3,34 \pm 0,19 \\
(0,00-7,70)\end{array}$ & $\begin{array}{l}3,36 \pm 0,29 \\
(0,00-7,70)\end{array}$ & 0,91 \\
\hline Taxa de luteólise, \% (n/n) & $96,1(98 / 102)$ & $91,6(87 / 95)$ & 0,20 \\
\hline $\begin{array}{l}\text { Concentração de } \mathrm{E} 2 \text { no } 2^{\circ} \mathrm{GnRH}, \mathrm{pg} / \mathrm{mL} \\
\text { (variação) }\end{array}$ & $\begin{array}{c}3,64 \pm 0,32 \\
(0,18-28,70)\end{array}$ & $\begin{array}{c}3,24 \pm 0,19 \\
(0,26-10,83)\end{array}$ & 0,88 \\
\hline $\begin{array}{l}\text { Concentração de P4 no } 2^{\circ} \mathrm{GnRH}, \mathrm{ng} / \mathrm{mL} \\
\text { (variação) }\end{array}$ & $\begin{array}{c}0,15 \pm 0,01 \\
(0,00-0,94)\end{array}$ & $\begin{array}{c}0,27 \pm 0,06 \\
(0,00-4,20)\end{array}$ & 0,03 \\
\hline $\begin{array}{l}\text { Concentração de } \mathrm{P} 4 \text { no } 2^{\circ} \mathrm{GnRH}, \mathrm{ng} / \mathrm{mL} \text { das } \\
\text { vacas que não apresentaram luteólise (n) }\end{array}$ & $\begin{array}{c}0,68 \pm 0,04 \\
(n=4)\end{array}$ & $\begin{array}{c}1,69 \pm 0,28 \\
(n=8)\end{array}$ & $>0,01$ \\
\hline Espessura do endométrio, mm (variação) & $\begin{array}{l}10,4 \pm 0,12 \\
(6,5-15,0)\end{array}$ & $\begin{array}{l}10,4 \pm 0,13 \\
(7,0-14,0)\end{array}$ & 0,99 \\
\hline $\begin{array}{l}\text { Diâmetro do maior folículo no } 2^{\circ} \mathrm{GnRH}, \mathrm{mm} \\
\text { (variação) }\end{array}$ & $\begin{array}{c}16,3 \pm 0,37 \\
(10-21)\end{array}$ & $\begin{array}{c}16,1 \pm 0,39 \\
(10-22)\end{array}$ & 0,66 \\
\hline Taxa de ovulação ao $2^{\circ} \mathrm{GnRH}, \%$ (n/n) & $96,0(98 / 102)$ & $95,7(91 / 95)$ & 0,69 \\
\hline $\begin{array}{l}\text { Concentração de } \mathrm{P} 4 \text { seis dias após o } 2^{\circ} \mathrm{GnRH} \text {, } \\
\mathrm{ng} / \mathrm{mL} \text { (variação) }\end{array}$ & $\begin{array}{r}1,01 \pm 0,05 \\
(0,00-2,46)\end{array}$ & $\begin{array}{l}1,14 \pm 0,08 \\
(0,00-6,00)\end{array}$ & 0,15 \\
\hline $\begin{array}{l}\text { Concentração de } \mathrm{P} 4 \text { treze dias após o } 2^{\circ} \mathrm{GnRH} \text {, } \\
\mathrm{ng} / \mathrm{mL} \text { (variação) }\end{array}$ & $\begin{array}{l}3,37 \pm 0,16 \\
(0,00-9,05)\end{array}$ & $\begin{array}{c}3,54 \pm 0,19 \\
(0,00-11,95)\end{array}$ & 0,36 \\
\hline
\end{tabular}




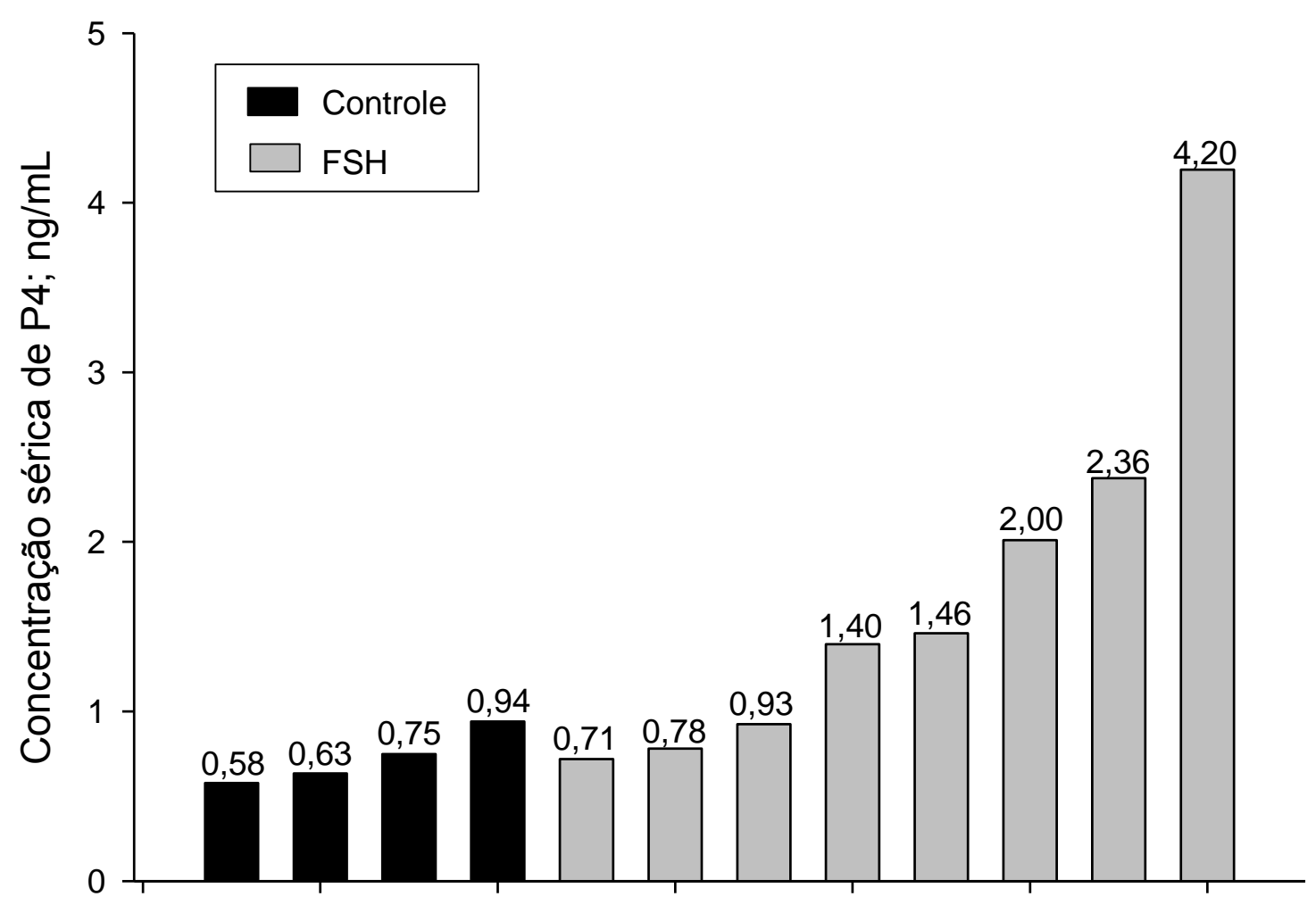

Animais

Figura 2 - Concentração sérica de progesterona (P4) no momento da administração do $2^{\circ} \mathrm{GnRH}$ das vacas que não apresentaram luteólise após tratamento com protocolo Ovsynch com ou sem a suplementação de FSH, Madison, 2007

Não houve interação entre o tratamento e as demais variáveis $(P>0,10)$ analisadas. Além disso, porcentagens similares de vacas prenhes após a IATF foram observadas em ambas as fazendas [38,4\% (346/900) e 34,5\% (80/232), $\mathrm{P}=0,24]$ e ambos os tratamentos (Controle $=36,2 \%$ e FSH $=39,15 \%$; $\mathrm{P}=0,89$; Figura 3 ). No entanto, diferentes taxas de prenhez foram verificadas de acordo com o mês de realização da IATF $(P=0,04)$ e apenas no mês de outubro foi observado aumento da taxa de prenhez com o tratamento com FSH ( $P=0,04$; Figura 3 ).

Não houve efeito de paridade ( $P=0,10$; Tabela 4$)$ e classe de ECC ( $P=0,07$; Tabela 5) na taxa de prenhez. Entretanto, animais de primeiro serviço tiveram maior taxa de prenhez que os demais serviços $(P=0,002$; Tabela 6$)$. Ainda as curvas ROC foram utilizadas para determinar o ECC $(\geq 3,00$; Figura 4$)$ e o número de serviços ( $\leq$ 
1; Figura 5) que resultaram em maior acurácia para a predição da prenhez aos 30 e 60 dias após inseminação.

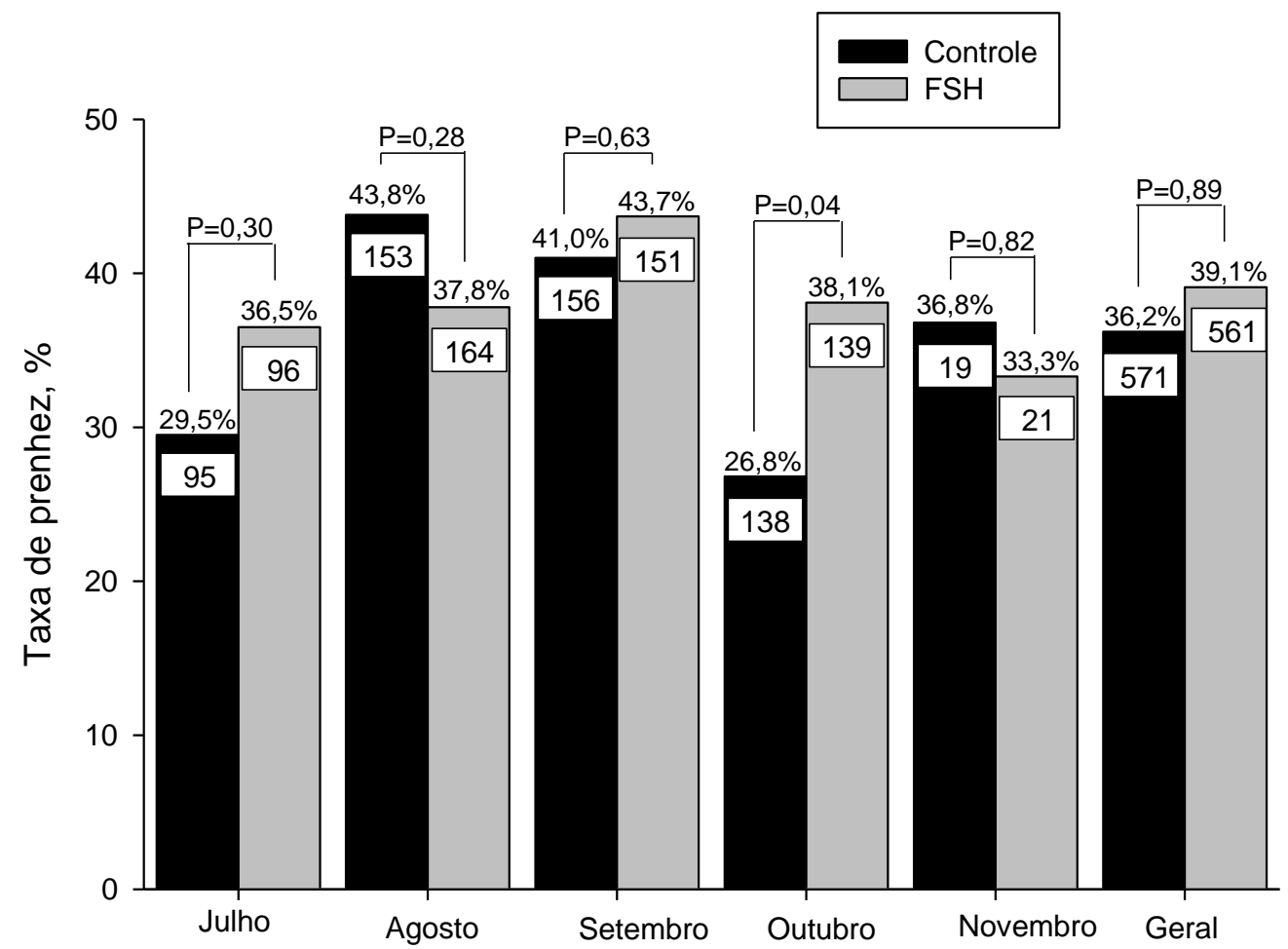

Figura 3 - Taxa de prenhez de vacas Holandesas em lactação tratadas ou não com FSH no momento da indução de luteólise $\left(\mathrm{PGF}_{2 a}\right)$ no protocolo Ovsynch, de acordo com o mês de inseminação, Madison, 2007

Tabela 4 - Efeito da paridade na taxa de prenhez de vacas Holandesas em lactação tratadas ou não com FSH no momento da indução de luteólise $\left(\mathrm{PGF}_{2 \alpha}\right)$ no protocolo Ovsynch, Madison, 2007

\begin{tabular}{lccc} 
& Primípara & Multípara & $P^{*}$ \\
\hline Controle, \% (n/n) & $41,6(96 / 231)$ & $32,4(107 / 330)$ & 0,04 \\
FSH, \% (n/n) & $42,0(103 / 245)$ & $36,8(120 / 326)$ & 0,74 \\
$P * \star$ & 0,31 & 0,58 & - \\
Geral, \% (n/n) & $41,8(199 / 476)$ & $34,6(227 / 656)$ & 0,10 \\
\hline
\end{tabular}

* $\mathrm{P}$ para comparação entre primípara e multípara.

** $\mathrm{P}$ para comparação entre Ovsynch e Ovsynch $+\mathrm{FSH}$.

Interação entre tratamento e serviço $P=0,21$ 


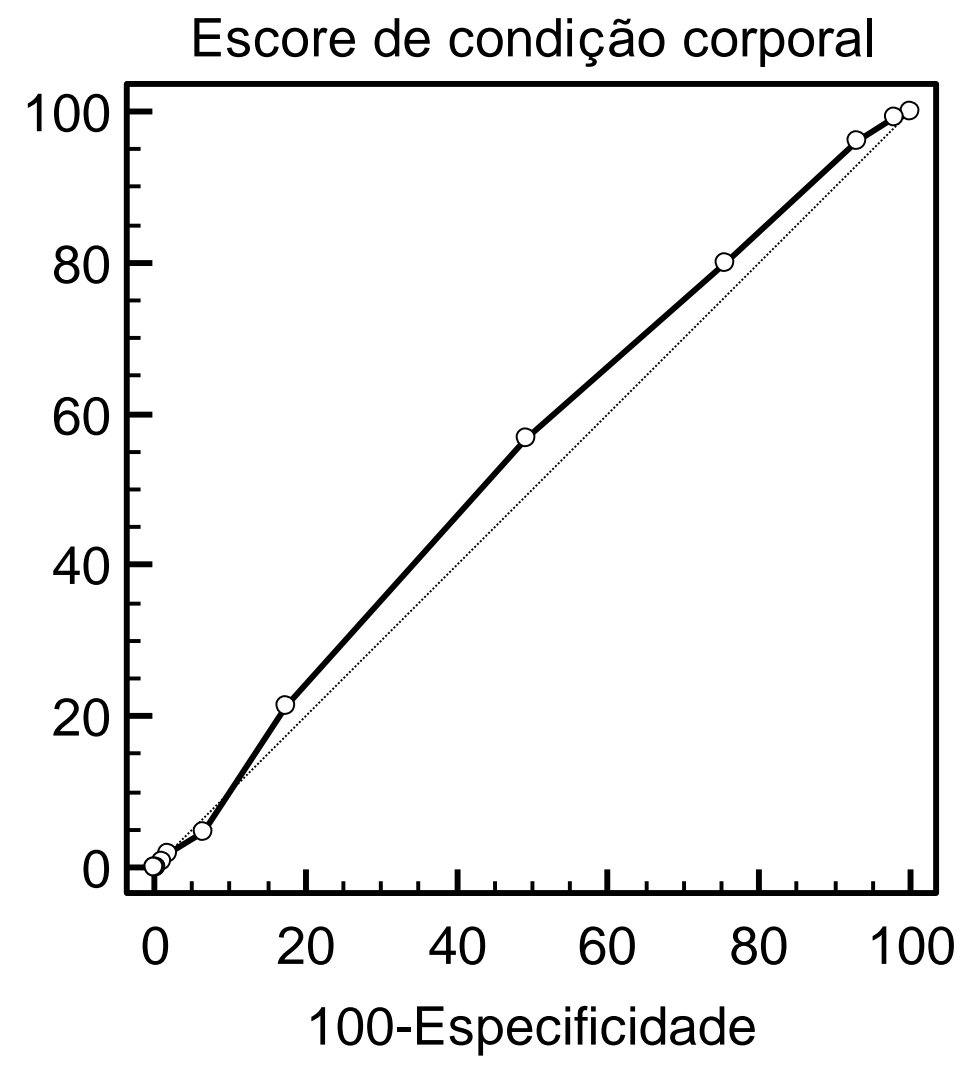

Figura 4 - Curva ROC representando a precisão com que o escore de condição corporal prevê a ocorrência de prenhez à inseminação. Maior sensibilidade combinada $(57,0 \%$, intervalo de confiança de $95 \%=53,0$ a 61,8$)$ e especificidade $(50,8 \%$, intervalo de confiança de $95 \%=$ 46,9 a $54,6 \%$ ) foi detectada em > 2,75. A área sob a curva foi de 0,54 (intervalo de confiança de $95 \%=0,51$ a 0,57). Madison, 2007

Tabela 5 - Efeito da classe de escore de condição corporal na taxa de prenhez de vacas Holandesas em lactação tratadas ou não com FSH no momento da indução de luteólise $\left(\mathrm{PGF}_{2 a}\right)$ no protocolo Ovsynch, Madison, 2007

\begin{tabular}{lccc}
\hline & Alto $(\geq 3.00)$ & Baixo $(<3.00)$ & $P^{*}$ \\
\hline Controle, \% (n/n) & $38,9(111 / 285)$ & $33,9(94 / 277)$ & 0,37 \\
FSH, \% (n/n) & $44,4(136 / 306)$ & $34,8(92 / 264)$ & 0,09 \\
$P * *$ & 0,25 & 0,78 & - \\
Geral, \% (n/n) & $41,8(247 / 591)$ & $34,4(186 / 541)$ & 0,07 \\
\hline
\end{tabular}

* P para comparação entre alto e baixo ECC.

** P para comparação entre Ovsynch e Ovsynch + FSH.

Interação entre tratamento e ECC $P=0,57$ 


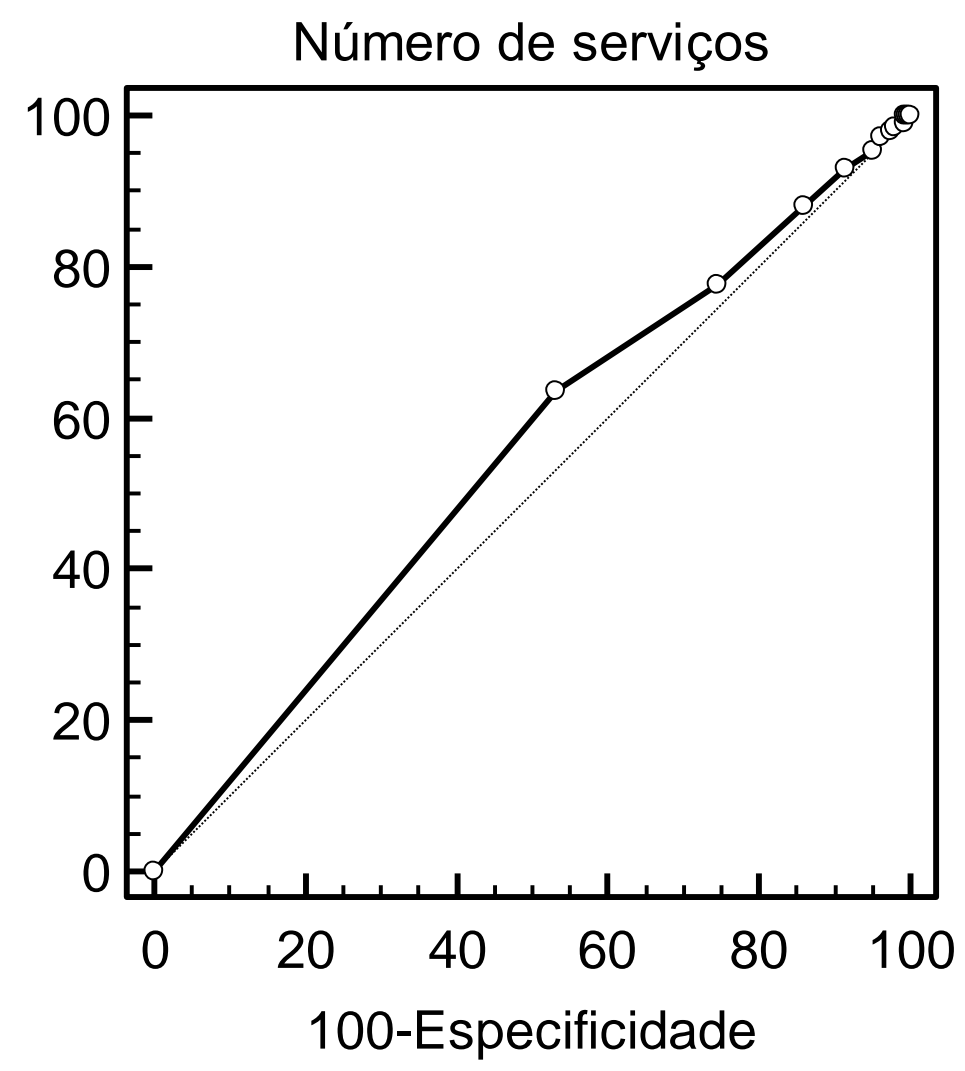

Figura 5.- Curva ROC representando a precisão com que o número de serviços prevê a ocorrência de prenhez à inseminação. Maior sensibilidade combinada $(63,6 \%$, intervalo de confiança de $95 \%=58,8$ a 68,2$)$ e especificidade $(46,7 \%$, intervalo de confiança de $95 \%=43,0$ a $50,5 \%$ ) foi detectada em $\leq 1$. A área sob a curva foi de 0,55 (intervalo de confiança de $95 \%=0,52$ a 0,58). Madison, 2007

Tabela 6 - Efeito do número de serviços na taxa de prenhez prenhez de vacas Holandesas em lactação tratadas ou não com FSH no momento da indução de luteólise $\left(\mathrm{PGF}_{2 a}\right)$ no protocolo Ovsynch, Madison, 2007

\section{Primeiro}

Segundo ou mais

$P^{*}$

Controle, \% (n/n)

41,3 (131/317)

$29,5(140 / 244)$

0,009

$\mathrm{FSH}, \%(\mathrm{n} / \mathrm{n})$

42,4 (72/330)

$34,4(83 / 241)$

0,08

$P$ **

0,61

0,70

Geral, \% (n/n)

41,9 (271/647)

$32,0(155 / 485)$

0,002

\footnotetext{
* P para comparação entre o primeiro e o segundo ou mais serviços.

** $\mathrm{P}$ para comparação entre Ovsynch e Ovsynch + FSH.

Interação entre tratamento e serviço $P=0,50$
} 


\section{EXPERIMENTO 2 - SUPLEMENTAÇÃO COM FSH OU ECG EM PROTOCOLO A BASE DE PROGESTERONA E ESTRADIOL}

\subsection{MATERIAIS E MÉTODOS}

\subsubsection{Animais e manejo}

Nesse experimento foram utilizadas 694 vacas da raça Holandesa em lactação de duas propriedades comerciais localizadas no sudeste do Brasil, sendo 89 vacas da fazenda Campestre e 605 da fazenda Santa Rita (Agrindus S/A). Durante o período de julho de 2008 e janeiro de 2009 foram conduzidos o teste de prenhez (com todas as vacas) e a dinâmica folicular ovariana, para a qual se utilizou um subgrupo de vacas $(n=89)$ do teste de prenhez. As vacas foram ordenhadas três vezes ao dia em intervalos de $8 \mathrm{~h}$ e alimentadas com dieta balanceada para atender ou exceder os requisitos mínimos nutricionais para bovinos leiteiros (NRC, 2001). Em ambas as fazendas, as vacas permaneceram alocadas em galpões com água ad libitum e camas com areia, às quais possuíam livre acesso. Os tratamentos, avaliações ultrassonográficas e coletas de sangue foram realizados após a ordenha enquanto as vacas estavam presas na linha de alimentação (fazenda Campestre) ou no centro de manejo (fazenda Santa Rita). Todas as vacas receberam somatotropina bovina (500 mg / dose; Bostin ${ }^{\circledR}$, Intervet, Brasil) a cada 14 dias, a partir de 60 dias pós-parto. O ECC e EL foram registrados utilizando o sistema de 5 pontos: $1=$ magra a 5 = obesa (FERGUSON et al., 1994), e 1 = normal a 5 = claudicação extrema (SPRECHER et al., 1997), respectivamente. Todos os procedimentos foram aprovados pela Comissão de Bioética da Faculdade de Medicina Veterinária e Zootecnia da Universidade de São Paulo. 
6.1.2 Protocolos hormonais e diagnóstico de gestação

Durante um período de 15 (quinze; fazenda Santa Rita) ou 7 (sete; fazenda Campestre) dias, em cada estação do ano [verão (janeiro) e inverno (agosto)], um grupo de vacas foi selecionado para iniciar os tratamentos do teste de prenhez. Em dia aleatório do ciclo estral, definido como Do do protocolo de sincronização da ovulação, as vacas receberam $2 \mathrm{mg}$ de benzoato de estradiol (BE; RICBE ${ }^{\circledR}$, Tecnopec, Brasil) i.m. e um dispositivo intravaginal de P4 (Primer ${ }^{\circledR}$, Tecnopec, Brasil. No dia da remoção do dispositivo (D8), $150 \mathrm{mg}$ de $\mathrm{PGF}_{2 \alpha}$ (Prolise ${ }^{\circledR}$, ARSA, Argentina) foram administrados e as vacas foram distribuídas homogeneamente (de acordo com a paridade, número de serviços prévios, ECC e presença de CL no início do protocolo) em três tratamentos: Controle $(n=232$; sem tratamento adicional); eCG ( $n=232 ; 400$ UI de eCG no D8; Folligon ${ }^{\circledR}$, Intervet, Brasil) e FSH ( $n$ $=230 ; 20 \mathrm{mg}$ de $\mathrm{FSH}$ no D8). Todas as vacas receberam $10 \mathrm{mg}$ de lecirelina (Gestran Plus ${ }^{\circledR}$, ARSA, Argentina) e foram inseminadas em tempo fixo 56 horas após a remoção do dispositivo (Figura 6).

O diagnóstico de gestação foi realizado por ultrassonografia e palpação transretal 30 e 60 dias após a IATF, respectivamente. Quando os animais foram diagnosticados como gestantes 30 dias após a IATF e não gestantes 60 dias após a IATF foi determinada a ocorrência de perda gestacional. 


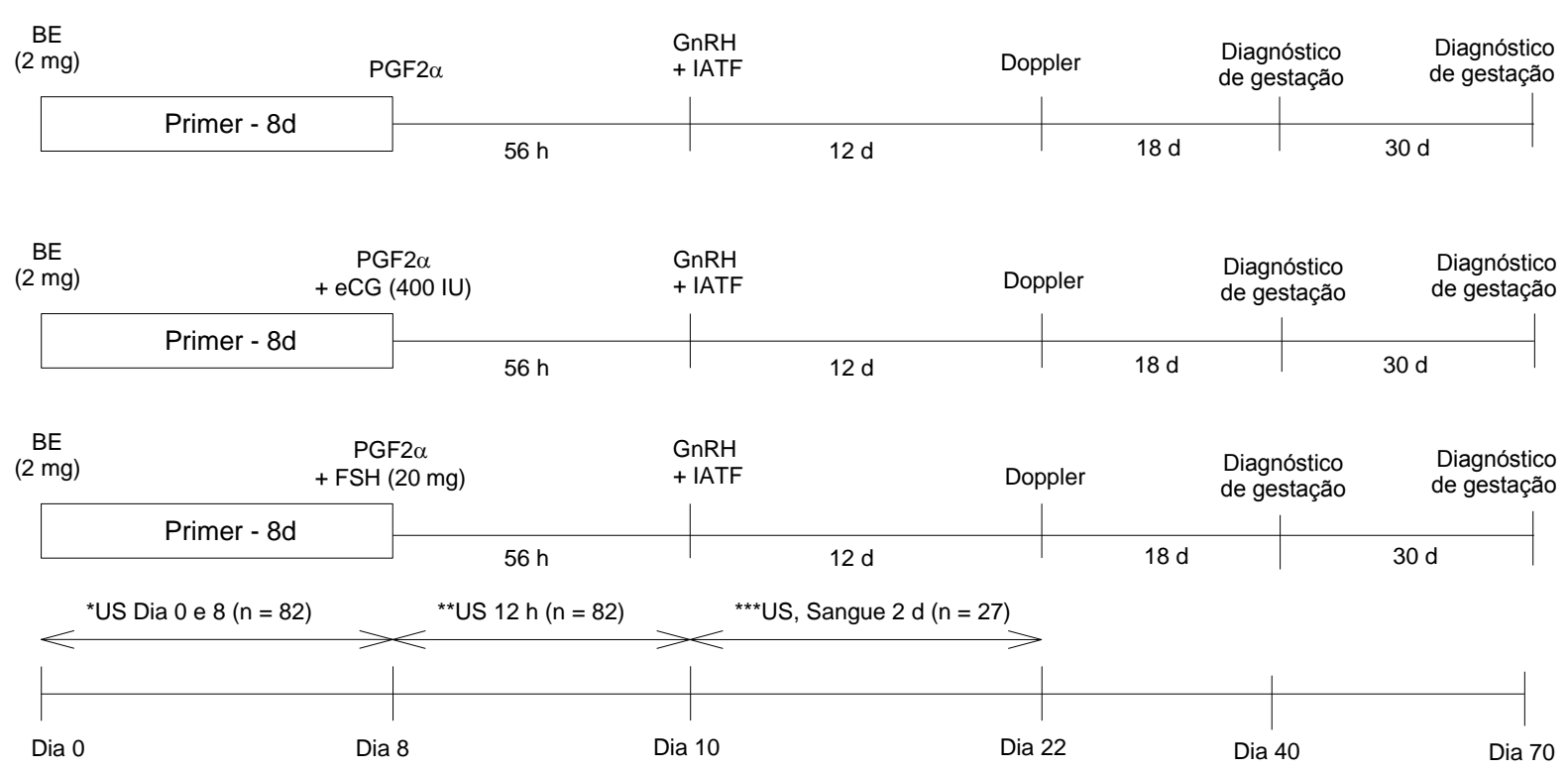

Figura 6 - Desenho esquemático experimental dos tratamentos para a inseminação artificial em tempo fixo sem $(n=232)$ ou com suplementação de eCG $(n=232)$ ou FSH $(n=230)$ de vacas Holandesas. US = Avaliações ultrassonográficas, Sangue $=$ coleta de sangue, $d=$ dias, $\mathrm{h}=$ horas. *Avaliações ultrassonograficas realizada no dia 0 e 8. ** Avaliações ultrassonográficas realizadas a cada $12 \mathrm{~h}$ por $96 \mathrm{~h}$ após a retirada do dispositivo de P4 ou até detecção da ovulação. ${ }^{\star \star \star}$ Coleta de sangue e avaliação ultrassonográfica realizada a cada 2 dias por 11 dias após a ovulação sincronizada. Diagnósticos de gestação realizados por ultrassonografia e palpação transretal 30 e 60 dias após a IATF, respectivamente.

\subsubsection{Avaliação ultrassonográfica ovariana e uterina}

Um subgrupo de 82 vacas (Controle, $n=27$; FSH, $n=26$; eCG, $n=29$ ) teve seus ovários avaliados por ultrassonografia transretal no D0 (inserção do dispositivo de P4) e D8 (remoção do dispositivo de P4) para detecção e mensuração de CL e diâmetro dos folículos. Após a remoção da fonte de P4, os exames de ultrassonográficos foram realizados a cada 12 horas até 96 horas ou até o desaparecimento do folículo(s) ovulatório(s). A ovulação foi caracterizada como o desaparecimento do folículo dominante e o aparecimento de um CL no mesmo ovário nos dias subsequentes. Múltipla ovulação foi caracterizada quando dois ou mais folículos dominantes foram visualizados 48 horas após a retirada do dispositivo de $\mathrm{P} 4$ e os mesmos desaparam e foi visualizados o mesmo núemro de $\mathrm{CL}$, no 
mesmo ovário, nos dias subsequentes. A porcentagem de animais com múltipla ovulação também foi determinada.

O momento de ovulação foi determinado com base na avaliação dos ovários de cada vaca a cada 12 horas do momento da retirada do dispositivo de P4 até o desaparecimento do folículo ovulatório ou 96 horas após a retirada da P4, o que aconteceu primeiro. O momento da ovulação foi definido como o momento em que o folículo dominante desapareceu menos 6 horas.

Uma vez que a presença de folículos persistentes apresenta uma freqüência de 20 \% em vacas de leite de alta produção criadas em condições brasileiras (dados não publicados) ${ }^{3}$ e a ocorrência de ovulação de folículos persistentes esta relacionada a baixas taxas de prenhez, os folículos com diâmetro superior a $14 \mathrm{~mm}$ no D0 e superior a $20 \mathrm{~mm}$ no D8 foram classificados como folículos persistentes e mensurados. A porcentagem de animais que possuíam um folículo persistente no ovário no dia da remoção do dispositivo de P4 e que ovularam esse folículo foi determinada (Taxa de ovulação do folículo persistente).

A taxa de crescimento do folículo ovulatório ( $\mathrm{mm} / \mathrm{dia}$ ) entre a retirada do dispositivo de P4 e o indutor de ovulação foi calculada subtraindo-se o diâmetro médio desse folículo nessas duas ocasiões e dividindo-se o resultado pelo número de dias avaliados.

Após a ovulação, o desenvolvimento do CL (mensuração de seu volume) foi avaliado a cada 48 horas por 11 dias. O volume do CL foi calculado pela seguinte fórmula:

$$
\text { Volume }=\left(4 / 3 \times \pi \times R_{C L}^{3}\right)-\left(4 / 3 \times \pi \times R_{\text {cavidade }}^{3}\right)
$$

onde: $\mathrm{R}_{\mathrm{CL}}=$ raio médio do $\mathrm{CL}$ [(maior diâmetro + secção transversal da maior diâmetro)/4]; $\mathrm{R}_{\text {cavidade }}$ = raio médio da cavidade do CL (maior diâmetro da cavidade + secção transversal da maior diâmetro da cavidade)/4 e $\pi=3,14159$.

\footnotetext{
${ }^{3}$ AYRES, dados não publicado.
} 


\subsubsection{Avaliação ultrassonográfica color-doppler}

O fluxo sanguíneo no CL foi determinado com o auxílio de ultrassom Doppler (modo color-Doppler; My Lab 30, Esaote, Genova, Itália) no 11 dias após a ovulação sincronizada no subgrupo de 82 vacas. Para tal fim, todas as vacas receberam anestesia epidural sacro-coccígea (4 mL de cloridrato de lidocaína $2 \%$, Lidovet ${ }^{\circledR}$, Bravet, Brasil) antes do exame. As imagens em tempo real do B-mode/color-Doppler foram gravadas com o auxílio de um sistema digital. Posteriormente, a partir das gravações efetuadas, uma imagem de cada CL e seu respectivo fluxo sanguíneo (porção colorida na imagem) foi selecionada por um único técnico sem conhecimento prévio dos grupos experimentais. Para a seleção das imagens foi levado em consideração o maior diâmetro do CL e a qualidade da imagem do fluxo sanguíneo detectado pelo Doppler. O número de pixels coloridos das imagens selecionadas foi determinado como descrito anteriormente (Ginther; Utt, 2004). A mesma escala de cor foi utilizada como controle positivo na seleção dos pixels coloridos em todas as imagens. A porcentagem do fluxo sanguíneo do CL foi calculada dividindo-se o número total de pixels coloridos pelo número de pixels não coloridos como descrito anteriormente (Ginther et al., 2007). O ganho do foco e ajustes de cor do ultrassom Doppler foram os mesmos durante todos os exames.

\subsubsection{Coleta de sangue e dosagem hormonal para avaliação da função ovariana}

Amostras de sangue foram coletadas, processadas, armazenadas e mensuradas para concetração sérica de P4 segundo o mesmo método e critério descrito no Experimento 1. Os coeficientes de variação intra e inter-ensaio foram de $4,3 \%$ e $4,6 \%$, respectivamente. 


\subsubsection{Análise estatística}

Os dados de distribuição binomial foram avaliados por regressão logística multivariada e os dados de distribuição normal foram analisados por ANOVA, ambos usando o procedimento GLIMMIX do SAS versão 9.2 (SAS/STAT, SAS Institute Inc., Cary, NC). A unidade experimental "vaca" foi incluída no modelo estatístico como variável de efeito aleatório. As informações de tratamento, DEL, número de inseminações prévias (uma ou duas ou mais), número de lactações, ECC [categorizada em baixo $(<3,00)$ ou alto $(\geq 2,75)$ ] e EL [normal (1) ou qualquer grau de alteração (2 a 5)] de cada vaca, assim como suas interações, foram utilizadas nos modelos estatísticos.

No modelo de regressão logística final (Quadro 2) algumas variáveis foram removidas por backward elimination baseando-se no critério de Wald para $P>0,20$. A análise univariada com procedimento GLIMMIX foi utilizada para avaliar os efeitos do tratamento sobre o DEL, número de lactações, ECC e EL. Todos os dados estão expressos como medias \pm E.P.M..

As curvas ROC foram geradas usando a opção de análise de curva de ROC do MedCalc versão 11.2.1 (MedCalc Software, Mariakerke, Bélgica) para determinar a precisão com que o EL e a paridade prevêem a prenhez aos 30 e 60 dias. 


\begin{tabular}{|c|c|}
\hline Item & Modelo \\
\hline Dias em lactação & Tratamento, réplica \\
\hline Número de lactações & Tratamento \\
\hline Número de serviços & Tratamento, estação \\
\hline Produção de leite & Tratamento, estação \\
\hline Escore de condição corporal & Tratamento, estação \\
\hline Escore de locomoção & Tratamento \\
\hline Diâmetro do folículo ovulatório & $\begin{array}{l}\text { Tratamento, lactação, diâmetro do folículo no } \\
\text { D0, estação }\end{array}$ \\
\hline Taxa de crescimento entre D8 e D10 & Tratamento \\
\hline Taxa de ovulação & $\begin{array}{l}\text { Tratamento, número de serviços, presença de } \\
\text { CL no } D 0 \text {, número de } C L\end{array}$ \\
\hline Momento de ovulação & Grupo \\
\hline Múltipla ovulações & $\begin{array}{l}\text { Tratamento, estação, diâmetro do folículo } \\
\text { ovulatório, presença de folículo persistente }\end{array}$ \\
\hline Numero de ovulações & Tratamento \\
\hline Taxa ovulação de folículo persistente & Tratamento \\
\hline Volume do CL & $\begin{array}{c}\text { Tratamento, tempo, tratamento*tempo, número } \\
\text { de ovulações, estação }\end{array}$ \\
\hline Concentração sérica de progesterona & $\begin{array}{c}\text { Tratamento, tempo, tratamento*tempo, número } \\
\text { de ovulações, estação }\end{array}$ \\
\hline Área do fluxo sanguíneo do CL, pixels & Tratamento \\
\hline Razão do fluxo sanguíneo/área total & Tratamento \\
\hline Taxa de prenhez 30 dias após a IATF & $\begin{array}{c}\text { Tratamento, classe de escore de locomoção, } \\
\text { estação, paridade }\end{array}$ \\
\hline Taxa de prenhez 60 dias após a IATF & $\begin{array}{l}\text { Tratamento, classe de escore de locomoção, } \\
\text { estação, paridade }\end{array}$ \\
\hline Perda gestacional & $\begin{array}{l}\text { Tratamento, classe de escore de locomoção, } \\
\text { dias em lactação, produção de leite, estação }\end{array}$ \\
\hline
\end{tabular}

Quadro 2 - Modelos finais de acordo com a variável analisada. 


\subsection{RESULTADOS DO EXPERIMENTO 2}

Similares valores de ECC $(2,86 \pm 0,05, P=0,87)$, de EL $(1,67 \pm 0,10, P=$ $0,29)$ e porcentagem de vacas com $C L$ no momento da inserção da fonte de $P 4$ $(76,8 \% ; 63 / 82, P=0,79)$ foram observados entre os tratamentos. Verificou-se, também, a presença de 89,9 \% (564/694) de animais com presença de CL ou diâmetro folícular superior a $10 \mathrm{~mm}$.

A taxa de ovulação ao final do protocolo de sincronização foi de $83,1 \%$ (70/82), ocorrendo em média às 79,4 $\pm 1,39$ horas após a retirada do dispositivo. Não houve efeito de tratamento, estação e interação entre os tratamentos e estação (Tabelas 7 e 8; Figura 7). Também foi verificado que 25 vacas tiveram ovulações duplas (25/82 $=30,5 \%$ de todas as vacas analisadas, $25 / 68=36,8 \%$ das ovuladas) e que 12 ovularam folículos persistentes $(12 / 82=14,6 \%$ de todas as vacas analisadas; $12 / 68=17,6 \%$ das ovuladas). Não houve diferença entre os tratamentos ou interações entre tratamento e diâmetro médio do folículo ovulatório, tratamento e taxa de dupla ovulação e tratamento e ovulação de folículos persistentes.

O diâmetro médio do folículo ovulatório no momento da retirada da fonte de P4 e no momento da administração do $\mathrm{GnRH}$ foi de $11,4 \pm 0,4$ e 14,1 $\pm 0,3 \mathrm{~mm}$, respectivamente. Já o diâmetro dos folículos que não ovularam até 96 horas após a retirada do dispositivo de $\mathrm{P} 4$ foi de $12,23 \pm 1,19 \mathrm{~mm}$ no D8. Houve diferença no diâmetro do folículo ovulatório conforme a natureza deste, persistente ou não, sendo o persistente de maior diâmetro (Figura 7).

A distribuição do momento de ovulação está representada da figura 8A. Foram observados dois momentos de concentração de ovulações, o primeiro entre 60 e 72 horas e o segundo entre 84 e 96 horas após a retirada da fonte de progesterona (Figura $8 \mathrm{~B}$ ). Foi também verificado que folículos ovulatórios de maior diâmetro $(P<0,01$; Figura $9 A$ e 10$)$ bem como folículos persistentes de maior diâmetro $(P<0,01$; Figura $9 B)$ apresentaram ovulação mais precoce. Assim, folículos que ovularam entre 60 e 72 horas foram maiores que os folículos ovulados entre 84 e 96 horas, tanto quando todos os animais que apresentaram ovulação foram considerados, quanto quando os animais que ovularam folículos persistentes foram excluídos (Figura 9A e B). Todos os folículos persistentes que ovularam $(100 \%, 12 / 12)$ o fizeram entre 60 e 72 horas após a retirada da fonte de P4. 
Tabela 7 - Dias em lactação, número de lactações, número prévios de serviços prévios, produção de leite, escore da condição corporal (ECC) e escore de locomoção (média \pm EPM) de vacas Holandesas de alta produção tratadas com protocolo para IATF com ou sem a adição de FSH ou eCG, São Pedro, 2008

\begin{tabular}{|c|c|c|c|c|c|c|}
\hline \multirow[b]{2}{*}{ Item } & \multicolumn{3}{|c|}{ Tratamento } & \multicolumn{3}{|c|}{$P$} \\
\hline & $\begin{array}{c}\text { Controle } \\
(n=27)\end{array}$ & $\mathrm{FSH}(\mathrm{n}=26)$ & eCG $(n=29)$ & Trat. & Estação $^{a}$ & $\begin{array}{c}\text { Trat. x } \\
\text { Estação }\end{array}$ \\
\hline Dias em lactação, d & $153,37 \pm 15,70$ & $\begin{array}{c}136,20 \pm \\
16,22\end{array}$ & $\begin{array}{c}143,73 \pm \\
14,22\end{array}$ & 0,82 & 0,03 & 0,87 \\
\hline Número de lactações & $2,20 \pm 0,32$ & $2,01 \pm 0,27$ & $2,10 \pm 0,26$ & 0,90 & 0,09 & 0,46 \\
\hline Número de serviços & $1,84 \pm 0,44$ & $1,86 \pm 0,43$ & $1,65 \pm 0,43$ & 0,93 & 0,07 & 0,62 \\
\hline Produção de leite, L & $33,19 \pm 1,82$ & $36,48 \pm 1,88$ & $32,22 \pm 1,76$ & 0,24 & 0,09 & 0,58 \\
\hline ECC & $2,86 \pm 0,09$ & $2,84 \pm 0,09$ & $2,91 \pm 0,08$ & 0,82 & 0,25 & 0,43 \\
\hline Escore de locomoção & $1,80 \pm 0,18$ & $1,41 \pm 0,18$ & $1,69 \pm 0,17$ & 0,35 & 0,62 & 0,75 \\
\hline
\end{tabular}

Tabela 8 - Efeito dos diferentes protocolos de IATF (sem suplementação ou suplementado com FSH ou eCG) sobre parâmetros foliculares (média \pm EPM) final de vacas Holandesas de alta produção, São Pedro, 2008

\begin{tabular}{|c|c|c|c|c|c|c|}
\hline \multirow[b]{2}{*}{ Item } & \multicolumn{3}{|c|}{ Tratamento } & \multicolumn{3}{|c|}{$P$} \\
\hline & $\begin{array}{l}\text { Controle } \\
(n=27)\end{array}$ & $\mathrm{FSH}(\mathrm{n}=26)$ & eCG $(n=29)$ & Trat. & Estação $^{a}$ & $\begin{array}{l}\text { Trat. x } \\
\text { Estação }\end{array}$ \\
\hline Diâmetro do FO ${ }^{b}$, mm & $13,90 \pm 0,60$ & $15,72 \pm 0,61$ & $14,62 \pm 0,57$ & 0,11 & 0,19 & 0,98 \\
\hline $\begin{array}{l}\text { Taxa de crescimento entre. } \\
\text { D8 e D10, mm/dia }\end{array}$ & $0,27 \pm 0,05$ & $0,24 \pm 0,05$ & $0,28 \pm 0,05$ & 0,84 & 0,61 & 0,99 \\
\hline Taxa de ovulação ${ }^{d}, \%(n / n)$ & $81,5(22 / 27)$ & $80,8(21 / 26)$ & $86,2(25 / 29)$ & 0,76 & 0,78 & 0,60 \\
\hline $\mathrm{MOV}^{\mathrm{e}}, \mathrm{h}$ & $82,80 \pm 2,47$ & $76,96 \pm 2,519$ & $78,46 \pm 2,31$ & 0,23 & 0,89 & 0,59 \\
\hline Múltipla ovulação. ${ }^{f}$, \% (n/n) & $22,7(5 / 22)$ & $38,1(8 / 21)$ & $48,0(12 / 25)$ & 0,23 & 0,43 & 0,28 \\
\hline Numero de ovulações & $1,23 \pm 0,10$ & $1,34 \pm 0,12$ & $1,47 \pm 0,10$ & 0,26 & 0,51 & 0,37 \\
\hline $\begin{array}{l}\text { Taxa ovulação de fol. } \\
\text { Persistente }^{\mathrm{g}}, \% \text { (n/n) }\end{array}$ & $100,0(2 / 2)$ & $100,0(5 / 5)$ & $83,3(5 / 6)$ & 1,00 & 0,99 & 1,00 \\
\hline
\end{tabular}

a Estação [Agosto (Inverno) ou Janeiro (Verão)].

${ }^{\mathrm{b}} \mathrm{FO}=$ folículo ovulatório.

c Taxa de crescimento do folículo ovulatório entre a retirada do dispositivo de P4 e o indutor de ovulação

d Taxa de ovulação = porcentagem de vacas que ovularam pelo menos um folículo até 96 h após a retirada do dispositivo de P4.

e MOV = momento de ovulação; os ovários de cada vaca foram visualizados a cada 12 h iniciando no momento da retirada do dispositivo de P4 até o desaparecimento do folículo ovulatório ou 96 h retirada da P4, o que acontecer primeiro; o momento da ovulação foi definido como o momento que o folículo dominante desapareceu menos 6 horas.

${ }^{f}$ Classificada quando dois ou mais folíolos dominantes foram visualizados $48 \mathrm{~h}$ após a retirada do dispositivo de P4 e o mesmo número de CL no mesmo ovário foi visualizado depois.

g Taxa de ovulação de folículo persistente = porcentagem de animais que possuíam um folículo maior que 14 mm no dia 0 e um folículo maior que $19 \mathrm{~mm}$ no mesmo ovário no dia da remoção do dispositivo de P4 e que ovularam esse folículo. 


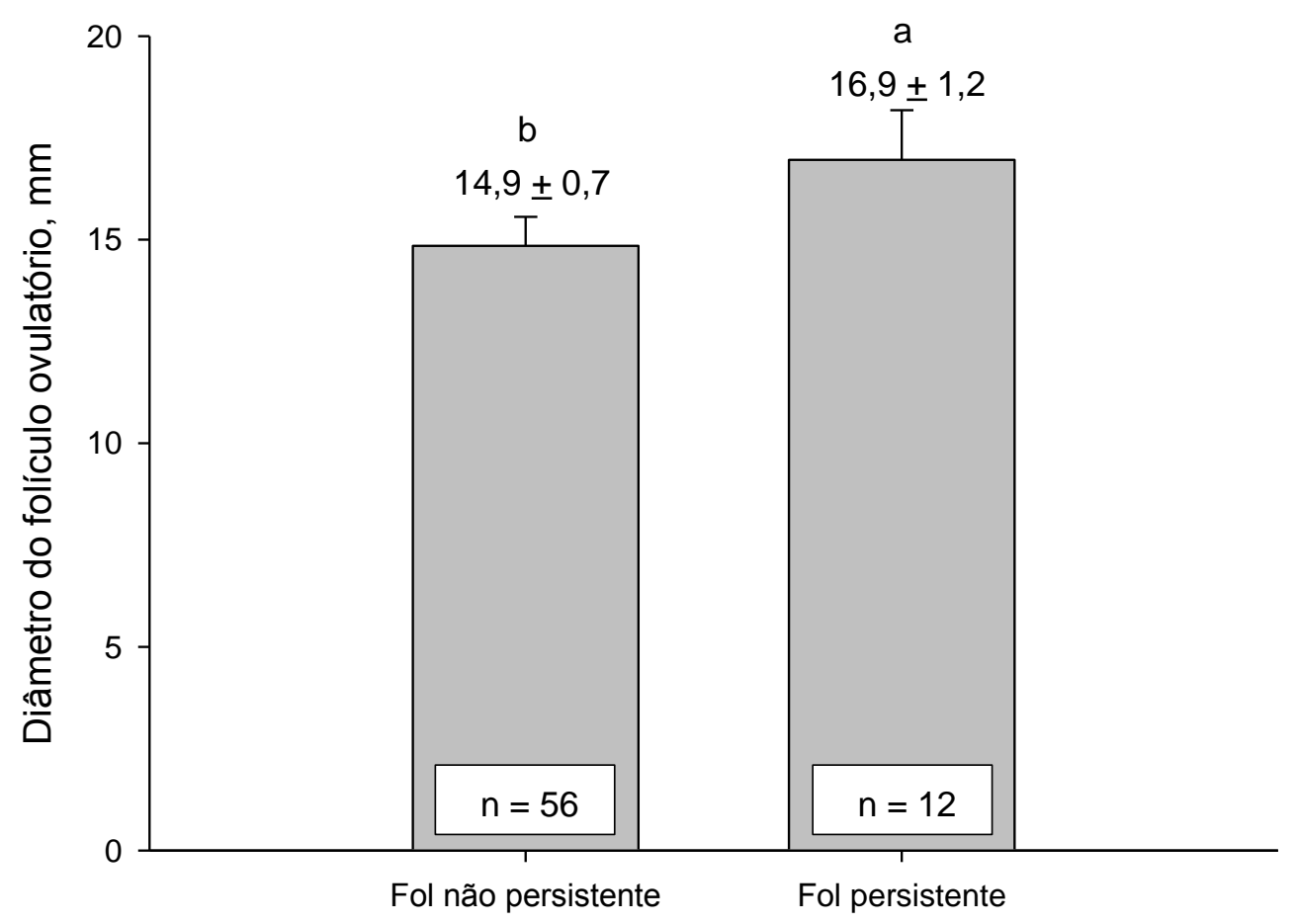

Figura 7 - Diâmetro ovulatório (LSmeans \pm EPM; mm) de folículos persistentes ou não 


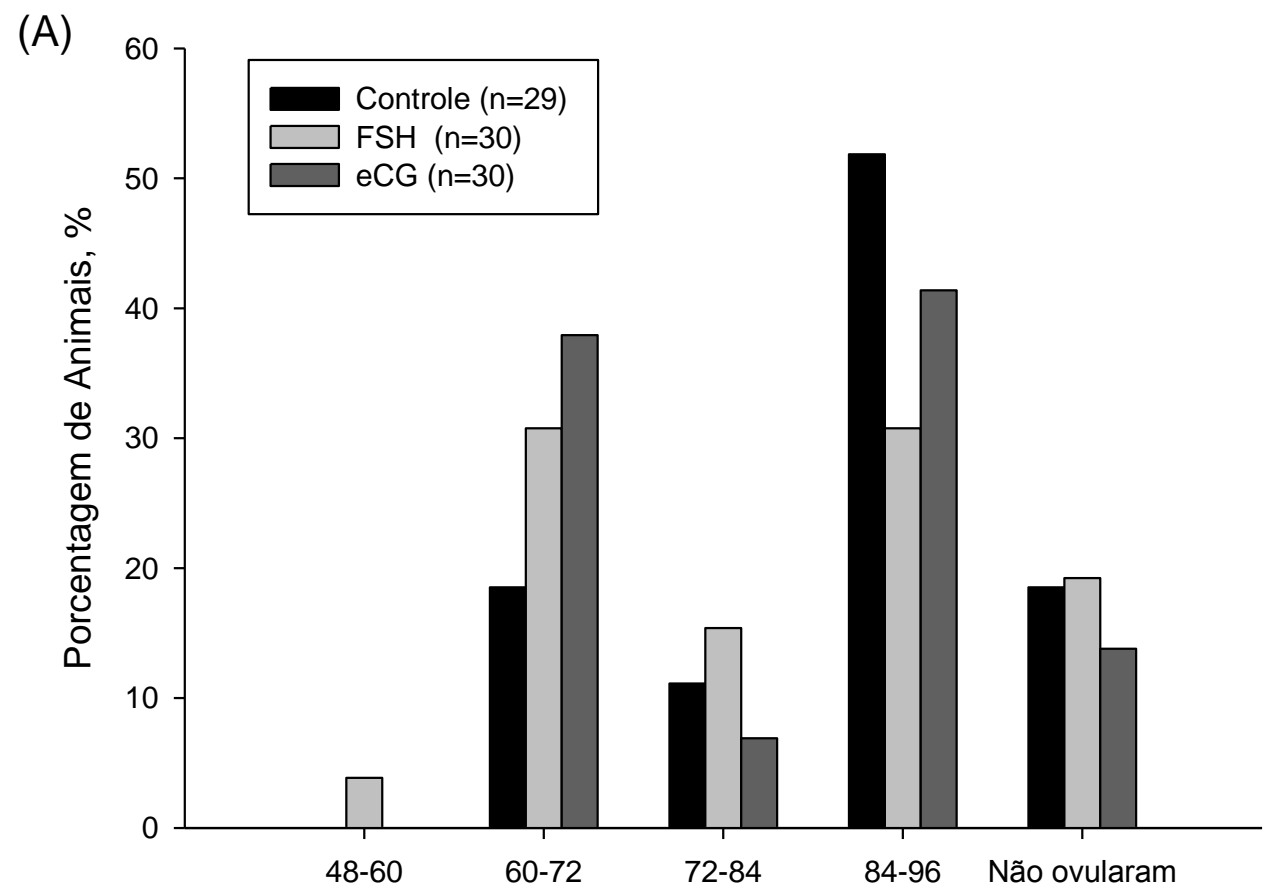

Horas após a retirada do dispositivo de progesterona, $\mathrm{h}$

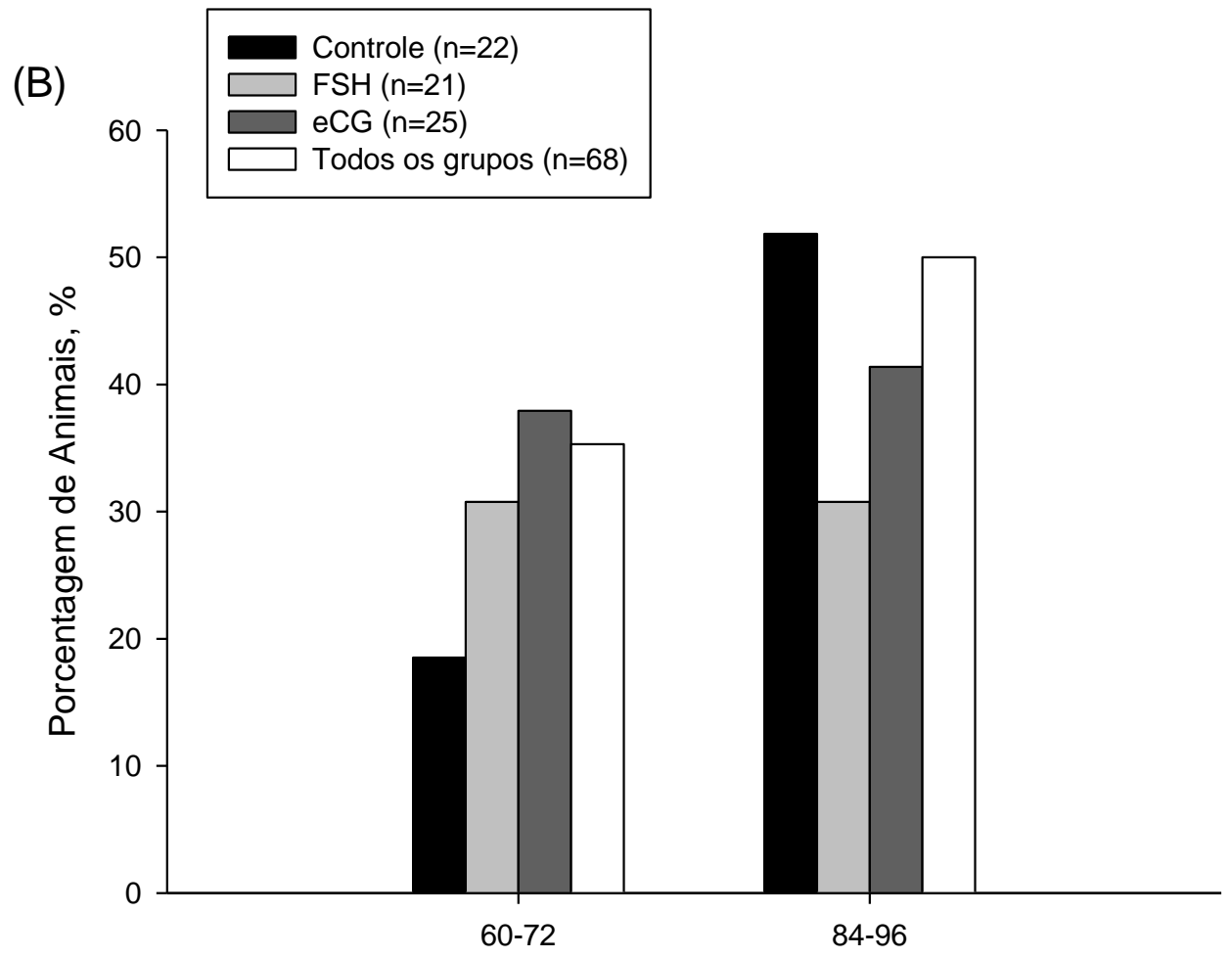

Horas após a retirada do dispositivo de progesterona, $\mathrm{h}$

Figura 8. - Distribuição do momento de ovulação $(h)$ após a remoção do dispositivo de progesterona conforme o intervalo entre os exames ultrassonográficos (A) e porcentagem de animais que apresentaram ovulação entre 60 e 72 horas e 84 e 96 horas após a retirada de fonte de P4 (B), São Pedro, 2008 


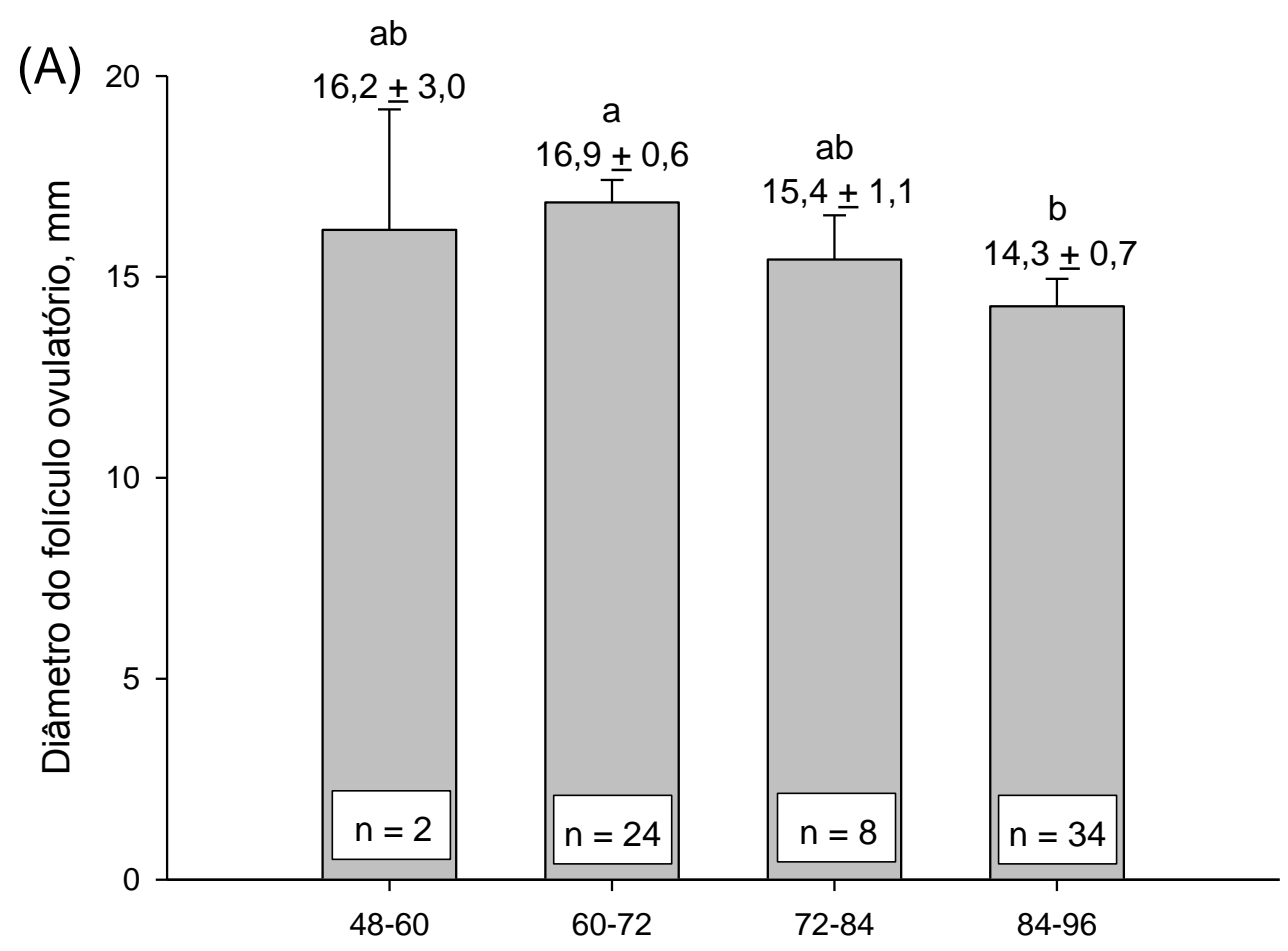

Horas após a retirada do dispositivo de progesterona, $\mathrm{h}$

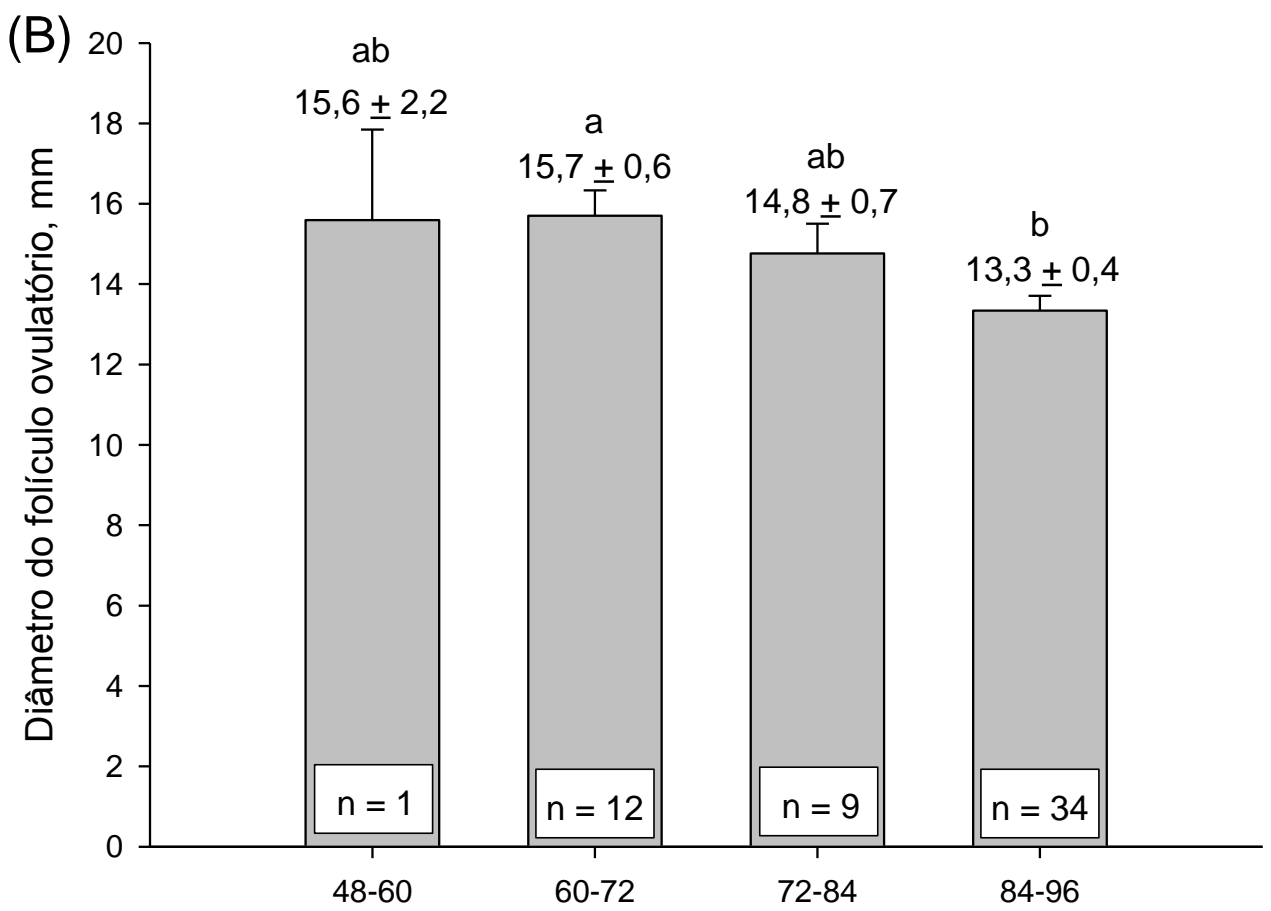

Horas após a retirada do dispositivo de progesterona, $\mathrm{h}$

Figura 9 - Diâmetro do folículo ovulatório (LSmeans \pm EPM; $\mathrm{mm}$ ) em cada intervalo entre os exames ultrassonográficos. O gráfico A contém dados de todos os animais que apresentaram ovulação (de folículo persistente ou não). O gráfico B contém dados apenas dos animais que ovularam folículo(s) que não foi(ram) classificado(s) como persistente(s), São Pedro, 2008 


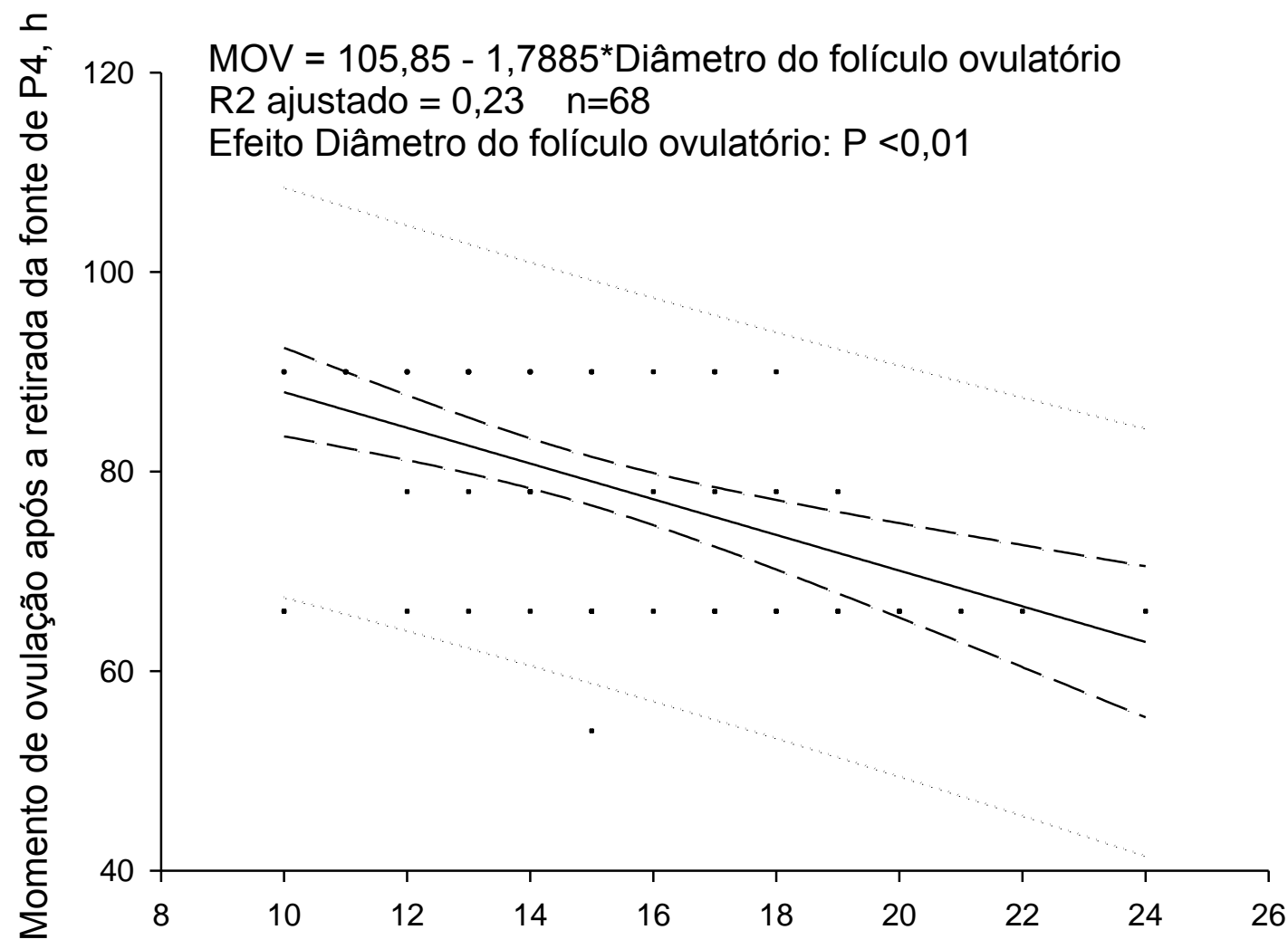

Diâmetro do folículo ovulatório, $\mathrm{mm}$

Figura 10 - Curva de regressão do momento de ovulação após a retirada da fonte de progesterona (MOV) e o diâmetro do folículo ovulatório $(\mathrm{mm})$. A linha contínua representa o valor previsto pela equação de regressão. As linhas tracejadas representam o intervalo de confiança de $95 \%$ para a média. As linhas pontilhadas representam o intervalo de confiança de 95\% para um valor previsto, São Pedro, 2008.

Foi possível verifacar que o aumento do diâmetro do folículo ovulatório resultou em ovulações mais prematuras (Figura 10).

Nas vacas tratadas com FSH houve aumento do volume do $C L(P<0,01$; Figura 11A), mas não das concentrações séricas de $P 4(P=0,15$; Figura 11B) durante o diestro subseqüente as ovulações sincronizadas. Tanto o volume do $\mathrm{CL}$ $(P<0,01$ e $P<0,01)$ quanto a concentração sérica de $P 4(P=0,04$ e $P<0,01)$ foram afetados pelo número de ovulações e pela ovulação de folículo(s) persistente(s), respectivamente, independentemente do tratamento recebido. Ainda, observou-se interação entre tratamento e dia quando o volume do $C L$ foi analisado $(P<0,01$; Figura 11A), o que não ocorreu na análise das concentrações séricas de P4 ( $P=$ 0,56; Figura 11B).

O exame ultrassongráfico Doppler demonstrou que o tratamento com FSH afetou a quantidade de pixels total observada no $\mathrm{CL}$, porém este efeito foi estação 
dependente (interação tratamento $x$ estação; Tabela 9). Já a área do fluxo sanguíneo do $C L$ e a razão do fluxo sanguíneo / área total não foram afetadas por nenhum dos tratamentos, estação ou interação entre estas variáveis (Tabela 10). 


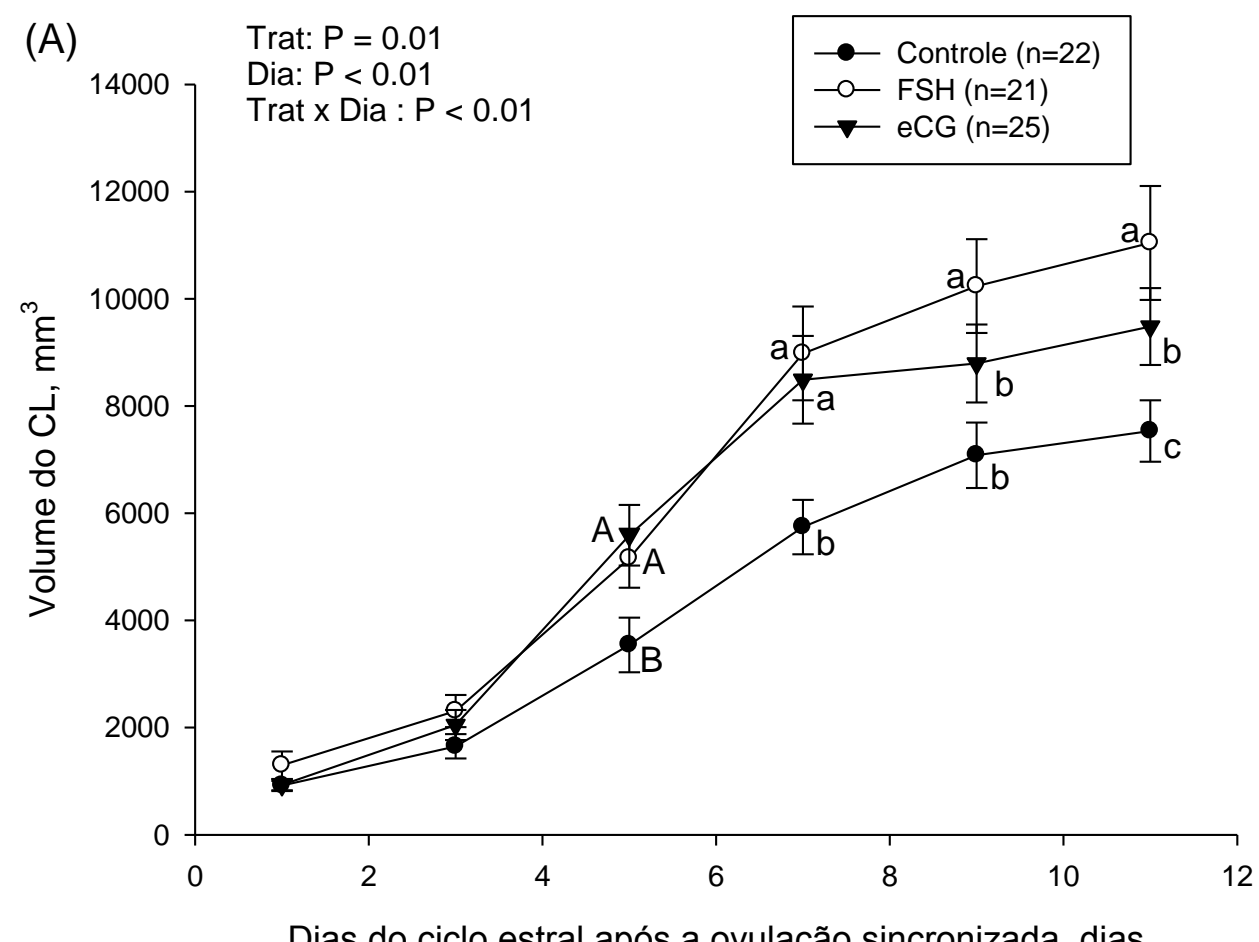

Dias do ciclo estral após a ovulação sincronizada, dias

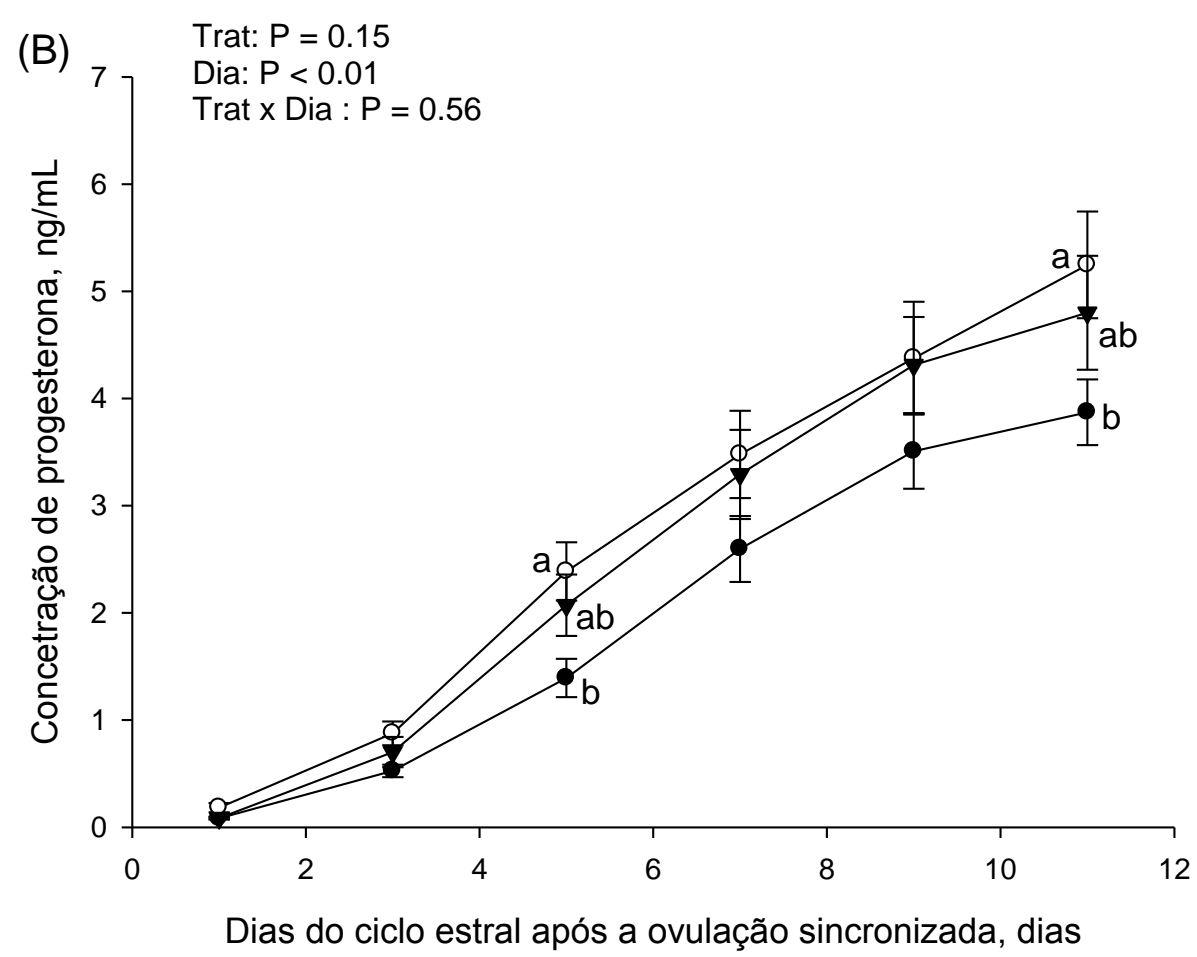

Figura 11 - Volume do CL (A) e concentração sérica de progesterona (B) durante o diestro após a ovulação sincronizada em vacas Holandesas suplementadas ou não com gonadotrofinas exógenas ( $F S H$ ou eCG; média $\pm E P M ; n=68$ ). Os dados foram normalizados para o dia da ovulação (dia 0). Médias seguidas por expoentes minúsculos $(a, b$ e $c)$ diferiram ( $P$ $<0,05)$ entre os dias do mesmo tratamento. Médias seguidas por expoentes maiúsculos $(A$ e $B)$ diferiram $(P<0,10)$ no mesmo dia entre tratamentos. São Pedro, 2008 
Tabela 9 - Área total (pixels) do CL (média \pm EPM) durante os 11 dias posteriores à ovulação sincronizada de vacas Holandesas de alta produção suplementadas ou não com gonadotrofinas exógenas (FSH ou eCG), em diferentes estaçãos do ano. São Pedro, 2008

\begin{tabular}{|c|c|c|c|c|c|c|}
\hline & \multicolumn{3}{|c|}{ Tratamento } & \multicolumn{3}{|c|}{$P$} \\
\hline & Controle & $\mathrm{FSH}$ & eCG & Trat. & Estação ${ }^{a}$ & $\begin{array}{l}\text { Trat. X } \\
\text { Estação }\end{array}$ \\
\hline Janeiro (Verão) & $25315 \pm 1913,0^{b}$ & $37047 \pm 2572,0^{a}$ & $33982 \pm 2756,9^{a}$ & & & \\
\hline Agosto (Inverno) & $32355 \pm 2251,0^{a}$ & $35527 \pm 2342,9^{a}$ & $25960 \pm 2392,5^{b}$ & 0,03 & 0,13 & $<0, U 1$ \\
\hline
\end{tabular}

Médias seguidas por letras minúsculas $(\mathrm{a}$ e $\mathrm{b})$ diferem $(\mathrm{P}<0,05)$ entre os tratamentos realizados na mesma estação.

Tabela 10 - Características ultrassonográficas do CL (média \pm EPM) durante 11 dias posteriores à ovulação sincronizada de vacas Holandesas de alta produção suplementadas ou não com gonadotrofinas exógenas (FSH ou eCG), em diferentes estaçãos do ano. São Pedro, 2008

\begin{tabular}{|c|c|c|c|c|c|c|}
\hline & \multicolumn{3}{|c|}{ Tratamento } & \multicolumn{3}{|c|}{$\mathrm{P}$} \\
\hline & Controle & $\mathrm{FSH}$ & eCG & Trat. & Estação $^{a}$ & $\begin{array}{c}\text { Trat. } x \\
\text { Estação }\end{array}$ \\
\hline $\begin{array}{l}\text { Área do fluxo sanguíneo do CL, } \\
\text { pixels }\end{array}$ & $3187,4 \pm 368,6$ & $3193,7 \pm 460,7$ & $3589,8 \pm 504,7$ & 0,79 & 0,67 & 0,87 \\
\hline Razão do fluxo sanguíneo/área total & $0,11 \pm 0,01$ & $0,09 \pm 0,02$ & $0,12 \pm 0,02$ & 0,33 & 0,37 & 0,66 \\
\hline
\end{tabular}


Para realização do teste de prenhez foram utilizadas 727 vacas Holandesas, no entanto, 31 vacas foram removidas da análise estatística devido à perda de dispositivo intravaginal $(n=22 ; 3,0 \%)$, descarte ou morte durante o experimento $(n=5 ; 0,7 \%)$ e remoção do dispositivo intravaginal em momento errôneo $(n=4$; $0,6 \%)$.

No geral, a taxa de prenhez aos 30 e 60 dias foi influenciada pela estação ( $P$ $<0,0001$; Tabela 11), no entanto, não foi observado efeito de interação tratamento e estação. As vacas suplementadas com FSH apresentaram menor taxa de prenhez aos 30 dias quando comparadas àquelas tratadas com eCG e sem tratamento adicional (controle), tanto no inverno $(P=0,02$; Tabelas 12 e 13), quanto na análise geral (verão + inverno; $P=0,01$ ). Entretanto, essa diferença não foi observada aos 60 dias de gestação. Além disso, tanto o tratamento $(P=0,39)$ quanto à estação $(P$ $=0,90 ;$ Tabelas 11) não afetaram a perda gestacional. 
Tabela 11 - Taxa de prenhez aos 30 e 60 dias (média \pm EPM) após a IATF e perda gestacional em vacas Holandesas de alta produção suplementadas ou não com gonadotrofinas exógenas. Descalvado e São Pedro, 2008-09

\begin{tabular}{|c|c|c|c|c|c|c|}
\hline \multirow{2}{*}{ Item } & \multicolumn{3}{|c|}{ Tratamento } & \multicolumn{3}{|c|}{$P$} \\
\hline & $\begin{array}{l}\text { Controle } \\
(n=232)\end{array}$ & $\begin{array}{c}\text { FSH } \\
(n=230)\end{array}$ & $\begin{array}{c}\text { eCG } \\
(n=232)\end{array}$ & Trat & Estação $^{a}$ & $\begin{array}{c}\text { Trat x } \\
\text { Estação }\end{array}$ \\
\hline $\begin{array}{l}\text { Tx. Prenhez } 30 \text { dias; } \% \\
(\mathrm{n} / \mathrm{n})\end{array}$ & $\begin{array}{c}28,0 \\
(65 / 232)^{x}\end{array}$ & $\begin{array}{c}18,7 \\
(43 / 230)^{y}\end{array}$ & $\begin{array}{c}29,7 \\
(69 / 232)^{x}\end{array}$ & 0,01 & $<0,01$ & 0,70 \\
\hline $\begin{array}{l}\text { Tx. Prenhez } 60 \text { dias; } \% \\
(\mathrm{n} / \mathrm{n})\end{array}$ & $\begin{array}{c}21,6 \\
(50 / 232)\end{array}$ & $\begin{array}{c}16,1 \\
(37 / 230)\end{array}$ & $\begin{array}{c}24,1 \\
(56 / 232)\end{array}$ & 0,08 & $<0,01$ & 0,53 \\
\hline $\begin{array}{l}\text { Perda Gestacional }{ }^{\mathrm{b}} ; \% \\
(\mathrm{n} / \mathrm{n})\end{array}$ & $\begin{array}{c}18,8 \\
(15 / 65)\end{array}$ & $\begin{array}{c}14,0 \\
(6 / 43)\end{array}$ & $\begin{array}{c}18,4 \\
(13 / 69)\end{array}$ & 0,39 & 0,90 & 0,27 \\
\hline \multicolumn{7}{|c|}{$\begin{array}{l}\text { a Estação [Agosto (Inverno) ou Janeiro (Verão)]. } \\
\text { b Perda Gestacional entre } 30 \text { e } 60 \text { dias após Al. } \\
\text { Médias seguidas por letras minúsculas }(x \text { e y) diferem }(P<0,05) \text { na mesma linha }\end{array}$} \\
\hline \multirow[t]{2}{*}{ Tabela 12 - } & \multicolumn{6}{|c|}{$\begin{array}{l}\text { zas } 30 \text { e } 60 \text { dias (média } \pm \text { EPM) após a IATF e perda gestacional em } \\
\text { sas de alta produção suplementadas ou não com gonadotrofinas } \\
\text { te o verão. Descalvado e São Pedro, 2008-09 }\end{array}$} \\
\hline & & & Tratamento & & & $P$ \\
\hline Item & & Controle $(n=232)$ & $\mathrm{FSH}(\mathrm{n}=230)$ & \multicolumn{2}{|c|}{ eCG $(n=232)$} & Trat \\
\hline \multicolumn{2}{|c|}{ Tx. Prenhez 30 dias;\% (n/n) } & $17,8(21 / 118)$ & $13,0(15 / 115)$ & \multicolumn{2}{|c|}{$19,5(23 / 118)$} & 0,43 \\
\hline \multicolumn{2}{|c|}{ Tx. Prenhez 60 dias;\% $\%(n / n)$} & $12,7(15 / 118)$ & $11,3(13 / 115)$ & \multicolumn{2}{|c|}{$17,8(21 / 118)$} & 0,33 \\
\hline \multicolumn{2}{|c|}{ Perda Gestacional ${ }^{a} ; \%(n / n)$} & $28,6(6 / 21)$ & $13,3(2 / 15)$ & \multicolumn{2}{|c|}{$8,7(2 / 23)$} & 0,23 \\
\hline
\end{tabular}

Tabela 13 - Taxa de prenhez aos 30 e 60 dias (média \pm EPM) após a IATF e perda gestacional em vacas Holandesas de alta produção suplementadas ou não com gonadotrofinas exógenas durante o inverno. Descalvado e São Pedro, 2008-09

\begin{tabular}{|c|c|c|c|c|}
\hline \multirow[b]{2}{*}{ Item } & \multicolumn{3}{|c|}{ Tratamento } & \multirow{2}{*}{$\begin{array}{c}P \\
\text { Trat }\end{array}$} \\
\hline & Controle $(n=232)$ & $\mathrm{FSH}(\mathrm{n}=230)$ & eCG $(n=232)$ & \\
\hline Tx. Prenhez 30 dias;\% (n/n) & $38,6(44 / 114)^{x}$ & $24,4(28 / 115)^{y}$ & $40,4(46 / 114)^{x}$ & 0,02 \\
\hline Tx. Prenhez 60 dias;\% (n/n) & $30,7(35 / 114)$ & $20,9(24 / 115)$ & $30,7(35 / 114)$ & 0,14 \\
\hline Perda Gestacional $^{a} ; \%(\mathrm{n} / \mathrm{n})$ & $20,5(9 / 44)$ & $14,3(4 / 28)$ & $23,9(11 / 46)$ & 0,61 \\
\hline
\end{tabular}




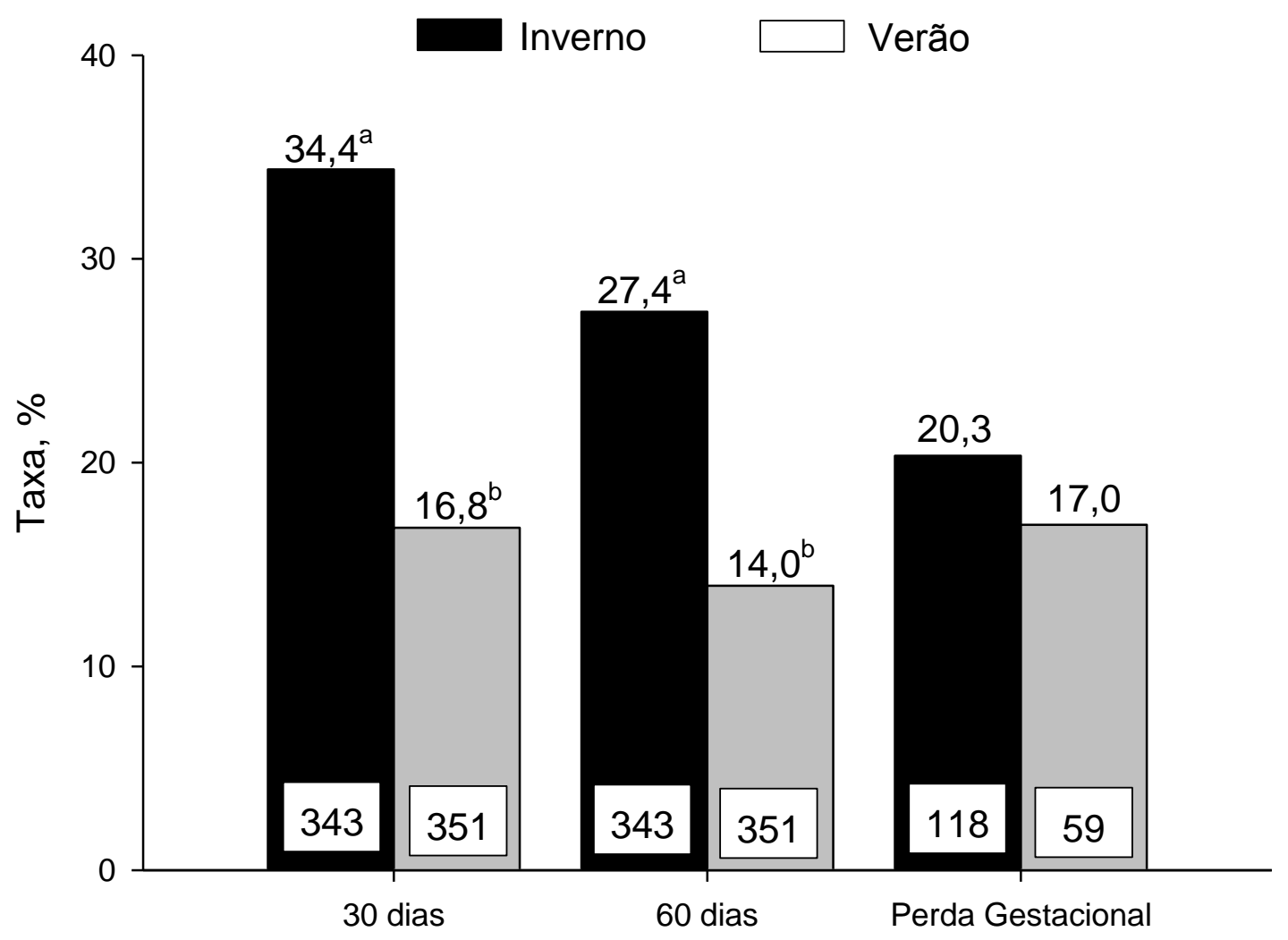

Figura 12 - Taxa de prenhez aos 30 e 60 dias após a IATF e perda gestacional em vacas Holandesas de alta produção suplementadas com gonadotrofinas exógenas de acordo com a estação do ano (verão ou inverno)

Foi verifcado efeito de estação do ano $(P<0,01)$, sendo que no inverno as vacas tiveram maior taxa de prenhez aos 30 e 60 dias (Figura 12). Além disso, quando foram analisados apenas animais de primeiro serviço, com DEL inferior a 80 dias e sem presença de CL, verificou-se que o tratamento com eCG aumentou a taxa de prenhez em comparação aos outros dois grupos (controle e FSH; $\mathrm{P}<0,07$, Tabela 14). 
Tabela 14 - Taxa de prenhez aos 30 dias após a IATF em vacas Holandesas de alta produção com DEL inferior a 80 dias, de primeiro serviço, com ou sem presença de CL no início do protocolo de sincronização e tratadas ou não com gonadotrofinas exógenas. Descalvado e São Pedro, 2008-09

Status ovariano

\begin{tabular}{lcc} 
Tratamento & Sem CL $(\mathrm{n}=72)$ & Com CL $(\mathrm{n}=111)$ \\
\hline Grupo Controle & $19,2 \%(5 / 26) \mathrm{b}$ & $35,1 \%(13 / 37)$ \\
Grupo FSH & $21,7 \%(5 / 23) \mathrm{b}$ & $20,0 \%(7 / 35)$ \\
Grupo eCG & $47,8 \%(11 / 23) \mathrm{a}$ & $39,5 \%(13 / 39)$ \\
\hline
\end{tabular}

Curvas ROC foram utilizadas para determinar o ponto de corte de EL $(\leq 1$; Figuras 13 e 14$)$ e de paridade ( $\leq 1$; Figuras 16 e 17 ). Nestes pontos obteve-se maior acurácia para predição da prenhez aos 30 e 60. Ainda, as taxas de prenhez aos 30 e 60 dias foram afetadas pelo $E L(P=0,004$ e $P=0,002$, respectivamente; Figura 15) e paridade ( $P=0,04$ e $P=0,02$, respectivamente; Figura 18). Entretanto, a perda gestacional foi afetada apenas pela produção de leite $(P=0,03$; Figura 19). 


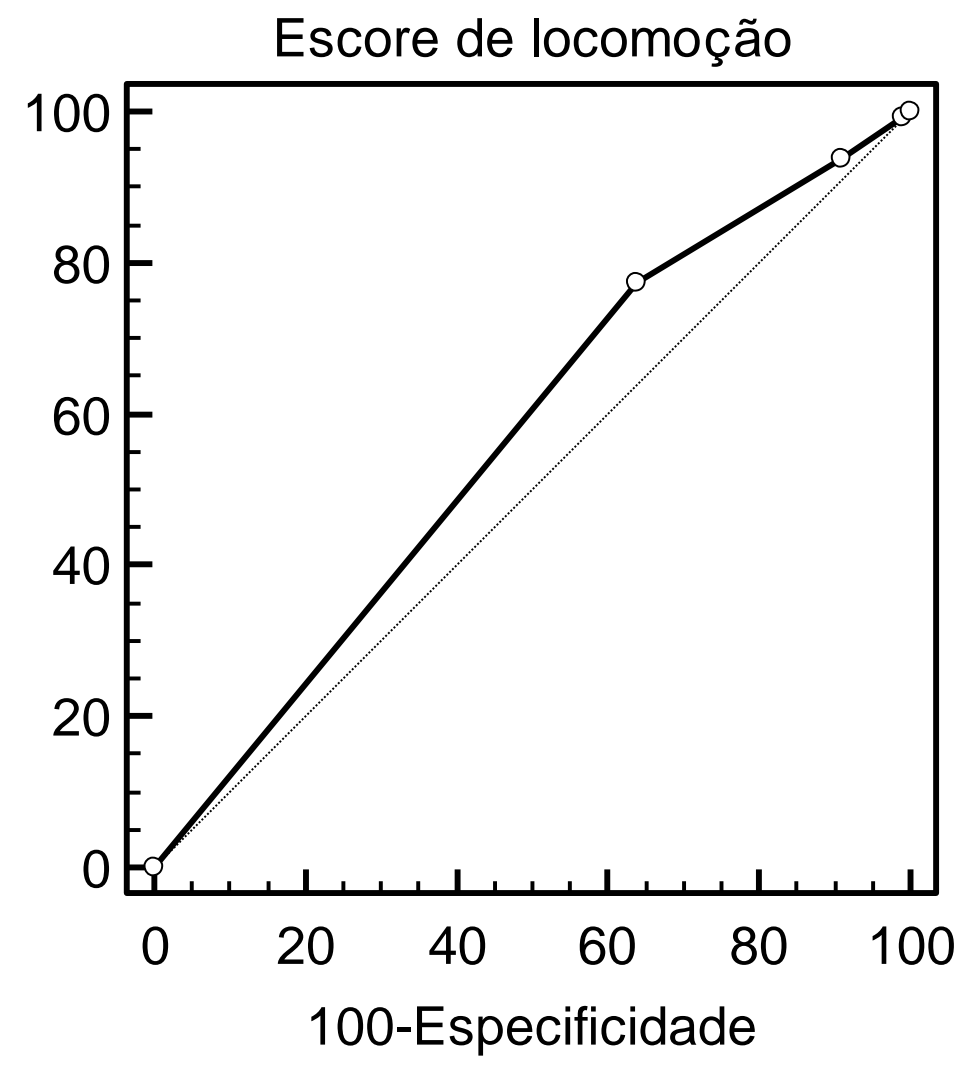

Figura 13 - Curva ROC representando a precisão com que o escore de locomoção prevê a ocorrência de prenhez aos 30 dias. Maior sensibilidade combinada $(77,4 \%$, intervalo de confiança de $95 \%=70,5$ a 83,3\%) e especificidade $(36,2 \%$, intervalo de confiança de $95 \%=32,0$ a $40,5 \%$ ) foram detectadas no valor $\leq 1$. A área sob a curva foi de 0,57 (intervalo de confiança de 95\% = 0,53 a 0,60). São Pedro, 2008 


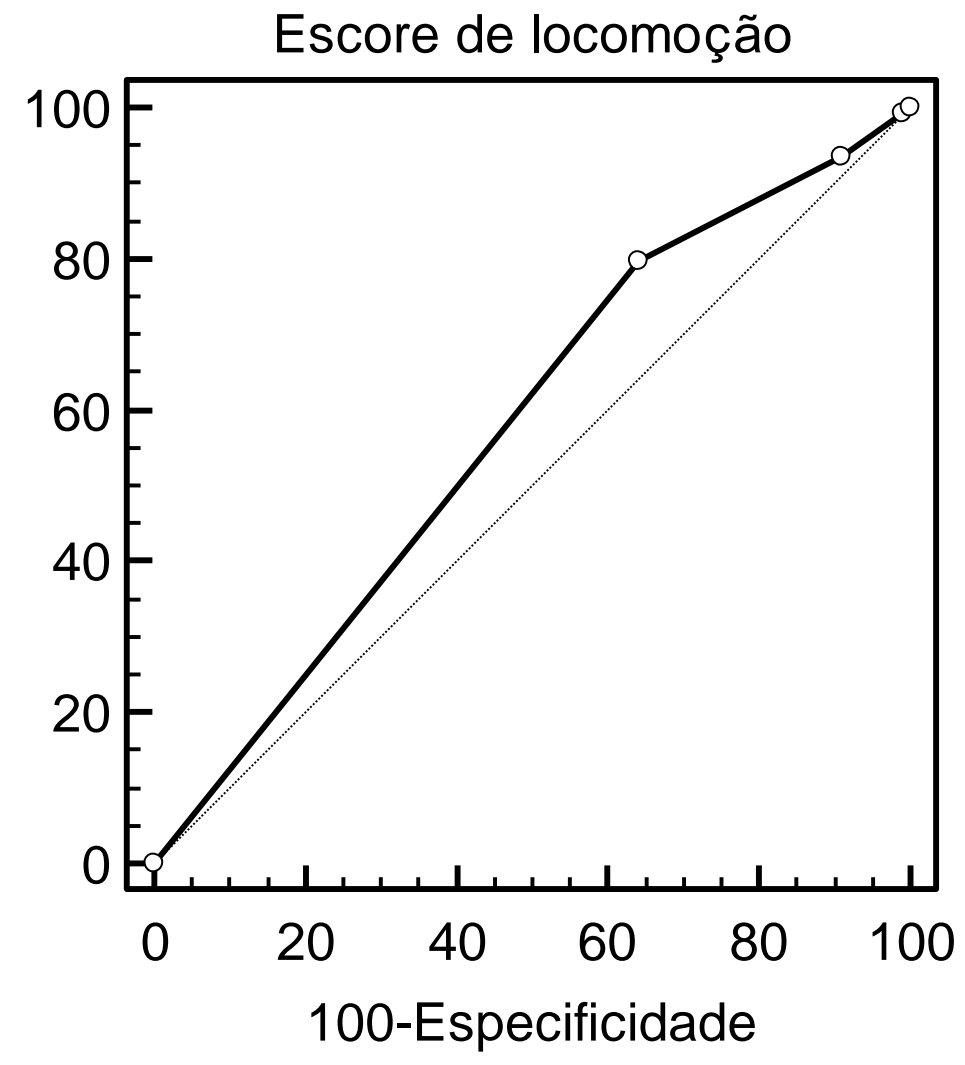

Figura 14 - Curva ROC representando a precisão com que o escore de locomoção prevê a ocorrência de prenhez aos 60 dias. Maior sensibilidade combinada $(79,7 \%$, intervalo de confiança de $95 \%=72,2$ a $86,0 \%)$ e especificidade $(35,9 \%$, intervalo de confiança de $95 \%=31,9$ a $40,1 \%)$ foram detectadas no valor $\leq 1$. A área sob a curva foi de 0,58 (intervalo de confiança de $95 \%=0,54$ a 0,61). São Pedro, 2008 
Probabilidade de prenhezaos 30 dias $=\frac{\exp (-0,4845-0,4281 . L S)}{1+\exp (-0,4845-0,4281 . L S)}$

Probabilidade de prenhezaos 60 dias $=\frac{\exp (-0,6869-0,4877 . L S)}{1+\exp (-0,6869-0,4877 . L S)}$

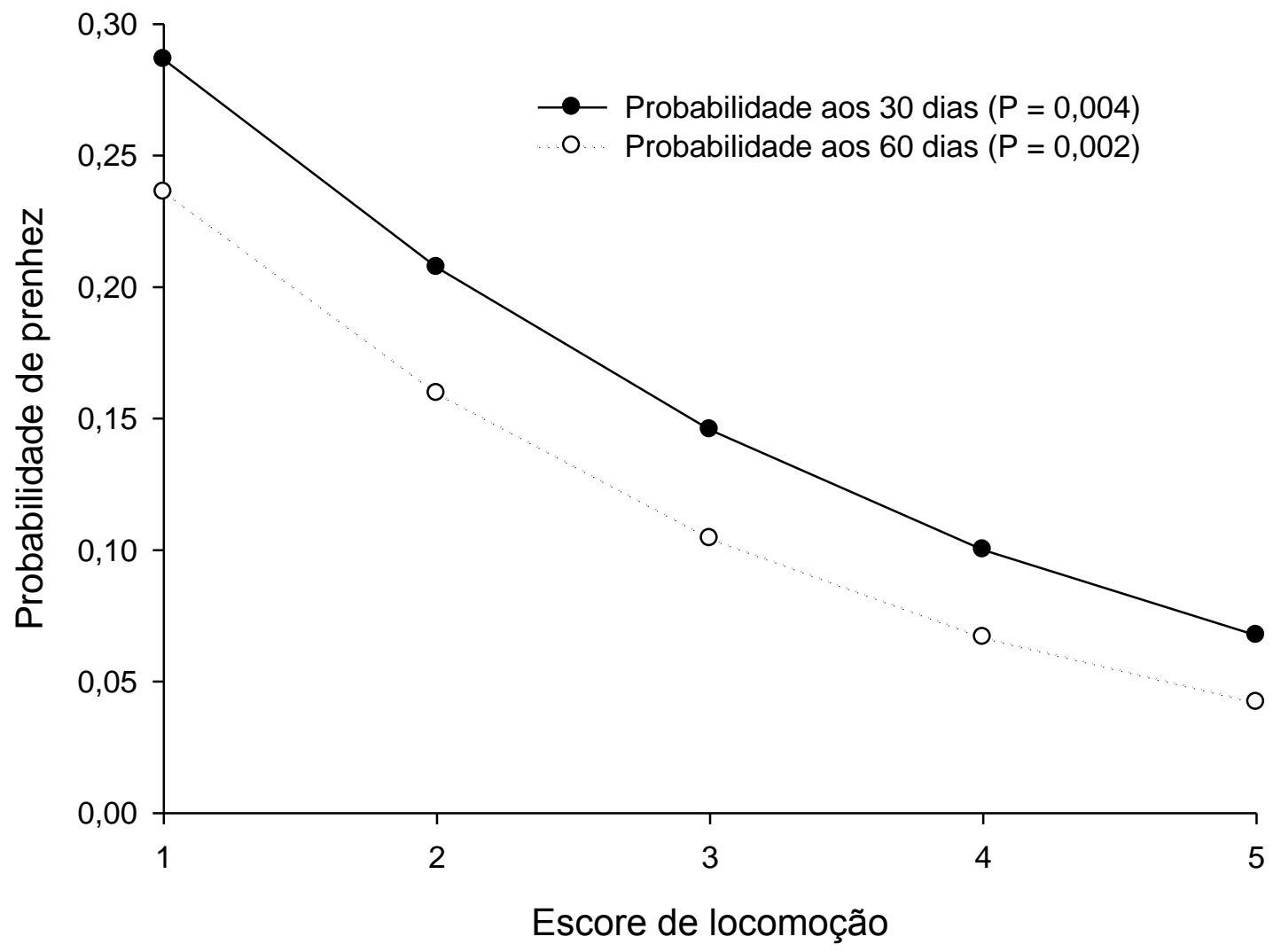

Figura 15 - Equações e representação gráfica da probabilidade de prenhez aos 30 e 60 dias em relação ao escore de locomoção no início do protocolo de sincronização da ovulação para a IATF de vacas Holandesas de alta produção de leite $(P=0,004$ e $P=0,002$, respectivamente). São Pedro, 2008 


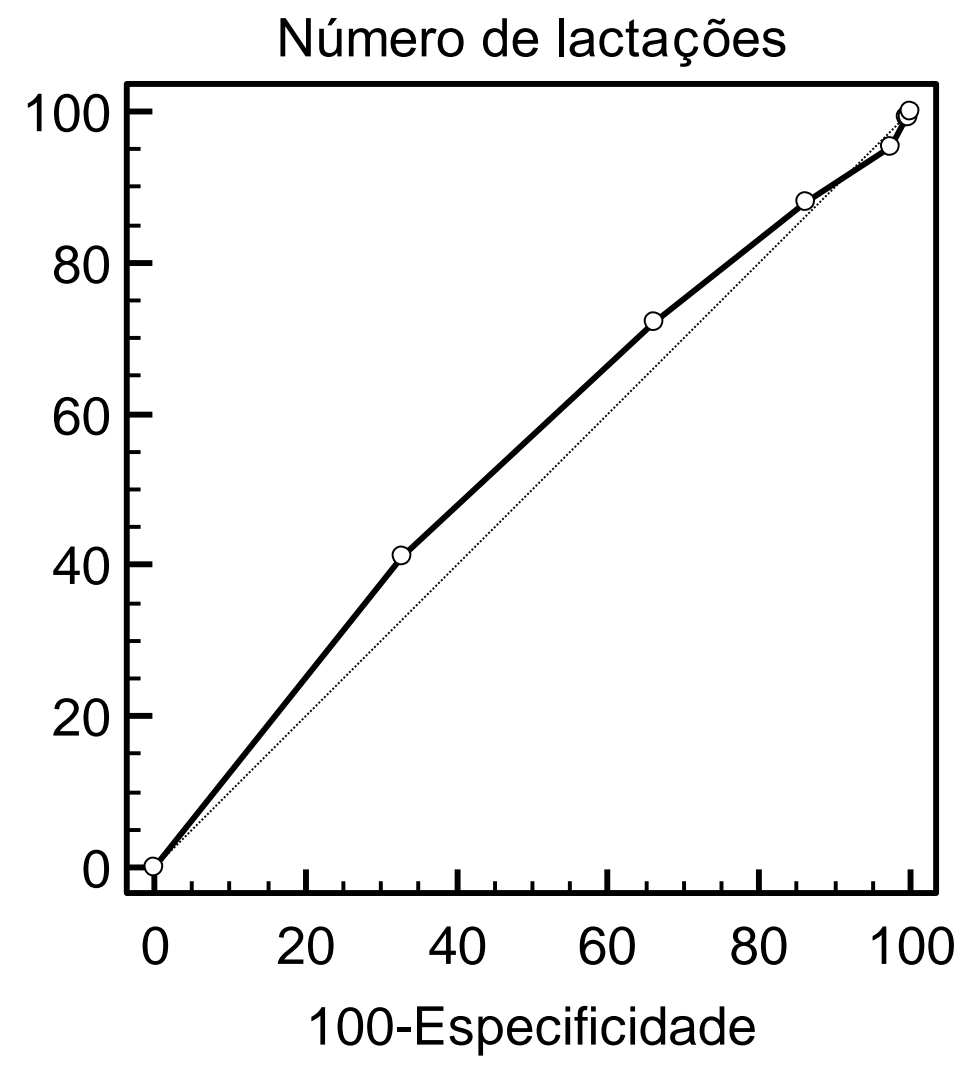

Figura 16 - Curva ROC representando a precisão com que o número de lactações prevê a ocorrência de prenhez aos 30 dias. Maior sensibilidade combinada (41,2\%, intervalo de confiança de $95 \%=33,9$ a 48,9\%) e especificidade $(67,1 \%$, intervalo de confiança de $95 \%=62,8$ a $71,1 \%$ ) foram detectadas no valor $\leq 1$. A área sob a curva foi de 0,55 (intervalo de confiança de 95\% = 0,50 a 0,58). São Pedro, 2008 


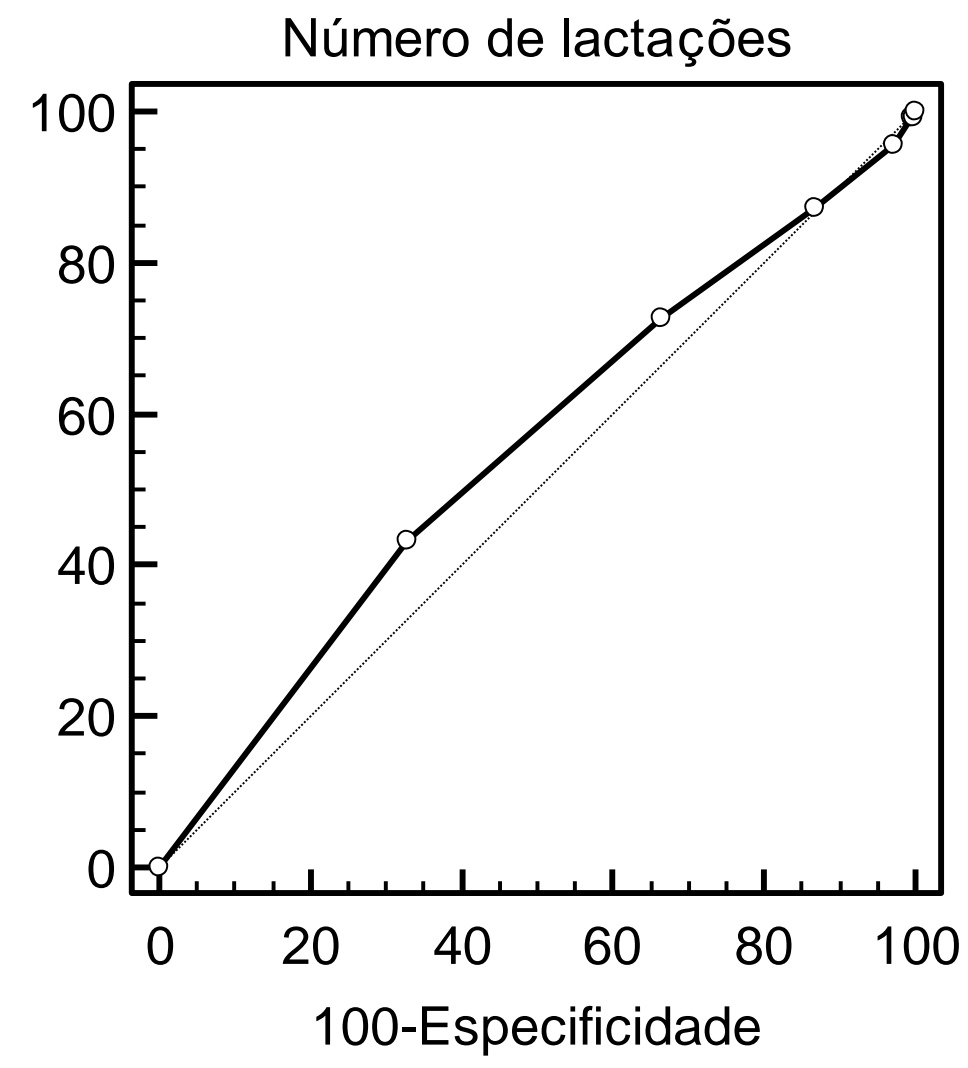

Figura 17 - Curva ROC representando a precisão com que o número de lactações prevê a ocorrência de prenhez aos 60 dias. Maior sensibilidade combinada (43,4\%, intervalo de confiança de $95 \%=35,1$ a 51,9\%) e especificidade $(67,1 \%$, intervalo de confiança de $95 \%=63,0$ a $71,0 \%$ ) foram detectadas no valor $\leq 1$. A área sob a curva foi de 0,55 (intervalo de confiança de 95\% = 0,51 a 0,59). São Pedro, 2008 
Probabilidade de prenhezaos 30 dias $=\frac{\exp (-1,2049+0,3596 . \text { Paridade })}{1+\exp (-1,2049+0,3596 \text { Paridade })}$

Probabilidade de prenhezaos 60 dias $=\frac{\exp (-1,5191+0,4477 . \text { Paridade })}{1+\exp (-1,5191+0,4477 . \text { Paridade })}$

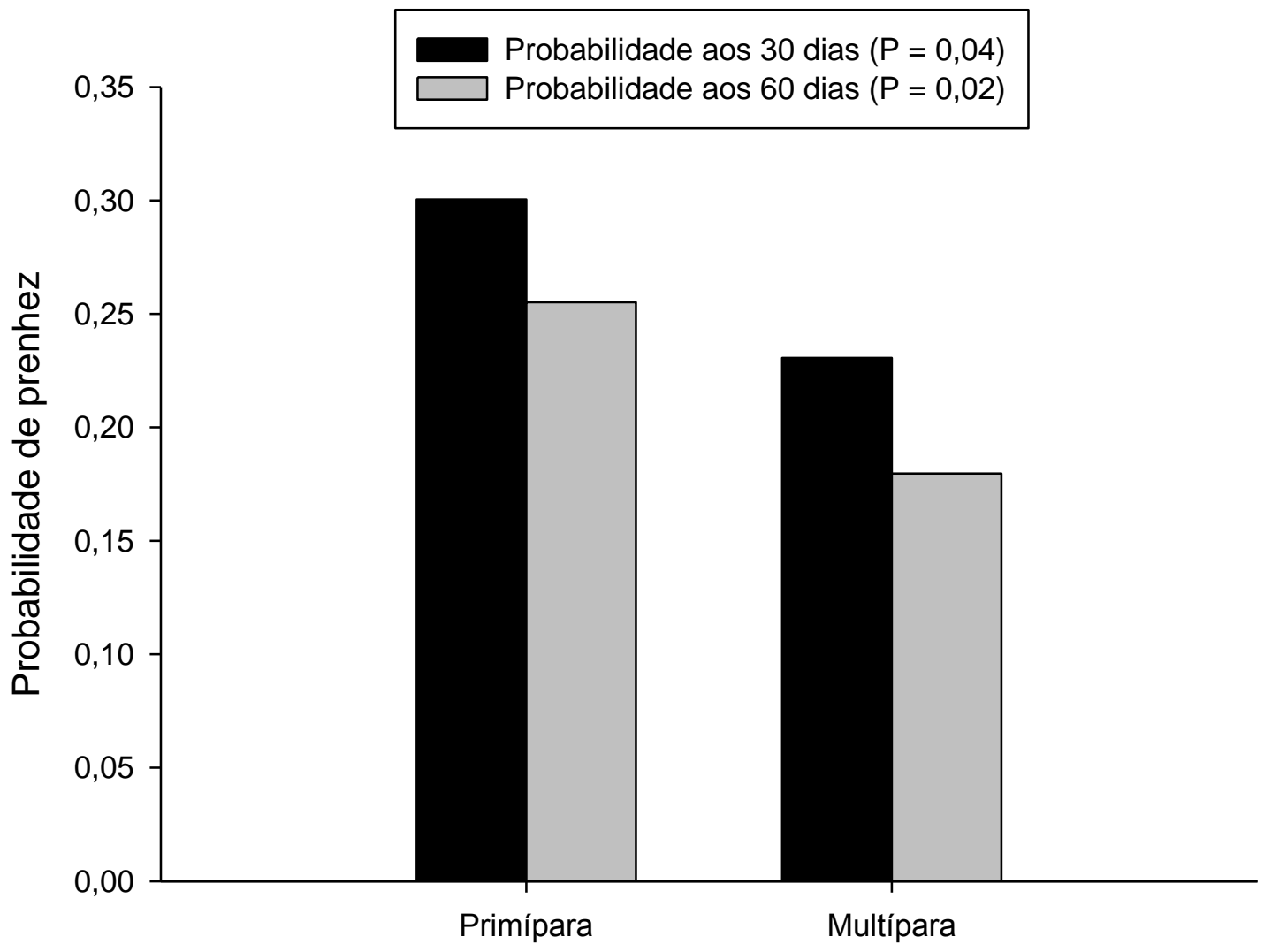

Paridade

Figura 18 - Equações e representação gráfica da probabilidade de prenhez aos 30 e 60 dias em relação à paridade de vacas Holandesas de alta produção de leite com ovulação sincronizada para IATF $(P=0,04$ e $P=0,02$, respectivamente; Primípara $=1$ e multípara = 0). São Pedro, 2008 
Probabilidade de perda gestaciona $=\frac{\exp (-2,5693+0,0361 . \text { Leite })}{1+\exp (-2,5693+0,0361 \text {.Leite })}$

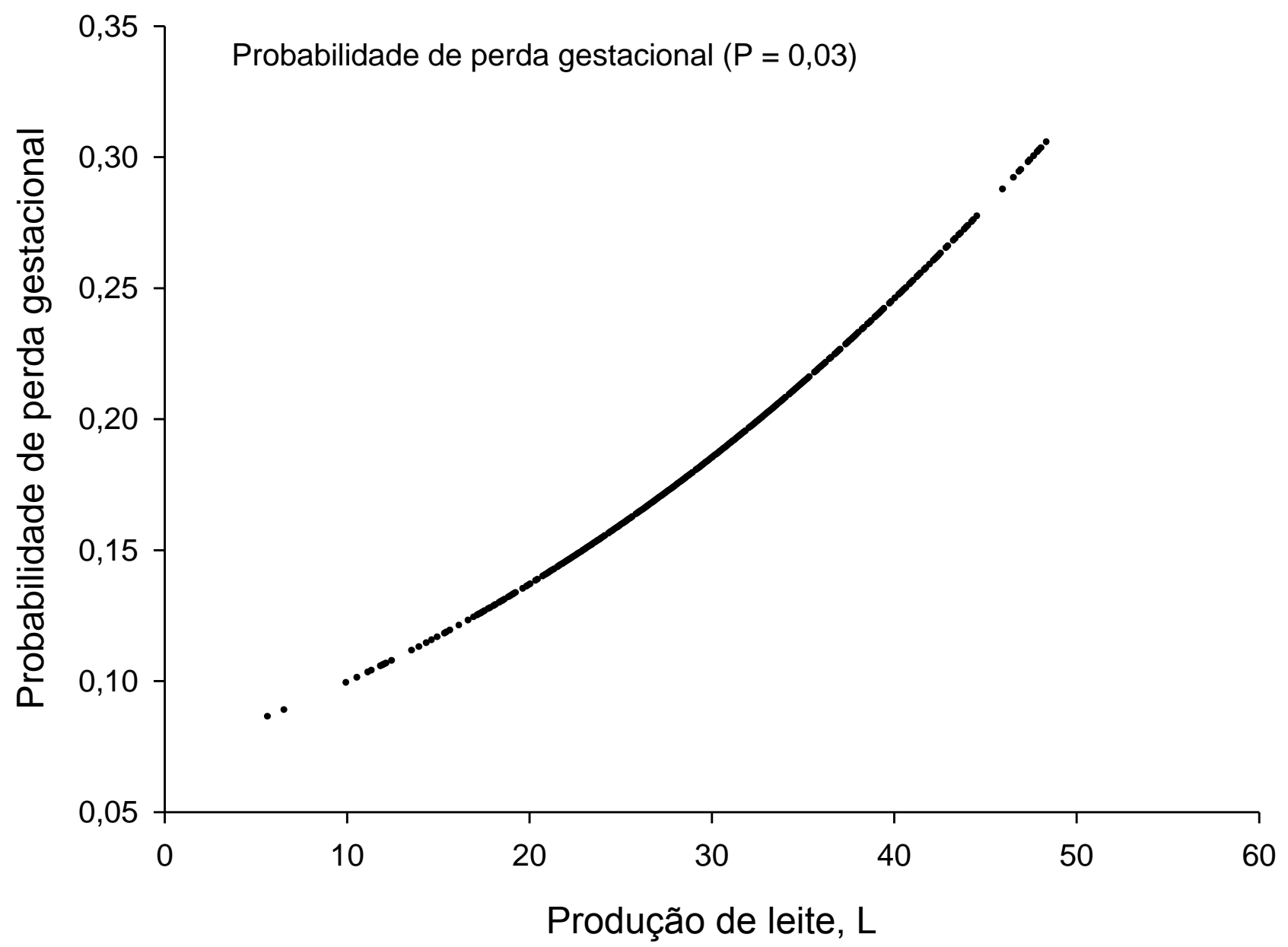

Figura 19 - Representação gráfica da probabilidade de perda gestacional entre 30 e 60 dias em relação à produção de leite de vacas Holandesas de alta produção de leite com ovulação sincronizada para IATF (P = 0,03). São Pedro, 2008 


\section{DISCUSSÃO}

Diferentemente da hipótese do presente estudo, o tratamento com FSH não influenciou a taxa de crescimento folicular e o momento, número e taxa de ovulação de vacas Holandesas de alta produção leiteira submetidas a protocolos para IATF a base de GnRH e PGF $2 \alpha$ (Experimento 1) ou de P4 e E2 (Experimento 2). No Experimento 2, a utilização do $\mathrm{FSH}$ favoreceu o crescimento luteínico, porém não promoveu aumeno da fertilidade dessas vacas.

Já foi demonstrado que após a divergência folicular, o folículo dominante torna-se mais depende do LH do que do FSH para manter seu crescimento (GINTHER et al., 1996). O aumento da quantidade de mRNA e do número de receptores de $\mathrm{LH}$ nas células da granulosa do folículo dominante detectados próximo a divergência folicular reforçam a importância do LH nesse período (XU et al., 1995; IRELAND; ROCHE, 1983). Sabe-se que o LH estimula as células da teca a produzirem andrógenos, que, por difusão, alcançam as camadas de células da granulosa, onde é produzida a aromatase (FORTUNE; ARMSTRONG, 1978). Então, a aromatização dos andrógenos em estrógeno é estimulada na presença do $\mathrm{FSH}$ (GORE-LANGTONA; DORRINGTON, 1981). Ainda, observou-se que o nível de mRNA para receptores de FSH não é alterado durante a primeira onda de crescimento folicular (XU et al., 1995) e tampouco há variação na habilidade das células da granulosa em se ligarem ao FSH de acordo com o aumento de diâmetro folicular (RICHARDS, 1980). No entanto, Gore-Langtona e Dorrington (1981) sugeriram que o FSH poderia ter uma ação dose-dependente com relação ao aumento da concentração celular de aromatase ativa.

Dessa forma, no presente estudo, o esperado era que o tratamento com FSH promovesse alterações na dinâmica folicular e na concentração sérica de estradiol devido ao maior estímulo a aromatização e consequentemente, maior produção de estrógeno. No entanto, a dinâmica folicular e a concentração sérica de estradiol permaneceram inalteradas quando $20 \mathrm{mg}$ de $\mathrm{FSH}$ foram administrados no momento da PGF2 $\alpha$. Além disso, a espessura endometrial manteve-se semelhante nas vacas tratadas ou não com FSH, demonstrando que o tratamento com essa gonadotrofina não promoveu os efeitos previstos. 
Rao et al. (1978) mostraram que a associação de estrógenos e FSH estimulam o crescimento folicular e proliferação das células da granulosa de folículos em diferentes estágios de desenvolvimento e diferenciação, no entanto, essa capacidade é limitada. Ainda, quando FSH humano (altamente purificado) foi administrado isoladamente a ratos, observou-se aumento progressivo, durante 4 dias, na quantidade de receptores de FSH. Porém, a quantidade de receptores de LH permaneceu inalterada. No entanto, quando os ratos foram pré-tratados com estradiol, a resposta dos folículos ao FSH foi realçada (RICHARDS et al., 1976). Assim, uma das possíveis explicações para a ausência do efeito positivo do tratamento com FSH em protocolos para IATF pode ser devido ao fato que as vacas do presente estudo não foram tratadas com qualquer tipo de estradiol exógeno próximo a administração do FSH.

Tanto o tratamento com FSH quanto com eCG não promoveu aumento do tamanho do folículo dominante $48 \mathrm{~h}$ após a remoção da fonte de P4. Estes resultados estão de acordo com estudos prévios em bovinos de corte (BARUSELLI et al., 2004; SÁ FILHO et al., 2010) e leite (SOUZA, 2008). No entanto, em outros estudos foi demonstrado que vacas em anestro tratadas com eCG apresentam aumento do diâmetro do folículo ovulatório (MARAÑA et al., 2006; SÁ FIHO et al., 2010).

Sabe-se que vacas em anestro apresentam baixas concentrações sanguíneas de LH (WILTBANK et al., 2002). Entretanto, a incidência de anestro devido à insuficiência de pulsos de LH é menos freqüente em vacas leite quando comparada a vacas de corte (WILTBANK et al., 2002). Ainda, está bem descrito na literatura que a incidência de anestro em vacas de leite, ao redor de 50 dias em lactação, é próximo a 20 \% (MOREIRA et al., 2000; GALVÃO et al., 2007; SOUZA et al., 2008). No presente estudo houve alta incidência de folículos superiores a $10 \mathrm{~mm}$, o que é normalmente observado em vacas sem comprometimento do estoque e/ou liberação de LH. Além disso, apesar do desenho experimental impossibilitar a mensuração de incidência de anestro nos animais do presente estudo (somente uma avaliação ultrasonográfica no início do protocolo de sincronização), pode-se inferir que o índice de anestro não foi superior a $10 \%$. Verificou-se que apenas 72 animais em um universo de 727 não apresentavam CL no início do protocolo. Esses animais também não tinham recebido serviço prévio. 
Dessa forma, essa diferença entre animais de diferentes aptidões (corte e leite) pode estar relacionada a diferentes concentrações de LH sanguíneo, ou mesmo às condições ambientais e de manejo as quais estão submetidos. Portanto, há indícios de que as vacas utilizadas nesse estudo apresentavam baixa incidência de anestro e, a utilização de 400 UI de eCG ou 20 mg de FSH não apresentou efeito sobre o diâmetro do folículo ovulatório, corroborando com as justificativas supracitadas.

No entanto, quando a análise foi realizada apenas em animais de primeiro serviço, com DEL inferior a 80 dias e sem presença de CL no dia de inicio do protocolo, verificou-se que o tratamento com eCG foi capaz de aumentar a prenhez em relação aos animais tratados com FSH e ao grupo controle. Este dados estão de acordo com os resultados encontrados em animais de corte (BARUSELLI et al., 2004; SÁ FILHO et al., 2010). Ainda, Ayres (dados não publicados) realizando levantamento de dados em vacas de leite usando o mesmo critério de avaliação (primeiro serviço, DEL inferior a 80 dias e sem presença de $C L$ ) verificou que o tratamento com eCG aumentou a taxa de prenhez (34,3\%; 57/166) em relação aos animais não tratados $(24,8 \% ; 46 / 185 ; P=0,04)$.

Após o desvio, apesar da menor dependência do folículo ao FSH , Ginther et al. (2000) demonstraram que o folículo dominante mantém a necessidade de concentrações mínimas de FSH para seu desenvolvimento, sendo a concentração basal de FSH suficiente para suprir essa exigência. No presente experimento, vacas tratadas com FSH apresentaram taxas de prenhez (entre 39 e 60 dias) semelhantes as vacas que não receberam FSH. Semelhantemente, em relato anterior, a administração de FSH não melhorou a taxa de concepção de vacas de corte (SALES et al., 2009; LIMA et al., 2010). Além disso, outro estudo demonstrou redução na taxa de prenhez em bovinos de corte após tratamento com FSH (Folltropin-V ou Pluset) quando comparado aos tratamentos com eCG (400 UI) e desmame temporário (SÁ FILHO et al., 2009).

D'Occhio et al. (dados não publicados) tratando novilhas zebu com agonista de $\mathrm{GnRH}$ por seis meses observaram restrição do crescimento folicular antral à diâmetros inferiores a $4 \mathrm{~mm}$. Após esse tratamento, os mesmos animais receberam suplementação exógena de FSH (8 aplicações consecutivas a cada 12 horas). Então, as novilhas reestabeleceram seu crescimento folicular e, ainda, apresentaram capacidade ovulatória quando estimuladas com LH exógeno. Observou-se que tanto 
o crescimento folicular, quanto a taxa de ovulação foram semelhantes entre novilhas tratadas ou não com agonista de $\mathrm{GnRH}$ e submetidas a 8 aplicações consecutivas de FSH. Este achado é sugestivo que o tratamento apenas com FSH pode ser capaz de estimular o crescimento e desenvolvimento folicular até a fase ovulatória em novilhas.

De forma semelhante, o uso de uma única administração de FSH em solução de liberação lenta (PVP), possibilitou que os folículos de $4 \mathrm{~mm}$ alcançassem diâmetros superiores a $10 \mathrm{~mm}$ e apresentassem capacidade ovulatória. Já os folículos dos animais tratados uma única dose de FSH em solução salina (FolltropinV; MAPLETOFT; PIERSON, 1993) atingiram diâmetro máximo de $6 \mathrm{~mm}$. Segundo a literatura, o FSH é um hormônio de meia-vida curta (5 horas), consequentemente de rápida metabolização (DEMOSTIER et al., 1988). Assim, o efeito inesperado do tratamento com FSH encontrado neste estudo pode ser devido a uma dose inadequada e/ou devido a curta meia-vida do fármaco, o qual pode não ter permanecido tempo suficiente na circulação para estimular o desenvolvimento folicular.

No presente estudo, as vacas tratadas com FSH durante o protocolo Ovsynch apresentaram maior concentração de P4 no momento da segunda administração de GnRH quando comparadas às vacas não tratadas. Pela análise da figura 2 e da tabela 3, pode-se verificar que este resultado é devido à maior concentração de P4 nos animais do Grupo FSH que não tiveram resposta luteolítica adequada a PGF2a.

No Experimento 2, tanto a suplementação com FSH quanto com eCG promoveram aumento do volume do CL, principalmente entre os dias 5 e 11 após a ovulação sincronizada. Inesperadamente, não houve aumento na concentração sérica de P4, aumento da área de fluxo sanguíneo no CL ou aumento da razão entre área de fluxo sanguíneo e a área total. Souza (2008), trabalhando com delineamento experimental semelhante, não encontraram aumento de volume no CL, área de fluxo sanguíneo no CL e razão entre área de fluxo sanguíneo e a área total. No entanto, os mesmos pesquisador observou tendência do tratamento com eCG em aumentar as concentrações circulantes de P4 durante o diestro subsequente. Porém, tanto no presente estudo, quanto no estudo prévio (SOUZA, 2008) a utilização de gonadotrofinas exógenas não promoveu melhora da taxa de prenhez quando todos os animais foram analisados. 
Ao analisar o gráfico de dispersão das ovulações, foram observados dois intervalos de concentração das ovulação, o primeiro entre 60 e 72 horas e o segundo entre 84 e 96 horas após a retirada da fonte de P4. Este mesmo fato foi observado por Souza et al. (2008) e Ferreira et al. (2010), quando o mesmo protocolo foi utilizado em vacas leiteiras. Adicionalmente, observou-se que nos dois intervalos de ovulação mencionados acima, diferentes diâmetros foliculares foram detectados, sendo o primeiro com folículos de maior diâmetro do que o segundo. Ainda, todas as ovulações de folículos persistentes ocorreram entre 60 e 72 horas, representando metade das ovulações (12/24) desse priemiro intervalo. Acredita-se que as ovulações do primeiro intervalo devam ter ocorrido como resposta a um pico endógeno de LH, (32 a 40 horas após a retirada da fonte de P4), uma vez que o GnRH exógeno foi administrado apenas 56 horas após a retirada da fonte de P4, 0 que levaria a indução de ovulação entre 80 e 86 horas da remoção.. Semelhantemente, Bisinotto (2010) verificou que folículos maiores apresentaram maior concentração de E2 no plasma e antecipação de 24 horas no pico de E2 em relação aos folículos menores. Este dado corrobora ao achado de outro estudo no qual animais com maiores concentrações de E2 anteciparam o pico de E2, o que refletiu em antecipação do pico de LH (ROBERSON et al., 1989).

No presente estudo, a probabilidade de ocorrência de prenhez foi afetada pela paridade, número de serviços prévios (primeiro ou segundo ou mais) e escore de locomoção. Está bem descrito na literatura que vacas leiteiras de primeira cria apresentam maiores taxas de prenhez que multíparas (SOUZA et al, 2008), assim como são verificadas maiores taxas de prenhez no primeiro serviço (SOUZA et al, 2008). Ainda, sabe-se que vacas com comprometimento no escore de locomoção apresentam maior incidência de cisto e menor taxa de concepção (MELEZEZ et al., 2003). Além disso, a probalidade de perda gestacional aumentou com o incremento da produção de leite. Sabe-se que animais com aumento da ingestação de matéria seca apresentam maior fluxo sanguineo hepático, que por sua vez aumenta o metabolismo dos hormônios esteróides, diminuindo a concetração sanguinea (SANGSRITAVONG et al., 2002), comprometendo desempenho reprodutivo.

Por fim, foi verificado que as vacas inseminadas durante o verão tiveram menor taxa de prenhez aos 30 e 60 dias do que aquelas inseminadas durante 0 inverno. A diminuição da fertilidade durante períodos de estresse térmico é amplamente discutida na literatura. Acredita-se que a causa seja multifatorial e que a 
hipertermia afete a função celular de vários tecidos do trato reprodutivo feminino (WOLFENSON et al, 2000; HANSEN et al, 2001). Neste contexto, demonstro-se que o estresse térmico compromete a dinâmica folicular ovariana (BADINGA et al., 1993) e a divergência folicular (WOLFENSON et al., 1995). Além disso, no verão há aumento da ocorrência de codominância folicular (SARTORI et al, 2004;. TORRESJÚNIOR et al, 2008), diminuição da duração do ciclo estral e da competência do oócito para desenvolver a blastocisto (ROCHA et al, 1998; AL-KATANANI et al, 2002; FERREIRA et al., 2011). 


\section{CONCLUSÕES}

A hipótese inicial de que a suplementação com FSH melhoraria a fertilidade de vacas Holandesas de alta produção submetidas a protocolos de sincronização da ovulação para IATF foi rejeitatada. A suplementação com FSH no momento da indução da luteólise:

- não aumentou o diâmetro do maior folículo, a concentração circulante de estrógeno, a espessura do endométrio uterino no momento do segundo GnRH e a taxa de ovulação após o segundo GnRH do protocolo Ovsynch;

- não aumentou o diâmetro do folículo ovulatório, a taxa de ovulação e a concentração de progesterona após a ovulação sincronizada de vacas submetidas ao protocolo com progesterona e estrógeno;

- não aumentou taxa de prenhez de animais submetidos aos protocolos Ovsynch e a base de progesterona e estradiol;

- aumentou o volume do CL após a ovulação no protocolo de sincronização com progestrona e estradiol. 


\section{REFERÊNCIAS}

ACOSTA, T. J.; HAYASHI, K. G.; OHTANI, M.; MIYAMOTO, A. Local changes in blood flow within the preovulatory follicle wall and early corpus luteum in cows. Reproduction, v. 125, p. 759-767, 2003.

ACOSTA, T.J.; MIYAMOTO, A. Vascular control of ovarian function: ovulation, corpus luteum formation and regression. Animal Reproduction Science, v. 82-83, p. 127-140, 2004.

ACOSTA, T. J.; YOSHIZAWA, N.; OHTANI, M.; MIYAMOTO, A. Local changes in blood flow within the early and midcycle corpus luteum after prostaglandin F2 $\alpha$ injection in the cow. Biology of Reproduction, v. 66, p. 651-658, 2002.

ADAMS, G. P.; KOT, K.; SMITH, C. A.; GINTHER, O. J. Selection of a dominant follicle suppression of follicular growth in heifers. Animal Reproduction Science, v. 30, p. 259-271, 1993.

ADAMS, G. P.; MATTERI, R. L.; KASTELIC, J. P.; KO, J. C. H.; GINTHER, O. J. Association between surges of follicle-stimulating hormone and the emergence of follicular waves in heifers. Journal of Reproduction and Fertility, v. 94, p. 177-188, 1992.

ALILA, H. W.; HANSEL, W. Origin of different cell types in the bovine corpus luteum as characterized by specific monoclonal antibodies. Biology of Reproduction, v. 31, p. 1015-1025, 1984.

ALLEN, W. R.; MOOR, R. M. The origin of the equine endometrial cups. I.

Production of the PMSG by fetal trofoblast cells. Journal of Reproduction Fertility, v. 29, p. 313-316, 1972.

ALLRICH, R. D. Endocrine and neural control of estrus in dairy cows. Journal of Dairy Science, v. 77, p. 2738-2744, 1994.

AUSTIN, E. J.; MIHM, M.; EVANS, A. C. O.; IRELAND, L. H.; IRELAND, J. J.; ROCHE, J. F. Effects of oestradiol and progesterone on secretion of gonadotrophins and health of first wave follicles during the oestrus cycle of beef heifers.

Reproduction, v. 124, p. 531-541, 2002.

BARUSELLI, P. S.; MARQUES, M. O.; NASSER, L. F.; REIS, E. L.; BÓ, G. A. Effect of eCG on pregnancy rates of lactating zebu beef cows treated with cidr-b devices for timed artificial insemination. Theriogenology, v. 59, p. 214, 2003.

BARUSELLI, P. S.; MARTINS, C. M.; SALES, J. N. S.; FERREIRA, R. M. Novos avanços na superovulação de bovinos. Acta Scientiae Veterinariae, v. 36, p. s433s448, 2008. Supplement, 2. 
BARUSELLI, P. S.; REIS, E. L.; MARQUES, M. O.; NASSER, L. F.; BÓ, G. A. The use of treatments to improve reproductive performance of anestrus beef cattle in tropical climates. Animal Reproduction Sciencie, v. 82-83, p. 479-486, 2004.

BEG, M. A.; BERGFELT, D. R.; KOT, K.; WILTBANK, M. C.; GINTHER, O. J. Follicular fluid factors and granulosa cell gene expression associated with follicle deviation in cattle. Biology of Reproduction, v. 64, p. 432-441, 2001.

BERGFELT, D. R.; KULICK, L. J.; KOT, K.; GINTHER, O. J. Follicular and hormonal response to experimental suppression of FSH during follicle deviation in cattle. Theriogenology, v. 54, p. 1191-1206, 2000.

BERISHA, B.; SCHAMS, D. Ovarian function in ruminants. Domestic Animal Endocrinology, v. 29, p. 305-317, 2005.

BISINOTTO, R. S. Manipulating the ovulatory follicle: impacts on reproductive tissue gene expression and fertility of dairy cows. 2010. 105 p. Dissertação (Mestrado em Ciência Animal) - Departamento de Ciência Animal, Universidade da Florida, Gainesville, Florida, 2010.

BLACHE, D.; FABRE-NYS, C. J.; VENIER, G.. Ventromedial hypothalamus as a target for oestradiol action on proceptivity, receptivity and luteinizing hormone surge of the ewe. Brain Research, v. 546, p. 241-249, 1991.

BÓ, G. A. Sincronizacion de celos para programas de inseminacion artificial y transferencia de embriones bovinos. In: SIMPÓSIO SOBRE O CONTROLE FARMACOLÓGICO DO CICLO ESTRAL EM RUMINANTES, 1., 2000, São Paulo. Anais... São Paulo: Fundação da Faculdade de Medicina Veterinária e Zootecnia, USP, 2000. p. 35-60.

BÓ, G. A.; ADAMS, G. P.; PIERSON, R. A.; MAPLETOFT, R. J. Exogenous control of follicular wave emergence in cattle. Theriogenology, v. 43, p. 31-40, 1995.

BO, G. A.; ADAMS, G. P.; PIERSON, R. A.; TRIBULO, H. E.; CACCIA, M.; MAPLETOFT, R. J. Follicular wave dynamics after estradiol-17ß treatment of heifers with or without a progestogen implant. Theriogenology, v. 41, p.1555-1569, 1994.

BO, G. A.; ADAMS, G. P.; NASSER, L. F.; PIERSON, R. A.; MAPLETOFT, R. J. Effect of estradiol valerate on ovarian follicles, emergence of follicular waves and circulating gonadotropins in heifers. Theriogenology, v. 40, n. 2, p. 225-39, 1993.

BO, G. A.; PIERSON, R. A.; MAPLETOFT, R. J. The effect of estradiol valerate on follicular dynamics and superovulatory response in cows with Syncro-Mate-B implants. . Theriogenology, v. 36, p. 169-183, 1991.

BOLAND, M. D.; CRODBY, T. F.; GORDON, I. Morphological normality of cattle embryos following superovulation using PMSG. Theriogenology, v. 10, p. 175-180, 1978.

BOUSFIELD, G. R.; BUTNEV, V. Y.; GOTSCHALL, R. R.; BAKER, V. L.; MOORE, W. T. Structural features of mammalian gonadotropins. Molecular and Cellular Endocrinology, v. 125, p. 3-19, 1996. 
BRUSVEEN, D. J.; CUNHA, A. P.; SILVA, C. D.; CUNHA, P. M.; STERRY, R. A.; SILVA, E. P. B.; GUENTHER, J. N.; WILTBANK, M. C. Altering the Time of the Second Gonadotropin-Releasing Hormone Injection and Artificial Insemination (AI) During Ovsynch Affects Pregnancies per Al in Lactating Dairy Cows. Journal of Dairy Science, v. 91, p. 1044-1052, 2008.

CACCIA, M.; BO, G. A. Follicle wave emergence following treatment of CIDR-B implanted beef heifers with estradiol benzoate and progesterone. Theriogenology, v. 49, p. 341, 1998. [Abstract].

CAFFREY, J. L.; FLETCHER, P. W.; DIEKMAN, M. A.; O'CALLAGHAN, P. L.; NISWENDER, G. D. The activity of ovine luteal cholesterol esterase during several experimental conditions. Biology of Reproduction, v. 21, p. 601-608, 1979.

CAVALIERI, J.; RUBIO, I.; KINDER, J. E.; ENTWISTLE, K. W.; FITZPATRICK, L. A. Synchonization of estrus and ovulation and associated endocrine changes in Bos indicus cows. Theriogenology, v. 47, p. 801-814, 1997.

CERRI, R. L.; RUTIGLIANO, H. M.; CHEBEL, R. C.; SANTOS, J. E. P. Period of dominance of the ovulatory follicle influences embryo quality in lactating dairy cows. Reproduction, v. 137, p. 813-823, 2009.

CHAPPEL, S. C. Heterogeneity of follicle stimulating hormone: control and physiological function. Human Reproduction, v. 1, p. 479-87, 1995.

CHEBEL, R. C.; SANTOS, J. E. P.; CERRI, R. L. A.; RUTIGLIANO, H. M.; BRUNO; R. G. S. Reproduction in dairy cows following progesterone insert presynchronization and resynchronization protocols. Journal of Dairy Science, v. 89, p. 4205-4219, 2006.

CHEGINI, N.; LEI, Z. M.; RAO, CH. V.; HANSEL, W. Cellular distribution and cycle phase dependency of gonadotropin and eicosanoid binding sites in bovine corpora lutea. Biology of Reproduction, v. 45, p. 506-513, 1991.

COLE, H. H.; HART, G. H. Potency of blood serum of mares in progressive stages of pregnancy in effecting the sexual maturity of the immature rat. American Journal of Physiology, v. 93, p. 57-58, 1930.

CRITSER, J. K.; ROWE, R. F.; DEL CAMPO, M. R.; GINTHER, O. J. Embryo transfer in cattle: factors affecting superovulatory resposnse, number of transferible embryos, and length of post-treatment estrous cycle. Theriogenology, v. 13, p. 397406, 1978.

CRUZ, L. C.; VALLE, E. R.; KESLER, D. J. Effect of prostaglandin and gonadotrofin releasing hormone-induced luteinizing hormone releases on ovulation and corpus luteum function of beef cows. Animal Reproduction Science, v. 49, n. 2, p. 135142, 1997.

DAELS, P. F.; ALBRECHT, B. A.; MOHAMMED, H. O. Equine Chorionic Gonadotropin regulates luteal steroidogenesis in pregnant mares. Biology Reproduction, v. 59, p. 1062-1068, 1998. 
DAVIS, A. J.; FLEET, I. R.; HANSFORD, P. A.; HARRISON, F. A.; WALKER. F.M.M. Pulmonary metabolism of prostaglandin $\mathrm{F} 2 \mathrm{a}$ in the conscious non-pregnant cow. Journal of Physiology, v. 358, p. 107, 1985. [Abstract].

DE LA SOTA, R. L.; LUCY, M. C.; STAPLES, C. R.; THATCHER, W. W. Effects of recombinant bovine somatotropin (Sometribove) on ovarian function in lactating and nonlactating dairy cows. Journal of Dairy Science, v. 76, p. 1002-1013, 1993.

DE ROOVER, R.; FEUGANG, J. M. N.; BOLS, P. E. J.; GENICOT, G.; HANZEN, C. $H$. Effects of Ovum Pick-up Frequency and FSH Stimulation: A Retrospective Study on Seven Years of Beef Cattle In Vitro Embryo Production. Reproduction in Domestic Animals, v. 43, n. 2, p. 239-245, 2008.

DEMOUSTIER, J. M.; BECKERS, J. F.; VAN DER ZWALMEN, P.; CLOSSET, J.; GILLARD, J.; ECTORS, F. R. Determination of porcine plasma Folltropin-V levels during superovulation treatment in cows. Theriogenology, v. 30, p. 379-386,1988.

DRANSFIELD, M. B. G.; NEBEL, R. L.; PEARSON, R. E.; WARNICK, L. D. Timing of insemination for dairy cows identified in estrus by a radiotelemetric estrus detection system. Journal Dairy Science, v. 81, p. 1874-1882, 1998.

ECHTERNKAMP, S. E.; HOWARD, H. J.; ROBERTS, A. J.; GRIZZLE, J.; WISE, T. Relationships among concentrations of steroids, insulin-like growth factor-I, and insulin-like growth factor binding proteins in ovarian follicular fluid of beef cattle. Biology of Reproduction, v. 51, p. 971-981, 1994.

ELSDEN, R. P.; NELSON, L. D.; SEIDEL, G. E. Superovulating cows with FSH and PMSG. Theriogenology, v. 9, p. 529-534, 1978.

FANNING, M. D.; SPITZER, J. C.; BURNS, G. L.; PLYLER, B. B. Luteal function and reproductive response in suckled beef cows after metestrus administration of a norgestomet implant and injection of estradiol valerate with various dosages of injectable norgestomet. Journal of Animal Science, v. 70, n.5, p. 1352-1356, 1992.

FARIN, C. E.; MOELLER, C. L.; SAWYER, H. R.; GAMBONI, F.; NISWENDER, G. D. Morphometric analysis of cell types in the ovine corpus luteum throughout the estrous cycle. Biology of Reproduction, v. 35, p. 1299-1308, 1986.

FARIN, C. E.; NETT, T. M.; NISWENDER, G. D. Effects of luteinizing hormone on luteal cell populations in hypophysectomized ewes. Journal of Reproduction and Fertility, v. 88, p. 61-70, 1990.

FERGUSON, J. D.; GALLIGAN, D. T.; Thomsen, N. Principal descriptors of body condition score in Holstein cows. Journal of Dairy Science, v. 77, p. 2695-2703, 1994.

FERNANDES, L. C.; THATCHER, W. W.; WILCOX, C. J.; CALL, E. P. LH release in response to $\mathrm{GnRH}$ during the postpartum period of dairy cows. Journal of Animal Science, v. 46, p. 443-448, 1978.

FERREIRA, R. M.; AYRES, H.; CHIARATTI, M. R.; FERRAZ, M. L.; ARAÚJO, A. B.; RODRIGUES C. A., WATANABE, Y. F.; VIREQUE, A. A.; JOAQUIM, D. C.; SMITH, 
L. C.; MEIRELLES, F. V.; BARUSELLI, P. S. The low fertility of repeat-breeder cows during summer heat stress is related to a low oocyte competence to develop into blastocysts. Journal of Dairy Science, v. 94, p. 2383-2392, . 2011.

FERREIRA, R. M.; AYERS, H.; GIMENES, L. U.; BARUSELLI, P. S. Effects of different ovulatory stimulus (GnRH vs estradiol cypionate) on follicular dynamics of a progesterone-based timed ai protocol in Holstein cows. Journal of Dairy Science, v. 93, 2010. E-Supplement, 1.

FITZ, T. A.; MAYAN, M. H.; SAWYER, H. R.; NISWENDER, G. D. Characterization of two steroidogenic cell types in the ovine corpus luteum. Biology of Reproduction, $\mathrm{V}$. 27, p. 703-711, 1982.

FORTUNE, J. E.; ARMSTRONG, D. T. Hormonal control of 17 beta-estradiol biosynthesis in proestrous rat follicles: estradiol production by isolated theca versus granulosa. Endocrinology, v. 102, n. 1, p. 227-235, 1978.

FRASER, H. M.; LUNN, S. F. Regulation and manipulation of angiogenesis in the primate corpus luteum. Reproduction, v. 121, p. 355-362, 2001.

GALVÃO, K. N.; SÁ FILHO, M. F.; SANTOS, J. E. P. Reducing the interval from presynchronization to initiation of timed artificial insemination improves fertility in dairy cows. Journal of Dairy Science, v. 90, p. 4212-4218, 2007.

GAYTAN, F.; MORALES, C.; GARCIA-PARDO, L.; REYMUNDO, C.; BELLIDO, C.; SANCHEZ-CRIADO, J. E. A quantitative study of changes in the human corpus luteum microvasculature during the menstrual cycle. Biology of Reproduction, $v$. 60, p. 914-919, 1999.

GINTER, O. J.; UTT, M. D. Doppler ultrasound in equine reproduction: principles, techniques, and potential. Journal of Equine Veterinary Science, v. 24, p. 516-526, 2004.

GINTHER, O. J.; BERGFELT, D. R.; KULICK, L. J.; KOT, K. Selection of the dominant follicle in cattle: Role of two-way functional coupling between folliclestimulating hormone and the follicles. Biology of Reproduction, v. 62, p. 920-927, 2000.

GINTHER, O. J.; KNOPF, L.; KASTELIC, J. P. Temporal associations among ovarian events in cattle during oestrous cycles with two and three follicular waves. Journal of Reproduction and Fertility, v. 87, v. 223-230, 1989.

GINTHER, O. J.; SHRESTHA, H. K.; FUENZALIDA, M. J.; SHAHIDUZZAMAN, A. K. M.; BEG, M. A. Characteristics of pulses of 13,14-dihydro-15-keto-prostaglandin F2alpha before, during, and after spontaneous luteolysis and temporal intrapulse relationships with progesterone concentrations in cattle. Biology of Reproduction, v. 82, p. 1049-1056, 2010.

GINTHER, O. J.; SILVA, L. A.; ARAUJO, R. R.; BEG, M. A. Temporal Associations among Pulses of 13,14-Dihydro-15-keto-PGF $2 \alpha$, Luteal Blood Flow, and Luteolysis in Cattle. Biology Reproduction, v. 76, p. 506-513, 2007. 
GINTHER, O. J.; WILTBANK, M. C.; FRICKE, P. M.; GIBBONS, J. R.; KOT, K. Selection of the dominant follicle in cattle. Biology of Reproduction, v. 55, p. 11871194, 1996.

GIRSH, E.; WANG, W.; MAMLUK, R.; ARDITI, F.; FRIEDMAN, A.; MILVAE, R. A.; MEIDAN, R. Regulation of endothelin-1 in the bovine corpus luteum: elevation by prostaglandin F2 alpha. Endocrinology, v. 137, p. 5191-5196, 1996.

GOLDENBERG,R. L.; REITER, E. O.; VAITUKAITIS, J. L.; ROSS, G. T. Interaction of FSH and hCG on follicle development in the ovarian augmentation reaction Endocrinology, v. 91, p. 533-536, 1972.

GONG, J. G.; MCBRIDE, D.; BRAMLEY, T. A.; WEBB, R. Effects of recombinant bovine somatotrophin, insulin-like growth factor-I and insulin on bovine granulosa cell steroidogenesis in vitro. Journal of Endocrinology, v. 143, p. 157-164, 1994.

GONZALES, A.; WANG, H.; CARRUTHERS, T. D.; MURPHY, B. D.; MAPLEOTOFT, R. J. Superovulation in the cow with pregnant mare serum gonadotrophin: effects of dose and antipregnant mare serum gonadotrophin serum. Canadian Veterinary Journal, v. 35, p. 158-162, 1994.

GONZALEZ, A.; LUSSIER, J. G.; CARRUTHERS, T. D.; MURPHY, B. D.; MAPLETOFT, R. J. Superovulation of beef heifers with Folltropin-V: a new FSH preparation containing reduced LH activity. Theriogenology, v. 33, p. 519-519,1990.

GONZALEZ-MENICO, F.; MANNS, J.; MURPHY, B. D. FSH and LH activity of PMSG from mares at different stages of gestation. Animals Reproduction Sciencie, v. 1, p. 137-144, 1978.

GORE-LANGTON, R. E.; DORRINGTON, J. H. FSH induction of aromatase in cultured rat granulosa cells measured by a radiometric assay. Molecular Cell Endocrinology, v. 22, n. 2, p. 135-151, 1981.

GOSPODAROWICS, D. Purification and physiochemical properties of the pregnant mare serum gonadotropin (PMSG). Endocrinology, v. 91, p. 101-106, 1972.

GÜMEN, A.; GUENTHER, J. N.; WILTBANK, M. C. Follicular size and response to Ovsynch versus detection of estrus in anovular and ovular lactating dairy cows.

Journal of Dairy Science, v. 86, p. 3184-3194, 2003.

HANSEN, P. J.; DROST, M.; RIVERA, R. M.; PAULA-LOPES, F. F.; AL-KATANANI, Y. M.; KRININGER III, C. E.; CHASE JR., C. C. Adverse impact of heat stress on embryo production: Causes and strategies for mitigation, Theriogenology, v. 55, p. 91-103, 2001.

HAYASHI, K.; ACOSTA, T. J.; BERISHA, B.; KOBAYASHI, S.; OZAWA T.; FUKUDA, R.; KOJIMA, A.; OTHANI, M.; SCHAMS, D.; MIYAMOTO, A. Real-time changes in the local angiotensin system and prostaglandin production in the regressing corpus luteum in the cow. Biology of Reproduction, v. 64, p. 132, 2001. Supplement, 1. [Abstract]. 
HAYASHI, K.; MIYAMOTO, A. Angiotensin II interacts with prostaglandin F2a and endothelin-1 as a local luteolytic factor in the bovine corpus luteum in vitro. Biology of Reproduction, v. 60, p. 1104-1109, 1999.

HUMBLOT, P.; GRIMARD, B.; RIBON, B.; KHIREDDINE, B.; DERVISHI, V.; THIBIER, M. Source of variation of postpartum cyclicity, ovulation and pregnancy rates in primiparous charolais cows treated with Norgestomet implants and PMSG. Theriogenology, v. 46, p. 1085-1096, 1996.

HUNTER, M. G.; ROBINSON, R. S.; MANN, G. E.; WEBB, R. Endocrine and paracrine control of follicular development and ovulation rate in farm species. Animal Reproduction Science, v. 82-83, p. 461-77, 2004.

IRELAND, J. J.; ROCHE, J. F. Development of non-ovulatory antral follicles in heifers: changes in steroids in follicular fluid and receptors for gonadotropins. Endocrinology, v. 12, p. 150-156, 1983.

JABLONKA-SHARIFF, A.; GRAZUL-BILSKA, A. T.; REDMER, D. A.; REYNOLDS, L. $P$. Growth and cellular proliferation of ovine corpora lutea throughout the estrous cycle. Endocrinology, v. 133, n. 4, p. 1871-1879, 1993.

JUENGEL, J. L.; MEBERG, B. M.; TURZILLO, A. M.; NETT, T. M.; NISWENDER, G. $D$. Hormonal regulation of mRNA encoding steroidogenic acute regulatory protein in ovine corpora lutea. Endocrinology, v. 136, p. 5423-5429, 1995a.

JUENGEL, J. L.; NETT, T. M.; TANDESKI, T. M.; ECKERY, D. C.; SAWYER, H. R.; NISWENDER, G. D. Effect of luteinizing hormone and growth hormone on luteal development in hypophysectomized ewes. Endocrinology, v. 3, p. 323-326, 1995b.

KINDAHL, H.; EDQUIST, L. E.; BANE, A.; GRANSTRÖM E. Blood levels of progesterone and 15-keto-13,14-dihydro-prostaglandin F2alpha during the normal oestrous cycle and early pregnancy in heifers. Acta Endocrinology, v. 82, p. 134149, 1976b.

KINDAHL, H.; EDQVIST, L. E.; GRANSTRÖM, E.; BANE, A. The release of prostaglandin $F_{2 \alpha}$ as reflected by 15 -keto-13,14, dihydroprostaglandin $F_{2 \alpha}$ in the peripheral circulation during normal luteolysis in heifers. Prostaglandins, v. 11, p. 871-878, 1976a.

KINDER, J. E.; KOJIMA, F. N.; BERGFELD, E. G.; WEHRMAN, M. E.; FIKE, K. E. Progestin and estrogen regulation of pulsatile $\mathrm{LH}$ release and development of persistent ovarian follicles in cattle. Journal of Animal Science, v. 74, p. 1424-40, 1996.

KOBAYASHI, S.; ACOSTA, T. J.; HAYASHI, K.; BERISHA, B.; OZAWA, T.; OHTANI, M.; SCHAMS, D.; MIYAMOTO, A. Intraluteal release of prostaglandin F2_ and E2 during corpora lutea development in the cow. Journa of Reproduction and Development, v. 48, p. 583-590, 2001b.

OBAYASHI, S.; BERISHA, B.; AMSELGRUBER, W. M.; SCHAMS, D.; MIYAMOTO, A. Production and localisation of angiotensin II in the bovine early corpus luteum: a 
possible interaction with luteal angiogenic factors and prostaglandin F2 $\alpha$. Journal of Endocrinology, v. 170, p. 369-380, 2001a.

KOMAR, C. M.; BERNDTSON, A. K.; EVANS, A. C. O.; FORTUNE, J. E. Decline in circulating estradiol during the periovulatory period is correlated with decreases in estradiol and androgen, and in messenger RNA for P450 aromatase and P450 17 $\alpha-$ hydroxylase, in bovine preovulatory follicles. Biology of Reproduction, v. 64, p. 1797-1805, 2001.

KULICK, L. J.; KOT, K.; WILTBANK, M. C.; GINTHER, O. J. Follicular and hormonal dynamics during the first follicular wave in heifers. Theriogenology, v. 52, p. 913921, 1999.

LEGARDINIER, S.; CAHOEAU, C.; KLETT, D.; COMBARNOUS, Y. Involvement of equine chorionic gonadotropin (eCG) carbohydrate side chains in its bioactivity: lessons from recombinant hormone expressed in insect cells. Reproduction Nutrition Development, v. 45, p. 255-259, 2005.

LIMA, L. A.; PINHEIRO, V. G.; CURY, J. R.; BARROS, C. M. Addition of FSH, in contrast to eCG, does not increase pregnancy rates in anestrous Nellore (Bos Indicus) cows treated with fixed-time ai protocol. Reproduction, Fertility and Development, v. 22, n. 1, p. 170, 2010. [Abstract].

LINDSELL, C. E.; RAJKUMAR, K.; MANNING. A. W.; EMERY, S. K.; MAPLETOFT, R. J.; MURPHY, B. D. Variability in FSH-LH ratios among batches of commercially available gonadotrophins. Theriogenology, v. 25, p. 167, 1986. [Abstract].

LOPEZ, H.; SARTORI, R.; WILTBANK, M. C. Reproductive hormones and follicular growth during development of one or multiple dominant follicles in cattle. Biology of Reproduction, v. 72, p. 788-795, 2005b.

LOPEZ, H.; SATTER, L. D.; WILTBANK, M. C. Relationship between level of milk production and estrous behavior of lactating dairy cows. Animal Reproduction Science, v. 81, p. 209-223, 2004.

MACMILLAN, K. L.; THATCHER, W. W. Effects of an agonist of gonadotropinreleasing hormone on ovarian follicles in cattle. Biology of Reproduction, v. 45, p. 883-889, 1991.

MANN, G. E.; HARESIGN, W. Effect of oestradiol treatment during GnRH-induced ovulation on subsequent PGF2alpha release and luteal life span in anoestrous ewes. Animal Reproduction Sciencie, v. 67, p. 245-252, 2001.

MAPLETOFT, R. J.; PIERSON, R. A. Factors affecting superovulation in the cow: practical considerations. Embryo Transfer News, v. 11, p. 15-24, 1993.

MARAÑA, D.; CUTAIA, L.; PERES, L.; PINCINATO, D.; BORGES, L. F. K.; BÓ, G. A. Ovulation and Pregnancy rates in postpartum bos indicus cows treated with progesterone vaginal devices and estradiol benzoate, with or without eCG and temporary weaning. Reproduction Fertility and Development, v. 18, p. 116-117, 2006. 
MARTINS, C. M.; TORRES JR., J. R. S.; GIMENES, L. U.; SOUZA, A. H.; BARUSELLI, P. S. Superovulação com eCG e FSH em doadoras Nelore (Bos indicus) inseminadas em tempo fixo. Acta Scientiae Veterinariae, v. 34, p. 527, 2006.

MARTINS, C. M.; VALENTIM, R.; BOMBONATTO, D. S.; SANTOS, I. C. C.; BARUSELLI, P. S. Efeito do FSH e do eCG na dinâmica folicular e taxa de prenhez de protocolos de IATF em vacas zebuínas em anestro. Acta Scientiae Veterinariae, v. 38, p. 731, 2010. Supplement, 2. [Abstract].

MARTINUK, S. D.; MANNING, A. W.; BLACK, W. D.; MURPHY, B. D. Effects of carbohydrates on the pharmacokinetics and biological activity of equine chorionic gonadotropin in vivo. Biology Reproduction, v. 45, p. 598-604, 1991.

MATTIOLI, M.; BARBONI, B.; TURRIANI, M.; GALEATI, G.; ZANNONI, A.; CASTELLANI, G.; BERARDINELLI, P.; SCAPOLO, P. A. Follicle activation involves vascular endothelial growth factor production and increased blood vessel extension. Biology of Reproduction, v. 65, p. 1014-1019, 2001.

MCCRACKEN, J. A.; CUSTER, E. E.; LAMSA, J. C. Luteolysis: A neuroendocrinemediated event. Physiology Revision, v. 45, p. 263-323, 1999.

MÉDURI, G.; CHARNAUX, N.; DRIANCOURT, M.; COMBETTES, L.; GRANET, P.; VANNIER, B.; LOOSFELT, H.; MILGROM, E. Follicle-Stimulating Hormone Receptors in Oocytes? Journal of Clinical Endocrinology and Metabolism, v. 87, p. 2266-2276, 2002.

MELENDEZ, P.; BARTOLOME, J.; ARCHBALD, L. F.; DONOVAN, A. The association between lameness, ovarian cysts and fertility in lactating dairy cows. Theriogenology, v. 59, p. 927-937, 2003.

MENZER, C.; SCHAMS, D. Radioimmunoassay for PMSG and its application to in vivo studies. Journal Reproduction Fertility, v. 55, p. 339-345, 1979.

MIHM, M.; GOOD, T. E. M.; IRELAND, J. L. H.; IRELAND, J. J.; KNIGHT, P. G.; ROCHE, J. F. Decline in follicle stimulating concentrations alters key intrafollicular growth factors involved in the selection of the dominant follicle in heifers. Biology of Reproduction, v. 63, p. 811-819, 1997.

MIYAMOTO, A.; OHTANI, M.; KOBAYASHI, S.; HAYASHI, K.; SAKAI, A.; ACOSTA, T. J.; OZAWA, T.; FUKUI, Y. Mechanisms of luteolysis during the estrous cycle in ruminants. Journal of Reproduction and Development, v. 43, p. j75-j81, 1997.

MOREIRA, F.; ORLANDI, C.; RISCO, C. A.; MATTOS, R.; LOPES, F.; THATCHER, W. W. Effects of presynchronization and bovine somatotropin on pregnancy rates to a timed artificial insemination protocol in lactating dairy cows. Journal of Dairy Science, v. 84, p. 1646-1659, 2001.

MOREIRA, F.; RISCO, C.; PIRES, M. F.; AMBROSE, J. D.; DROST, M.; DELORENZO, M.; THATCHER, W. W. Effect of body condition on reproductive efficiency of lactating dairy cows receiving a timed insemination. Theriogenology, $v$. 53, p. 1305-1319, 2000. 
MURPHY, B. D.; MARTINUK, S. D. Equine chorionic gonadotropin. Endocrine Reviews, v. 12, p. 27-43, 1991.

NAVANUKRAW C.; REDMER, D. A.; REYNOLDS, L. P.; KIRSCH, J. D.; GRAZULBILSKA, A. T.; FRICKE, P. M. A modified presynchronization protocol improves fertility to timed artificial insemination in lactating dairy cows. Journal of Dairy Science, v. 87, p. 1551-1557, 2004.

NEBEL, R. L.; JOBST, S. M.; DRANSFIELD, M. B.; PANDOLFI, S. M.; BAILEY, T. L. Use of a radio frequency data communication system, HeatWatch $\AA$, to describe behavioral estrus in dairy cattle. Journal Dairy Sciencie, v. 80, p. 179, 1997.

NIMZ, M.; SPITSCHAK, M.; SCHNEIDER, F.; FÜRBASS, R.; VANSELOW, J. Downregulation of genes encoding steroidogenic enzymes and hormone receptors in late preovulatory follicles of the cow coincides with an accumulation of intrafollicular steroids. Domestic Animal Endocrinology, v. 37, p. 45-54, 2009.

NISWENDER, G. D. Molecular control of luteal secretion of progesterone. Reproduction, v. 123, p. 333-339, 2002.

NISWENDER, G. D.; JUENGEL, J. L.; SILVA, P. J.; ROLLYSON, M. K.; MCINTUSH, E. W. 2000. Mechanisms controlling the function and life span of the corpus luteum. Physiological Reviews, v. 80, p. 1-29, 2000.

NRC. Nutrient Requirements of Dairy Cattle. 7th rev. ed. Washington, DC.: National Academic Press, 2001.

ODDE, K. G. A review of synchronization of estrus in postpartum cattle. Journal Animals Sciencie, v. 68, p. 817-830, 1990.

OHTANI, M.; KOBAYSHI, S.; MIYAMOTO, A.; HAYASHI, K.; FUKUI, Y. Real-time relationships between intraluteal and plasma concentrations of endothelin, oxytocin, and progesterone during prostaglandin F2 $\alpha$-induced luteolysis in the cow. Biology of Reproduction, v. 58, p. 103-108, 1998.

OLDS, D.; SEATH, D. M. Repeatability of the estrous cycle length in dairy cattle. Journal of Dairy Science, v. 34, p. 626-632, 1951.

PAPA, P. C.; MOURA, C. E. B.; ARTONI, L. P.; FÁTIMA, L. A.; CAMPOSA, D. B.; MARQUES JR., J. E. B.; BARUSELLI, P. S.; BINELLI, M.; PFARRER, C.; LEISER, R. VEGF system expression in different stages of estrous cycle in the corpus luteum of non-treated and superovulated water buffalo. Domestic Animal Endocrinology, v. 33, p. 379-389, 2007.

PENTEADO, L.; SÁ FILHO, M. F.; MARTINS, C. L.; GIMENES, L. U.; AYRES, H.; BARUSELLI, P. S. Conception rates in lactating Nelore cows treated with intravaginal progesterone device associated with estradiol benzoate or estradiol cypionate. Annual meeting of brazilian technology society. Acta Scientiae Veterinariae, v. 33, p. 260, 2005. 
PESCADOR, N.; SOUMANO, K.; STOCCO, D. M.; PRICE, C. A.; MURPHY, B. D. Steroidogenic acute regulatory protein in bovine corpora lutea. Biology of Reproduction, v.55, p.485-491, 1996.

PETER, A. T.; LEVINE, H.; DROST, M.; BERGFELT, D. R. Compilation of classical and contemporary terminology used to describe morphological aspects of ovarian dynamics in cattle. Theriogenology, v. 71, p. 1343-1357, 2009.

PETERS, K. E.; BERGFELD, E. G.; CUPP, A. S.; KOJIMA, F. N.; MARISCAL, V.; SANCHEZ, T.; WEHRMAN, M. E.; GROTJAN, H. E.; HAMERNIK, D. L.; KITTOK, R. J.; KINDER, J. E. Luteinizing hormone has a role in development of fully functional corpora lutea $(\mathrm{CL})$ but is not required to maintain $\mathrm{CL}$ function in heifers. Biology of Reproduction, v. 51, p. 1248-1254, 1994.

PIPER, P. J.; VANE, J. R.; WYLLIE, J. H. Inactivation of prostaglandins by the lungs. Nature, v. 225, p. 600-604, 1970.

PRATT, S. L.; SPITZER, J. C.; BURNS, G. L.; PLYLER; B. B. Luteal function, estrous response, and pregnancy rate after treatment with Norgestomet and various dosages of estradiol valerate in suckled cows. Journal of Animal Science, v. 69, p. 27212726, 1991.

PURSLEY, J. R.; MEE, M. O.; WILTBANK, M. C. Synchronization of ovulation in dairy cows using PGF $2 \alpha$ and GnRH. Theriogenology, v. 44, p. 915-923, 1995.

PURSLEY, J. R.; SILCOX, R. W.; WILTBANK, M. C. Effect of time of artificial insemination on pregnancy rates, calving rates, pregnancy loss, and gender ratio after synchronization of ovulation in lactating dairy cows. Journal of Dairy Science, v. 81, p. 2139-2144, 1998.

QUIRK, S. M.; FORTUNE, J. E. Plasma concentrations of gonadotrophins, preovulatory follicular development and luteal function associated with bovine follicular fluid-induced delay of oestrus in heifers. Journal of Reproduction and Fertility, v. 76, p. 609-621, 1986.

RAO M. C.; MIDGLEY JR., A. R.; RICHARDS, J. S. Hormonal regulation of ovarian cellular proliferation. Cell, v. 14, n. 1, p. 71-78, 1978.

RATHBONE, M.J.; KINDER, J. E.; FIKE, K.; KOJIMA, F.; CLOPTON, D.;OGLE, C. R.; BUNT, C.R. 2001. Recent advances in bovine reproductive endocrinology and physiology and their impact on drug delivery system design for the control of the estrous cycle in cattle. Advanced Drug Delivery Reviews, v. 5, p. 277-320.

REIMERS, T. J.; SMITH, R. D.; NEWMAN, S. K. Management factors affecting reproductive performance of dairy cows in the northeastern United States. Journal of Dairy Science, v. 68, p. 963-972, 1985.

REKAWIECKI, R.; NOWIK, M.; KOTWICA, J. Stimulatory effect of LH, PGE 2 and progesterone on StAR protein, cytochrome P450 cholesterol side chain cleavage and $3 \beta$ hydroxysteroid dehydrogenase gene expression in bovine luteal cells.

Prostaglandins \& Other Lipid Mediators, v. 78, p. 169-184, 2005. 
REYNOLDS, L. P.; KILLILEA, S. D.; REDMER, D. A. Angiogenesis in the female reproductive system. The FASEB Journal, v. 6, p. 886-892, 1992.

REYNOLDS, L. P.; REDMER, D. A. Growth and development of the corpus luteum. Journal of Reproduction and Fertility Supplements, v. 54, p.181-191, 1999.

RICHARDS, J. S. Content of nuclear estradiol receptor complex in rat granulosa cells during follicular development: modification by estradiol and gonadotropins.

Endocrinology, v. 97, n. 5, p. 1174-1184, 1975.

RICHARDS, J. S. Maturation of ovarian follicles: actions and interactions of pituitary and ovarian hormones on follicular cell differentiation. Physiology Revision, v. 60, p. 51-89, 1980.

RICHARDS, J. S.; MIDGLEY, A. R. Protein hormone action: a key to understanding ovarian follicular and luteal cell development. Biology of Reproduction, v. 14, p. 82-94, 1976.

ROBERSON, M. S.; WOLFE, M. W.; STUMPF, T. T.; KITTOK, R. J.; KINDER, J. E. Luteinizing hormone secretion and corpus luteum function in cows receiving two levels of progesterone. Biology of Reproduction, v. 41, n. 6, p. 997-1003, 1989.

ROCHA, A.; RANDEL, R. D.; BROUSSARD, J. R.; LIM, J. M.; BLAIR, R. M.; ROUSSEL, J. D.; GODKE, .A.; HANSEL, W. High environmental temperature and humidity decrease oocyte quality in Bos taurus but not in Bos indicus cows, Theriogenology, v. 49, p. 657-665, 1998.

RUBIANES, E.; BEARD, A.; DIERSCHKE, D. J.; BARTLEWSKI, P.; ADAMS, G. P.; RAWLINGS, N. C. Endocrine and ultrasound evaluation of the response to PGF and $\mathrm{GnRH}$ given at different stages of the luteal phase in cyclic ewes. Theriogenology, v. 48, p. 1093-1104, 1997.

SÁ FILHO, M. F.; AYRES, H.; FERREIRA, R. M.; MARQUES, M. O.; REIS, E. L.; SILVA, R. C.; RODRIGUES, C. A.; MADUREIRA, E. H., BÓ, G. A.; BARUSELLI, P. $S$. Equine chorionic gonadotropin and gonadotropin-releasing hormone enhance fertility in a norgestomet-based, timed artificial insemination protocol in suckled nelore (Bos indicus) cows. Theriogenology, v. 73, N. 5, p. 651-658, 2010.

SÁ FILHO, O. G.; MENEGHETTI, M.; PERES, R. F.; LAMB, G. C.; VASCONCELOS, J. L. Fixed-time artificial insemination with estradiol and progesterone for Bos indicus cows II: strategies and factors affecting fertility. Theriogenology, v. 72, n. 2, p. 210218, 2009.

SALES, J. N. S.; CREPALDI, G. A.; GIROTTO, R. W.; BARUSELLI, P. S. Effect of $\mathrm{FSH}$ and eCG on follicular dynamic and pregnancy rate in fixed-time Al protocol in anestrous beef cows. In: SIMPOSIO INTERNACIONAL DE REPRODUCCIÓN ANIMAL, 8., 2009, Córdoba. Anais... Córdoba: Instituto de Reproducción Animal de Córdoba, 2009.

SANGSRITAVONG, S.; COMBS, D. K.; SARTORI, R.; ARMENTANO, L. E.; WILTBANK, M. C. High feed intake increases liver blood flow and metabolism of 
progesterone and estradiol-17 $\beta$ in dairy cattle. Journal of Dairy Science, v. 85, p. 2831-2842, 2002.

SANTOS, I. C. C.; MARTINS, C. M.; BARUSELLI, P. S.; VALENTIM, R.; D'OCCHIO, $M$. Estudo da dinâmica folicular de vacas Nelore (Bos indicus) em anestro sincronizadas com Protocolo IATF, utilizando Folltropin ${ }^{\circledR}$ (FSHp) Como indutor de crescimento folicular. Acta Scientiae Veterinariae, v. 35, p. s1152, 2007a. Supplement, 2. [Abstract].

SANTOS, I. C. C.; MARTINS, C. M.; VALENTIM, R.; BARUSELLI, P. S. Taxa de prenhez a iatf de vacas zebuínas em anestro tratadas com dose única de FSHp (FOLLTROPIN®). Acta Scientiae Veterinariae, v. 35, p. s1151, 2007b. Supplement, 2. [Abstract].

SARTORI, R.; FRICKE, P. M.; FERREIRA, J. C. P.; GINTHER, O. J.; WILTBANK, M. C. Follicular deviation and acquisition of ovulatory capacity in bovine follicles. Biology of Reproduction, v. 65, p. 1403-1409, 2001.

SARTORI, R.; HAUGHIAN, J. M.; SHAVER, R. D.; ROSA, G. J. M.; WILTBANK, M. C. Comparison of ovarian function and circulating steroids in estrous cycles of holstein heifers and lactating cows. Journal of Dairy Science, v. 87, p. 905-920, 2004.

SARTORI, R.; ROSA, G. J. M.; WILTBANK, M. C. Ovarian structures and circulating steroids in heifers and lactating cows in summer and lactating cows and dry cows in winter. Journal Dairy Sciencie, v. 85, p. 2813-2822, 2002.

SAVIO, J. D.; BOLAND, M. P.; ROCHE, J. F. Development of dominant follicles and length of ovarian cycles in post-partum dairy cows. Journal of Reproduction and Fertility, v. 88, p. 581-591, 1990.

SENGER, P. L. Pathways to pregnancy and parturition. Pullman, USA: Current Conceptions Inc., 2003.

SOUZA, A. H. Inseminação artificial em tempo fixo em vacas holandesas de alta produção. 2008. 135 p. Tese (Doutorado em Mediciana Veterinária) - Faculdade de Medicina Veterinária e Zootecnia, Universidade de São Paulo, São Paulo, São Paulo, 2008.

SOUZA, A. H.; AYRES, H.; FERREIRA, R. M.; WILTBANK, M. C. A new presynchronization system (Double-Ovsynch) increases fertility at first postpartum timed Al in lactating dairy cows. Theriogenology, v. 70, p. 208-215, 2008.

SPICER, L. J.; ALPIZAR, E.; ECHTERNKAMP, S. E. Effects of insulin, insulin-like growth factor I, and gonadotropins on bovine granulosa cell proliferation, progesterone production, estradiol production, and(or) insulin-like growth factor I production in vitro. Journal of Animal Science, v. 71, p. 1232-1241, 1993.

SPINOSA, H. S.; GÓRNIAK, S. L.; BERNARDI, M. M. Farmacologia aplicada a medicina veterinária. 4. ed. Rio de Janeiro: Guanabara Koogan,2006. 
SPRECHER, D. J.; HOSTETLER, D. E.; KANEENE, J. B. A lameness scoring system that uses posture and gait to predict dairy cattle reproductive performance. Theriogenology, v. 47, p. 1179-1187, 1997.

STABENFELDT, G. H.; EWING, L. L.; MCDONALD, L. E. Peripheral plasma progesterone levels during the bovine oestrus cycle. Journal of Reproduction and Fertility, v. 19, p. 433-442, 1969.

STANTON, P. G.; ROBERTSON, D. M.; BURGON, P.G.; SCHMAUK-WHITE, B.; HEARN, M. T. W. Isolation and physicochemical characterization of human follicle stimulating hormone isoforms. Endocrinology, v. 139, p. 2820-2832, 1992.

SUNDERLAND, S. J.; KNIGHT, P. G.; BOLAND, M. P.; ROCHE, J. F.; IRELAND, J. $\mathrm{J}$. Alterations in intrafollicular levels of different molecular mass forms of inhibin during development of follicular- and luteal-phase dominant follicles in heifers. Biology of Reproduction, v. 54, n. 2, p. 453-462, 1996.

THATCHER, W. W.; MACMILLAN, K. L.; HANSEN, P. J.; DROST, M. Concepts for regulation of corpus luteum function by the conceptus and ovarian follicles to improve fertility. Theriogenology, v. 31, p. 149-164, 1989.

TURZILLO A. M.; FORTUNE, J. E. Effects of suppressing plasma FSH on ovarian follicular dominance in cattle. Journal of Reproduction an Fertility, v. 98, n. 1, p. 113-9, 1993.

URWIN, V. E.; ALLEN, W. R. Pituitary and chorionic gonadotrophic control of ovarian function during early pregnancy in equids. Journal Reproduction Fertility, v. 32, p. 371, 1982.

VASCONCELOS, J. L. M.; SILCOX, R. W.; ROSA, G. J.; PURSLEY, J. R.; WILTBANK, M. C. Synchronization rate, size of the ovulatory follicle, and pregnancy rate after synchronization of ovulation beginning on different days of the estrous cycle in lactating dairy cows. Theriogenology, v. 52, p. 1067-1078, 1999.

VASCONCELOS, J. L.; SARTORI, R.; OLIVEIRA, H. N.; GUENTHER, J. G.; WILTBANK, M. C. Reduction in size of the ovulatory follicle reduces subsequent luteal size and pregnancy rate. Theriogenology, v. 56, p. 307-314, 2001.

VOSS, A. K.; FORTUNE, J. E. Levels of messenger ribonucleic acid for cytochrome P450 17 alpha- hydroxylase and P450 aromatase in preovulatory bovine follicles decrease after the luteinizing hormone surge. Endocrinology, v. 132, p. 2239-2245, 1993a.

VOSS, A. K.; FORTUNE, J. E. Levels of messenger ribonucleic acid for cholesterol side-chain cleavage cytochrome $\mathrm{P}-450$ and 3 beta-hydroxysteroid dehydrogenase in bovine preovulatory follicles decrease after the luteinizing hormone surge.

Endocrinology, v. 132, p. 888-894, 1993b.

WANG, X. N.; GREENWALD, G. S. Synergistic effects of steroids with FSH on folliculogenesis, steroidogenesis and FSH- and hCG-receptors in hypophysectomized mice. Journal of Reproduction and Fertility, v. 99, n. 2, p. 403-413, 1993. 
WARD, D. N.; MOORE J. R., W. T. Comparative study of mammalian glycoprotein hormones. In: ALEXANDER, N. J. (Ed.). Animal models for research in fertility and contraception. Baltimore: Harper and Row, 1979. p. 151-164.

WASHBURN, S. P.; SILVIA, W. J.; BROWN, C. H.; MCDANIEL, B. T.; MCALLISTER, A. J. Trends in reproductive performance in southeastern Holstein and Jersey DHI herds. Journal Dairy Sciencie, v. 85, p. 244-251, 2002.

WETTEMANN, R. P.; HAFS, H. D.; EDGERTON, L. A.; SWANSON, L. V. Estradiol and progesterone in blood serum during the bovine estrous cycle. Journal of Animal Science, v. 34, p. 1020-1024, 1972.

WILLMOTT, N.; SAUNDERS. J.; BÓ, G. A.; PALASZ, A.; PIERSON, R. A.; MAPLETOFT, R. J. The effect of FSHILH ratio in pituitary extracts on superovulatory response in the cow. Theriogenology, v. 33, p. 347, 1990. [Abstract].

WILTBANK, M. C.; DYSKO, R. C.; GALLAGHER, K. P.; KEYES, P. L. Relationship between blood flow and steroidogenesis in the rabbit corpus luteum. Journal of Reproduction and Fertility, v. 84, p. 513-520, 1988.

WILTBANK, M. C.; GÜMEN, A.; SARTORI, R. Physiological classification of anovulatory conditions in cattle. Theriogenology, v. 57, p. 21-52, 2002.

WOLFENSON, D.; ROTH, Z.; MEIDAN, R. Impaired reproduction in heat-stressed cattle: Basic and applied aspects, Animal Reproducion Science, v. 60-61, p. 535547, 2000.

WOLFENSON, D.; SONEGO, H.; SHAHAM-ALBALANCY, A.; SHPIRER, Y.; MEIDAN. D R. Comparison of the steroidogenic capacity of bovine follicular and luteal cells, and corpora lutea originating from dominant follicles of the first or second follicular wave. Journal of Reproduction and Fertility, v. 117, p. 241-247, 1999.

XU, Z.; GARVERICK, H. A.; SMITH, G. W.; SMITH, M. F.; HAMILTON, S. A.; YOUNGQUIST, R. S. Expression of follicle-stimulating Hormone and luteinizing hormone receptor messenger ribonucleic acids in bovine follicles during the first follicular wave. Biology of Reproduction, v. 53, p. 951-957, 1995.

YAMAMOTO, M.; SUZUKI, T.; OOE, M.; TAKAGI, M. Superovulation in beef cows and heifers with a single injection of FSH dissolved in polyvinylpyrrolidone, Journal of Reproduction and Development, v. 39, p. 353-356, 1993. 